$\checkmark$

Design and Test of the CC Cryostat Head Cart

Engineering Note \#3740.215-EN-182

Issued: August 8, 1989

Originator: Al Jaques

Checked: 


\section{Design and Test of the CC Cryostat Head Cart}

\section{Al Jaques}

This Engineering Note documents the design of the stand to be used to transport the CC Cryostat heads into the D-Zero clean room. Due to the width of the clean room access door, the heads will have to be upright to fit through. This head cart will hold the heads upright and wheel them into the clean room on a guided track. Before the wheels are placed on the head cart, it will be used as a stand to place the heads on for the purpose of test fitting the super insulation. The head cart will not only be structurally sufficient to support the weight of the heads but also stiff enough to allow a maximum deflection of $1 / 2$ " at the end of the $48^{\prime \prime}$ cylinder (see sketch in Appendix A).

The heaviest head assembly weighs about 9000 lbs. Following A.I.S.C. specifications and using a $9000 \mathrm{lb}$. design load, the head cart was initially designed and built and later modified in order to meet the deflection requirements. Bending and tension stresses were limited to two thirds the yield strength. Weld and shear stresses are limited to $0.4 * F y$. The C7X12.25 channels, the L2.5X2.5X0.25 angles and the 1/2" plate are all A36 steel.

In order to validate the need for an end plate in the $48^{\prime \prime}$ cylinder, an ANSYS model was created of the cylinder itself to determine it's rigidity under a point load applied at it's outer end. Appendix $D$ contains the results which demonstrate the rigidity of the cylinder-end plate assembly. Also included is a Frame-Mac simulation of the head cart which was used to estimate the deflection at the cylinder end.

A load test was performed to $133 \%$ of the rated capacity, or $12,000 \mathrm{lbs}$. The test load was incrementally applied using a crane and hook scale. A graph of deflection vs. load is shown in Appendix E. A spreader beam was designed and built to properly test the head cart. Stress calculations for this test spreader beam are included in Appendix $C$. 


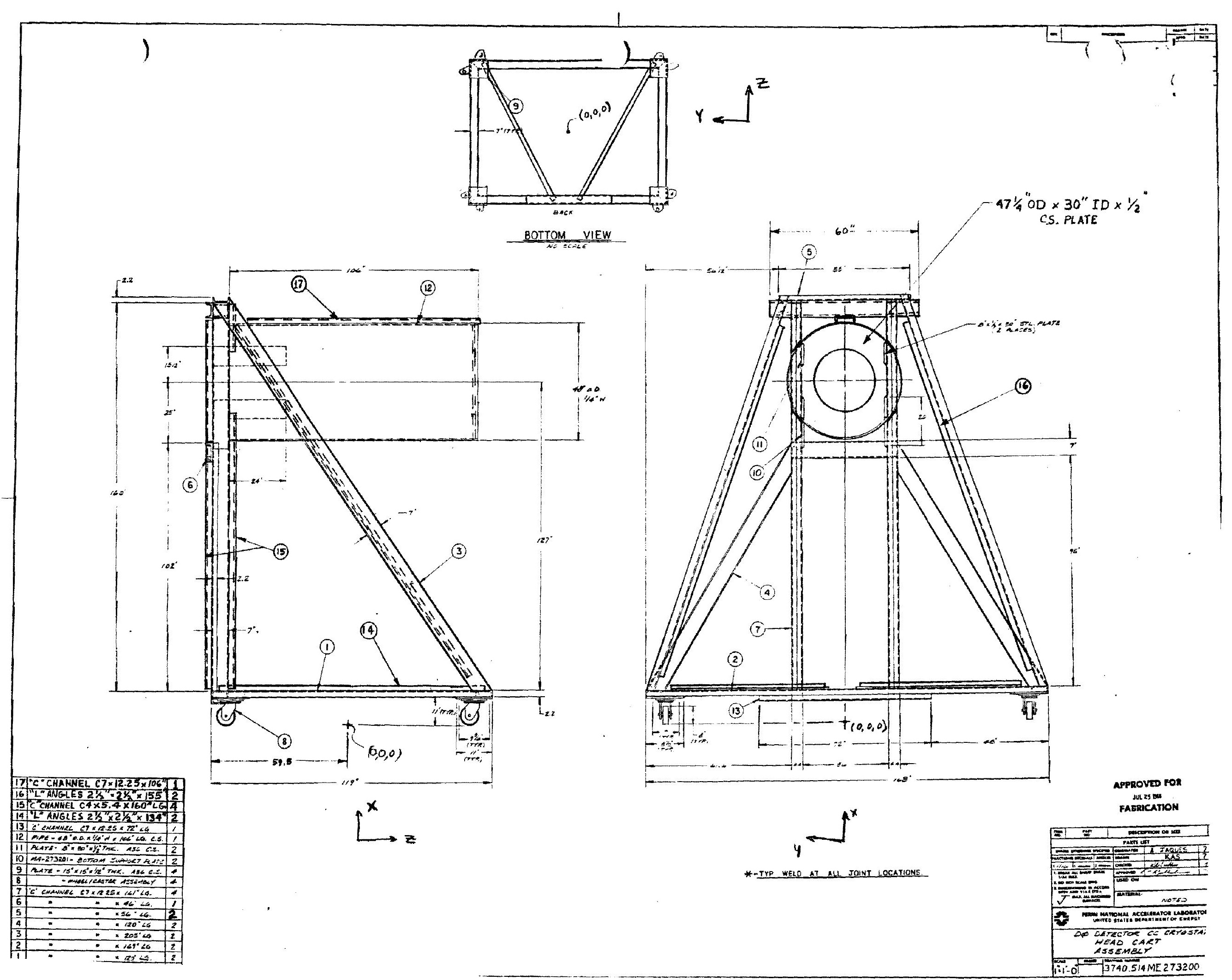




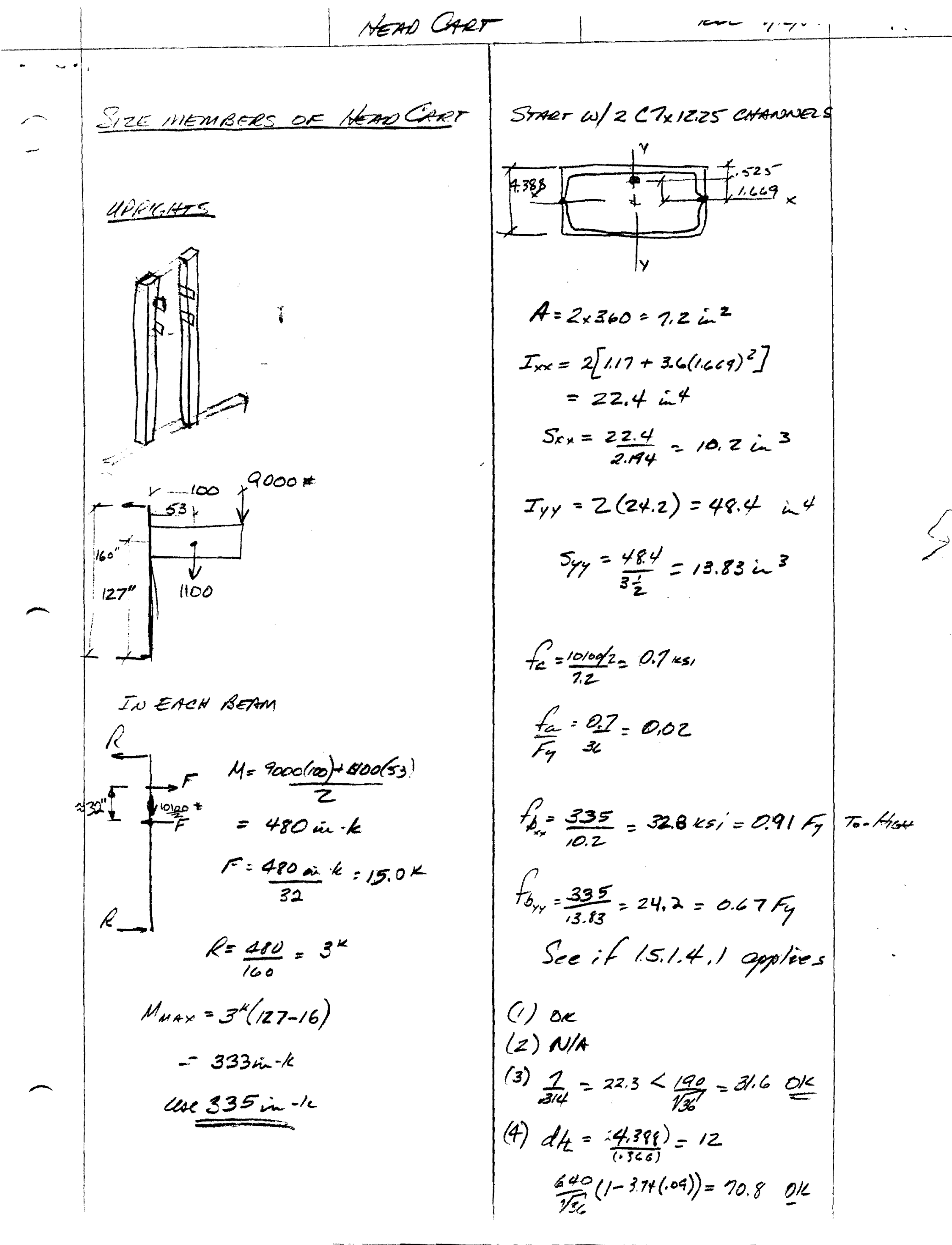




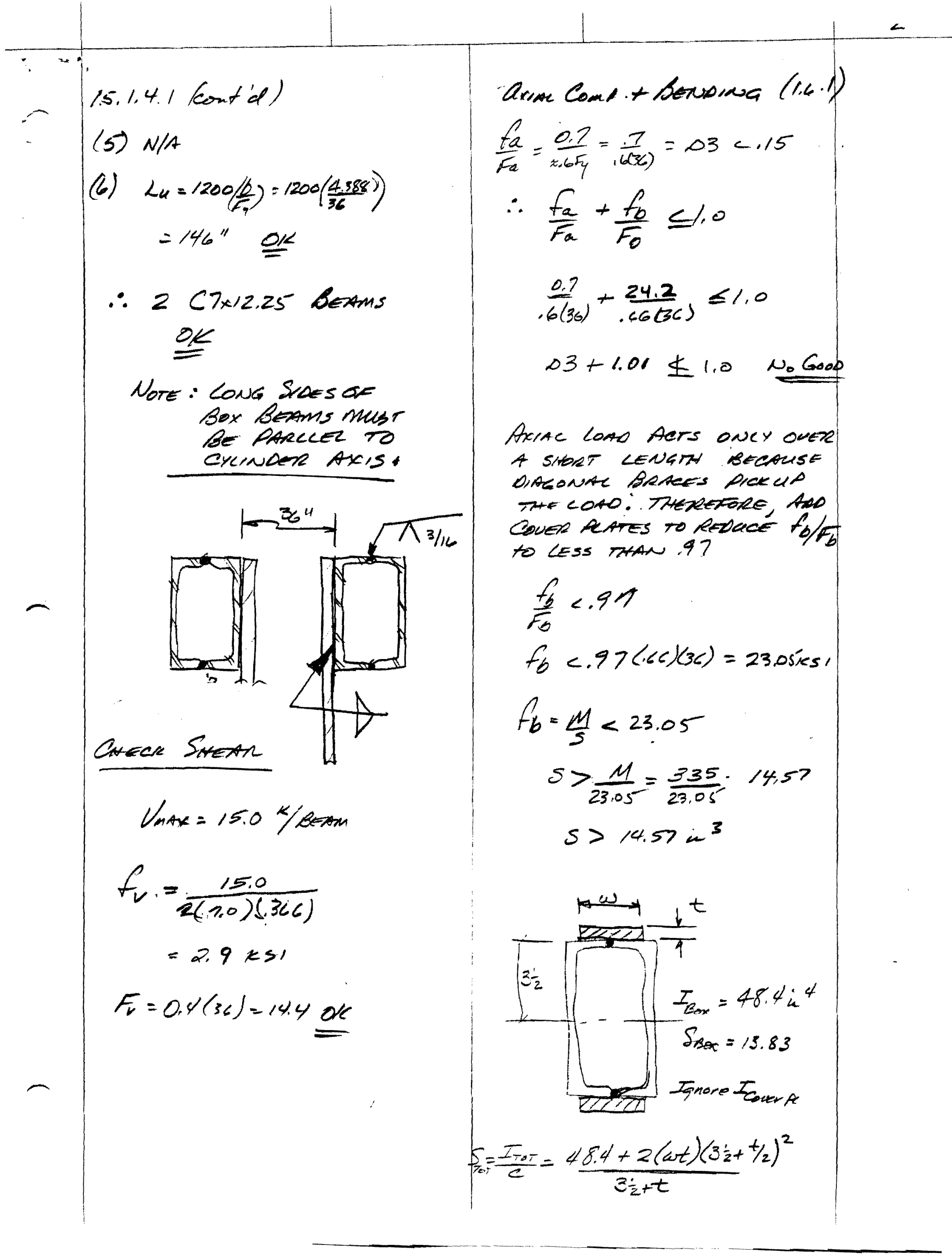




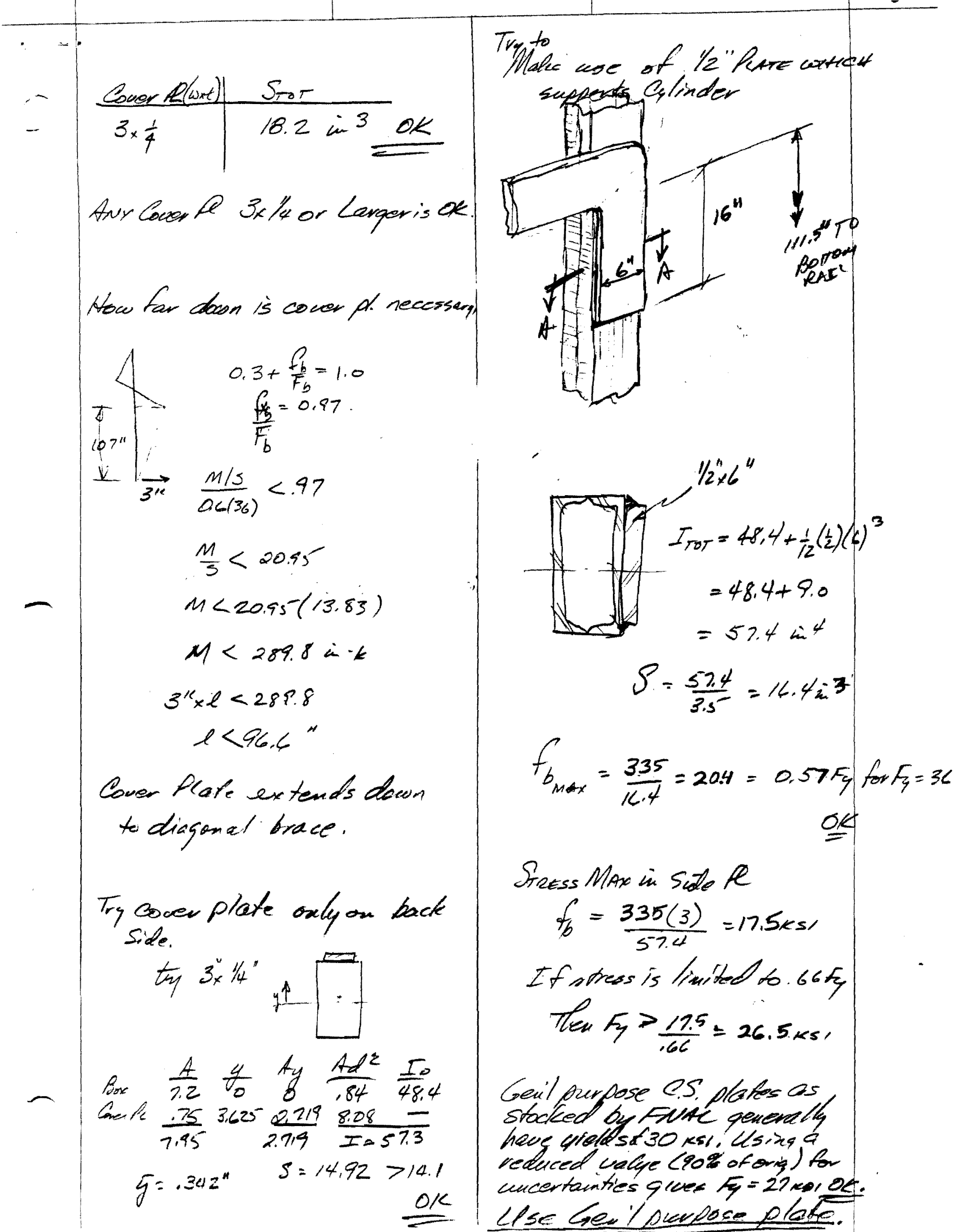


$\therefore$ Stiffened (see Frame Mac Model)

- Uprights ware sufficient to safely support load but allowed excessive deflection for our needs, thus stiffening was required.

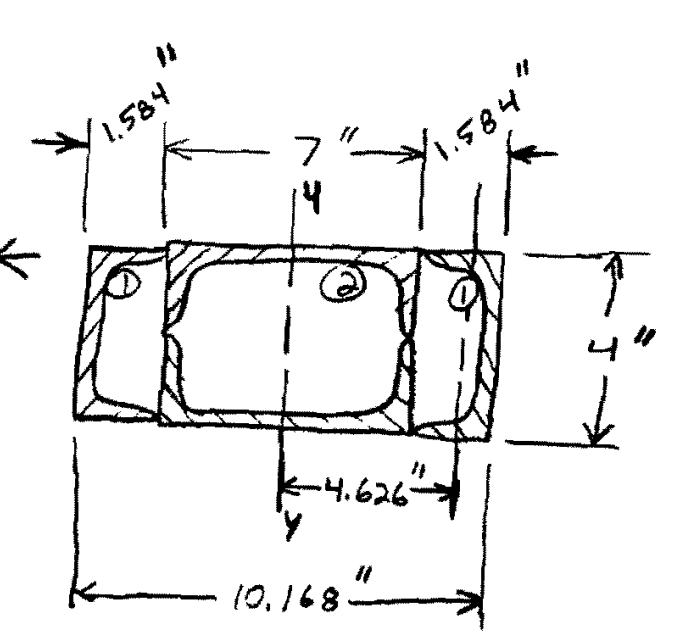

$$
\begin{aligned}
A= & 2 A_{1}+2 A_{2}=2(1.59)+2(3.60) \\
& =10.38 \mathrm{in} 2 \\
(4-4) I_{1, c} & =2(0.319)=0.638 \mathrm{in}^{4} \\
I_{2, c} & =2(24.2)=48.4 \mathrm{in}^{4} \\
I_{\text {TOT }} & =I_{1 c}+I_{2 c}+2 A_{1} d^{2} \\
& =0.638+48.4+2(1.59)(4.626) \\
& =\frac{117.09 \mathrm{in}^{4}}{C} \\
S= & \frac{I 11.09}{\left(\frac{10.168}{2}\right)}=23.03 \mathrm{in}^{3}
\end{aligned}
$$

$$
m_{\max }(\text { pose } 1)=335 \text { in }-k
$$$$
f_{b}=\frac{m}{s}=\frac{335}{23.03}=14.55 \mathrm{ksi}
$$$$
\frac{14.55}{36}=0.40 F_{y} \leq .66 F_{y} \text { or }
$$

This interim wow already. met, but a greater stiff was was required to reduce deflections.

* only single sided with .n radius of cylinder. 


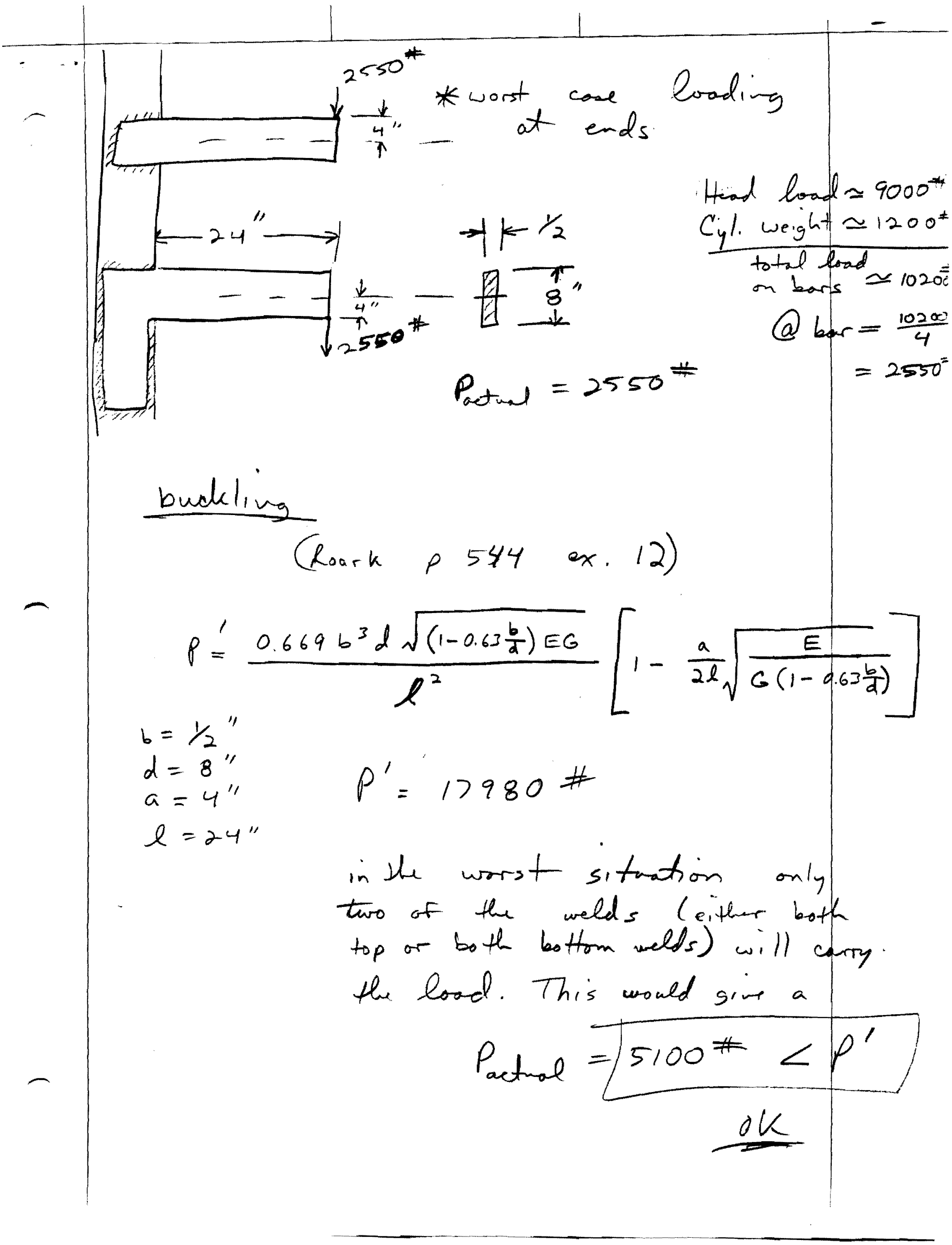




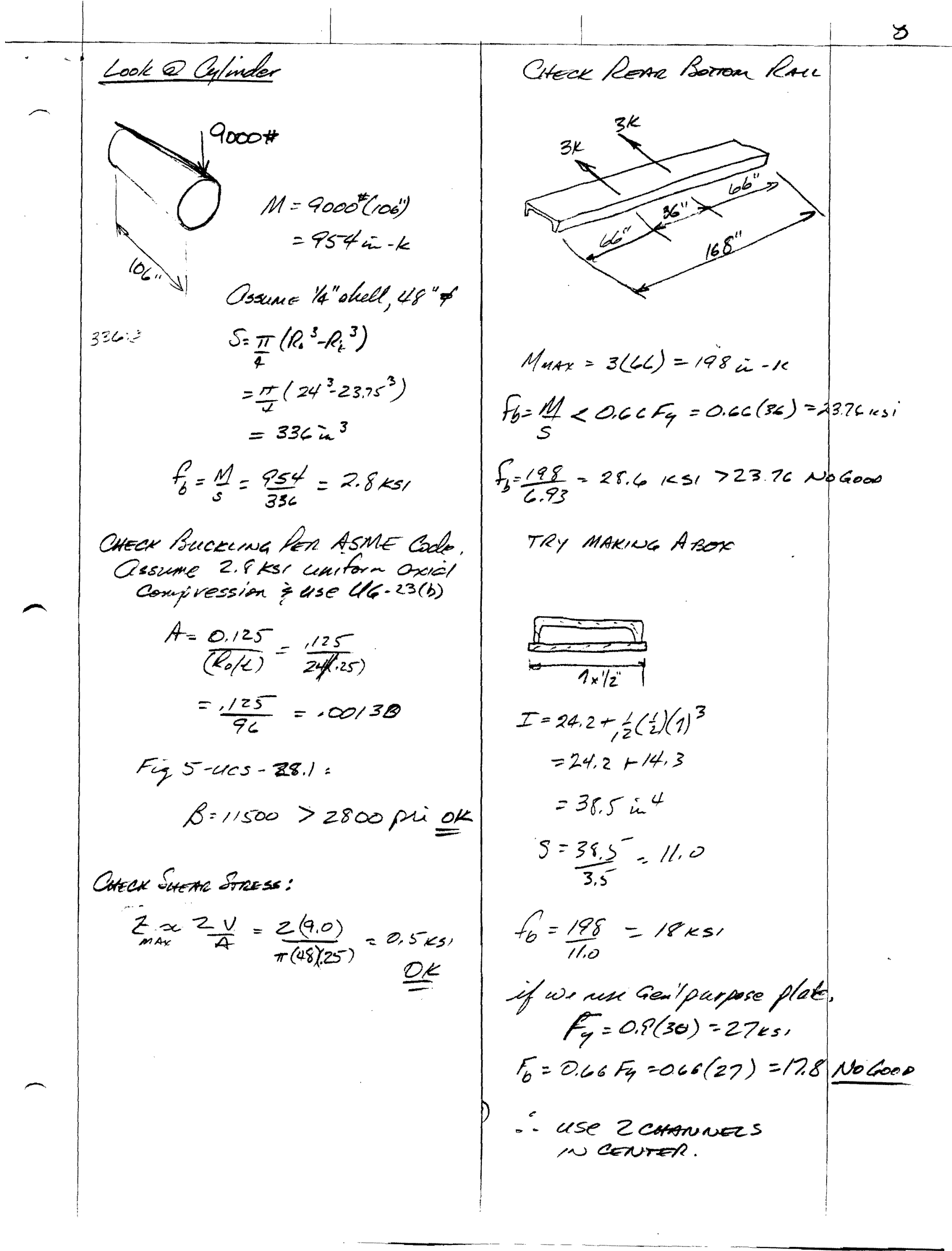




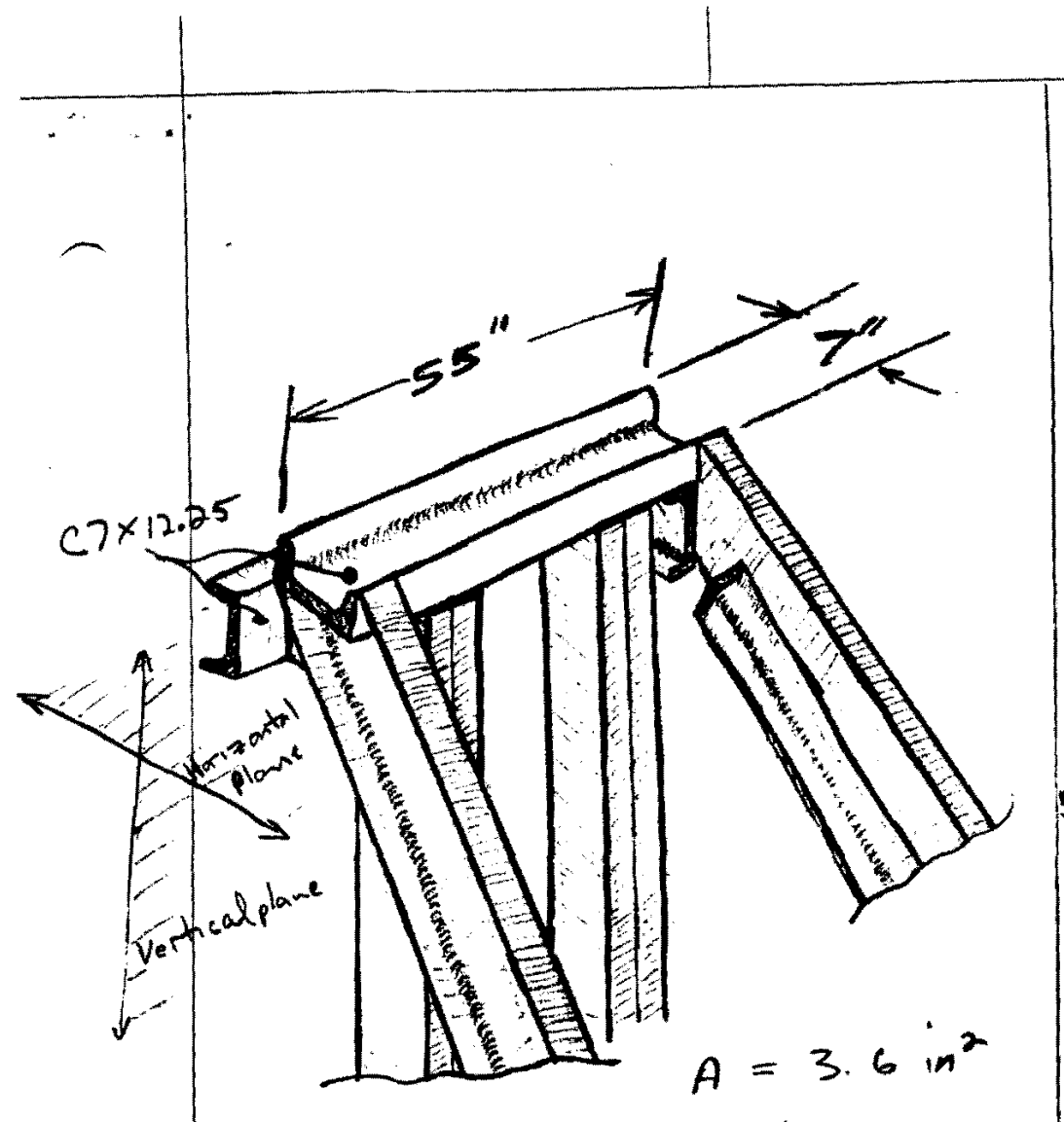

Horizontal $\quad S=\frac{24.2}{3.5}=6.9$ in

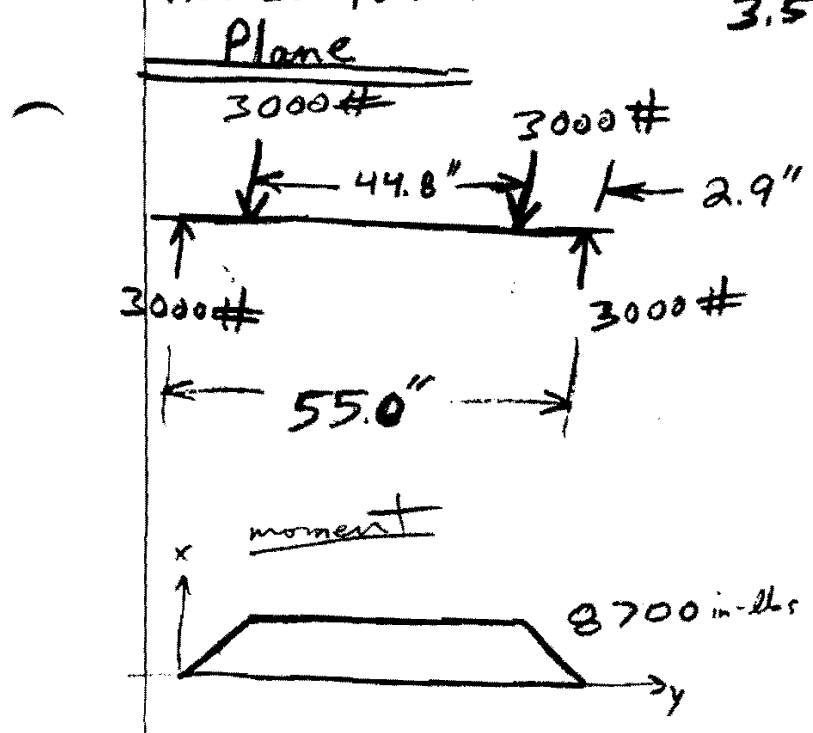

$$
\frac{\text { bending }}{\sigma_{b}}=\frac{m}{s}=\frac{8700}{\left(\frac{39.86}{5.5725}\right)}=1.2 \mathrm{ksi}
$$

ok

shear

$$
\tau_{v}=\frac{3000}{2(3.6)}=0.42 \mathrm{ksi}
$$

ok
Vertical

Plane

* assume total vertices load $(10100 \mathrm{chs})$ is supported by and $C$-channel (Worse Coal)

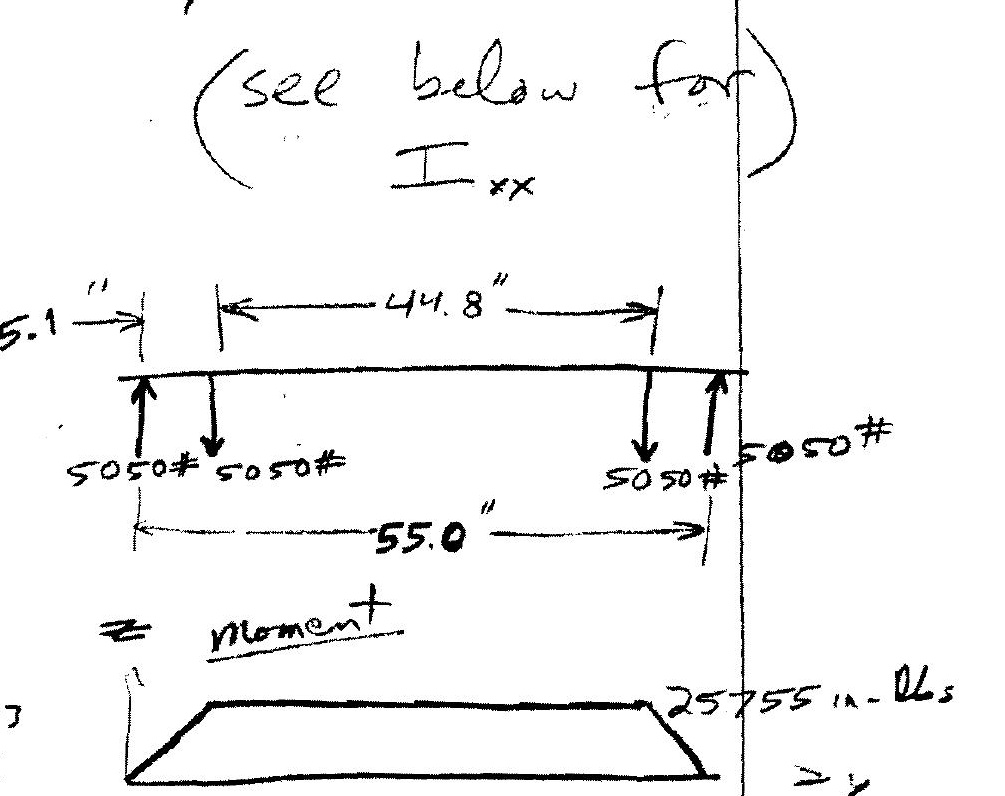

bend.

$$
\sigma_{b}=\frac{m}{s}=\frac{25755}{\left(\frac{39.86}{5.5125}\right)}=3.6 \mathrm{ksc}
$$

shear

$$
\tau_{v}=\frac{5050}{2(3.6)}=0.7 \mathrm{ksi}
$$

OK

$$
\begin{aligned}
& I_{1 x_{0}}=24.2 \mathrm{~m}^{4} \\
& I_{2 x_{c}}=1.17 \mathrm{in}^{4} \\
& A=3.6 \mathrm{in}^{2}
\end{aligned}
$$

$$
\begin{aligned}
I_{x x}= & I_{1 c}+I_{2 c}+A d_{1}+A d_{2} \\
= & 24.2+1.17+3.6(5.5125-3.1 \\
& +3.6(7.525-5.512 \\
& 79.86 .14
\end{aligned}
$$




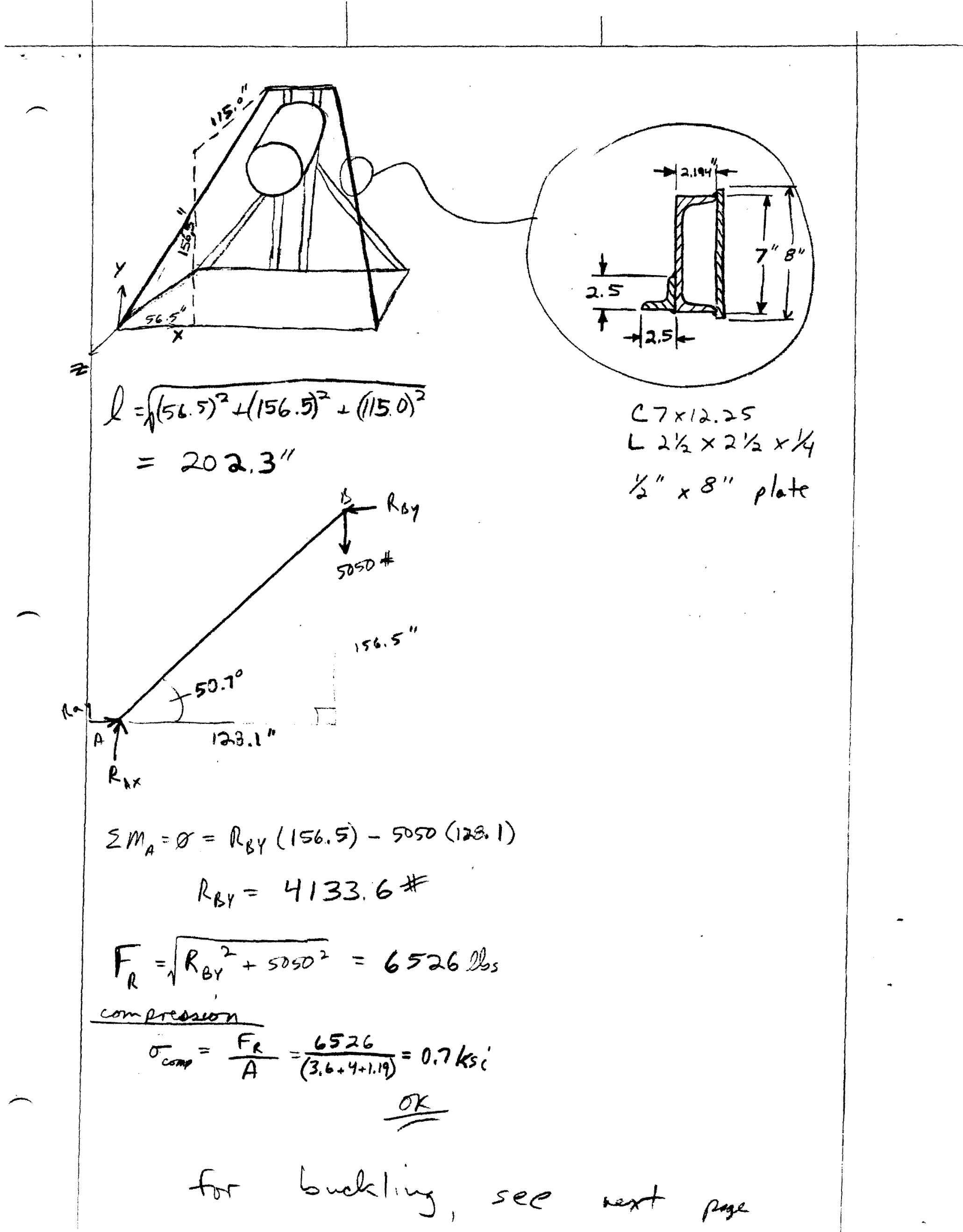




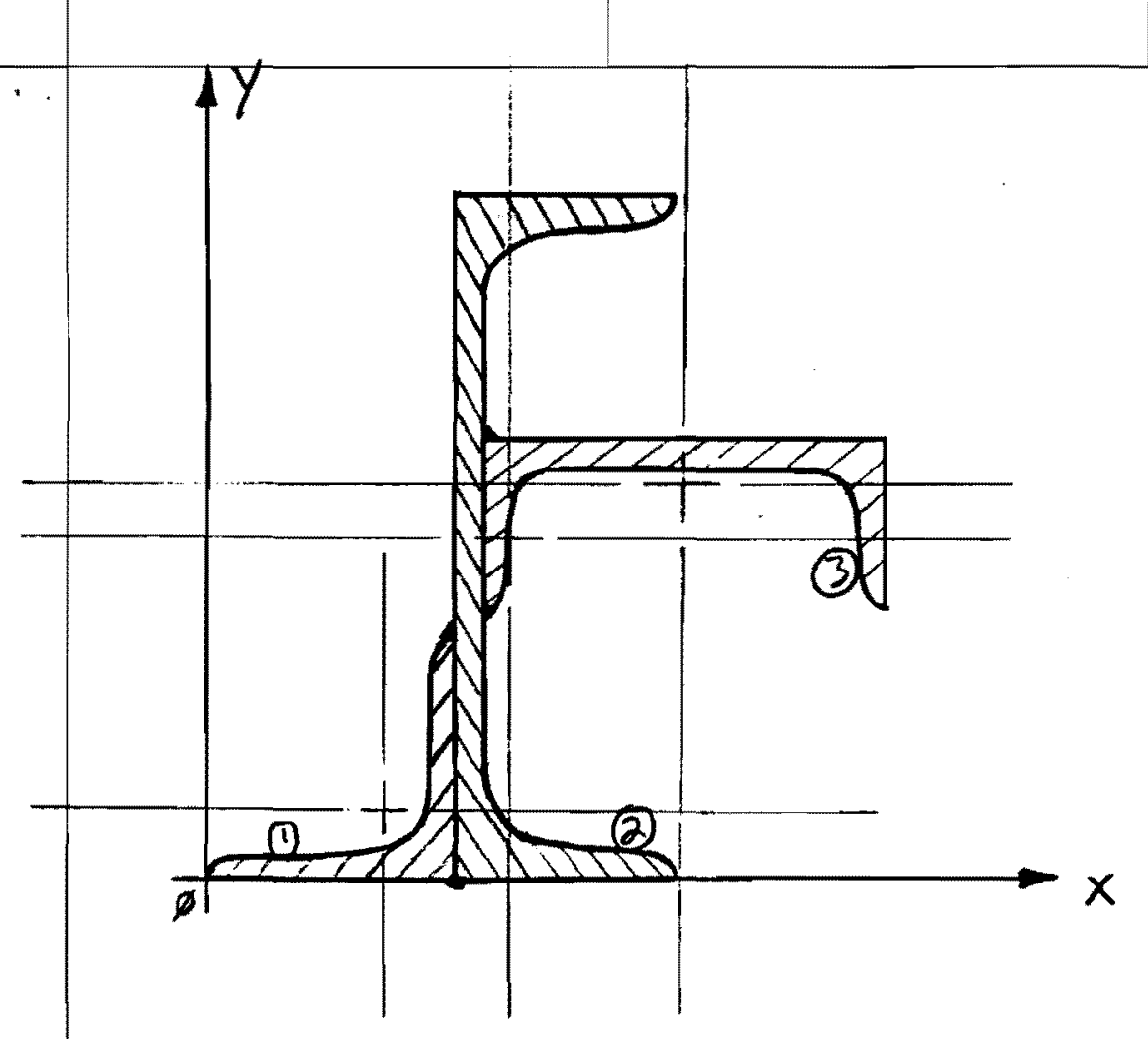

$$
\begin{aligned}
& A_{1}=1.19 \mathrm{in}^{2} \\
& A_{2}=3.6 \mathrm{in}^{2} \\
& A_{3}=2.13 \mathrm{in}^{2}
\end{aligned}
$$$$
\bar{x}_{1}=1.783 \mathrm{in}
$$$$
\bar{x}_{2}=3.025 \mathrm{in}
$$$$
\bar{x}_{3}=4.814 \mathrm{in}
$$$$
\bar{y}_{1}=8.717 \mathrm{in}
$$$$
\bar{y}_{2}=3.5 \mathrm{in}
$$

$$
\begin{aligned}
& \bar{x}=\frac{1.19(i .783)+3.6(3.025)+2.13(4.844)}{(1.19+3.6+2.13)}=3.36 \mathrm{in} \\
& \bar{y}=\frac{1.19(0.717)+3.6(3.5)+2.13(4.0)}{(1.19+3.6+2.13)}=3.18 \mathrm{in}
\end{aligned}
$$$$
\bar{y}_{3}=4.0 \mathrm{in}
$$$$
I_{1_{\overline{5}}}=0.703 \mathrm{in} 4
$$$$
I_{2_{5}}=1.17 \mathrm{in}^{4}
$$

$$
\begin{aligned}
& I_{\bar{x}}=I_{1 \bar{x}}+I_{2 \bar{x}}+I_{3 \bar{x}}+A_{1}\left(\overline{y_{1}}-\bar{y}\right)^{2}+A_{2}\left(\bar{y}_{2}-\bar{y}\right)^{2} \\
& I_{3 \frac{5}{4}}=4.59 \mathrm{in}^{4} \\
& +A_{3}\left(\overline{y_{2}}-\bar{y}\right)^{2} \\
& =0.783+24.2+0.433+1.19(0.717-3.18)^{2}+3.6(3.5-3.18)^{2} \\
& I_{1 \bar{x}}=0.703 \text { in }^{4} \\
& I_{2 \bar{x}}=24.2 \mathrm{in}^{4} \\
& I_{3 \bar{x}}=0.433 \mathrm{in}^{4}
\end{aligned}
$$

$$
\begin{aligned}
& I_{\bar{y}}=I_{1 \bar{q}}+I_{2 \bar{y}}+I_{3 \bar{g}}+A_{1}\left(\overline{x_{1}}-\bar{x}\right)^{2}+A_{2}\left(\bar{x}_{2}-\bar{x}\right)^{2}+A_{3}\left(\bar{x}_{3}-\bar{x}\right)^{2} \\
& =0.783+1.17+4.59+1.19(1.782-3.36)^{2}+3.6(3.025-3.36)^{2}+2.13(4.814-3.36)^{2} \text {. } \\
& =14.33 \text { in }^{4} \\
& r_{\overline{4}}=\sqrt{\frac{I_{\overline{7}}}{A}}=\sqrt{\frac{14.33}{1.19+3.6+2.13}}=1.44 \mathrm{in} \\
& r_{\bar{x}}=\sqrt{\frac{I_{\bar{x}}}{A}}=\sqrt{\frac{3436}{1.19+3.6+2.13}}=4.97 \mathrm{in}
\end{aligned}
$$

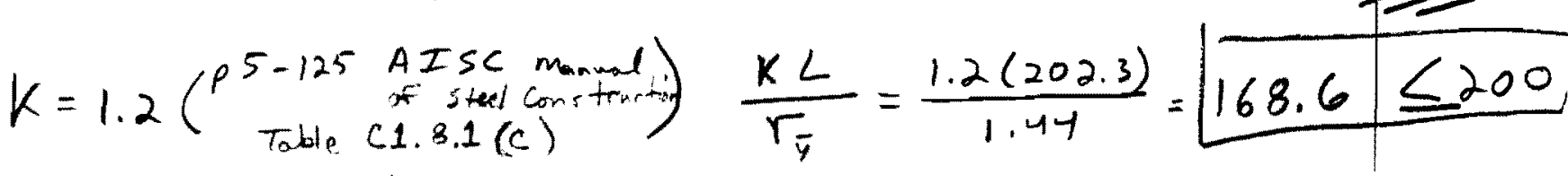


Size Rua Srrofevere fors terso Grar Guwoen.

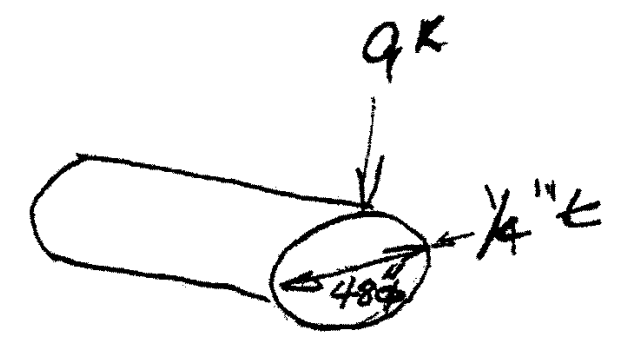

TREA AS A FinG:

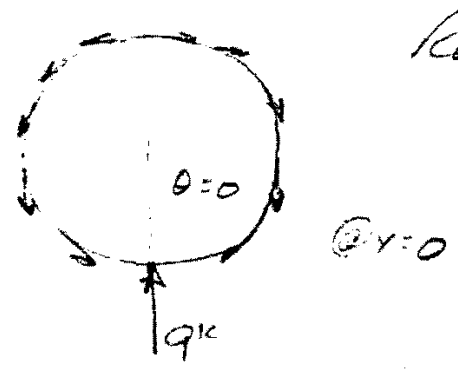

Contre $\div$ loung, P236, case 18

$$
M_{\text {AHX }}=.2382 \omega R \odot 60 \text { thom. }
$$

Limit Bersoing to O.6Fy Where Fy $=27 \mathrm{ks}$ (Geul Puop Co
$0.6 \mathrm{Fy}=16.2 \mathrm{ks}, \quad$ plote) $0.6 F_{y}=16.2 \mathrm{ks}$,

$\uparrow$

$$
\begin{aligned}
& \frac{M}{5}<16.2 \mathrm{ks} \\
& \frac{.2387 \omega 1 / 4 k}{16.2}<S \\
& \frac{=387(91 / 48)}{6.2}<5 \\
& s>6.37 \text { in }^{3}
\end{aligned}
$$

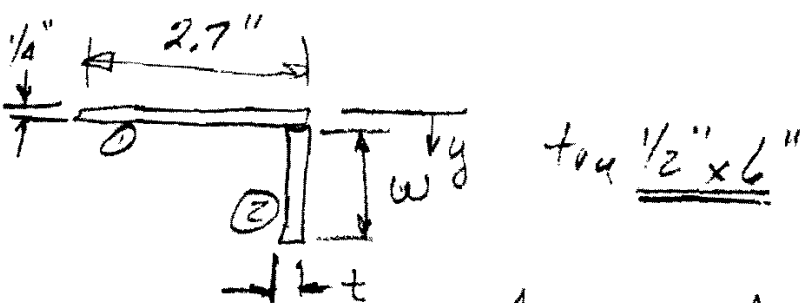

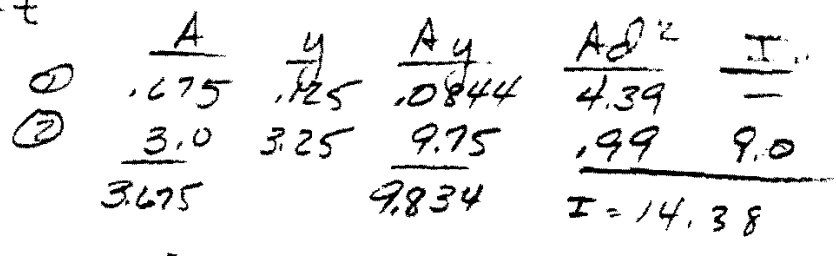

$$
\begin{aligned}
& 4=2.676 \quad s=5.37,4.02
\end{aligned}
$$

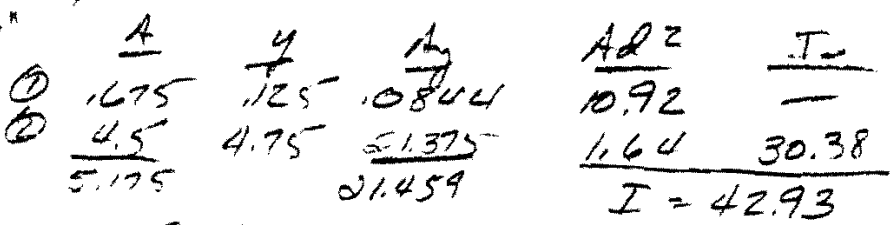

$$
\begin{aligned}
& S^{\prime}=4147 \quad S=10.35,8.4120 .1
\end{aligned}
$$$$
\frac{\pi+4 \sqrt{r t}=}{2}=
$$

dry "2"' $<9^{*}$ 
17

Check North head.

WT $\approx 665^{\circ}$ * ese 7000\%

$$
\begin{aligned}
\left(\frac{M_{x}}{\rho}\right)_{\operatorname{mar}} & \frac{27(.25)^{2}}{6(7)}=.0402 \\
\beta & =.135=.875 \frac{r_{0}}{R_{m}} \\
r_{0} & =\frac{.135(48)}{.875} \\
& =7.5^{\prime \prime}
\end{aligned}
$$

They 1/2" Cover flare

$$
\begin{aligned}
& \frac{R_{m}}{T}=\frac{48}{.75}=64 \\
& 27=\left(\frac{M_{x}}{P}\right)\left(\frac{6 P}{T^{2}}\right) \\
& \frac{M_{x}}{p}=\frac{27(.75)^{2}}{6(7)} \\
& =3 k 2 \\
& \beta_{\text {min }} \leq .02 \\
& r_{0} \approx \frac{.02(48)}{.875} \\
& =1.1 " \text { OK }
\end{aligned}
$$

use $1 / 2$ "Cover plate in area of north bead support. $\therefore$ Need "1/2"Platis,

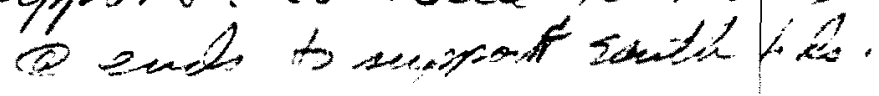




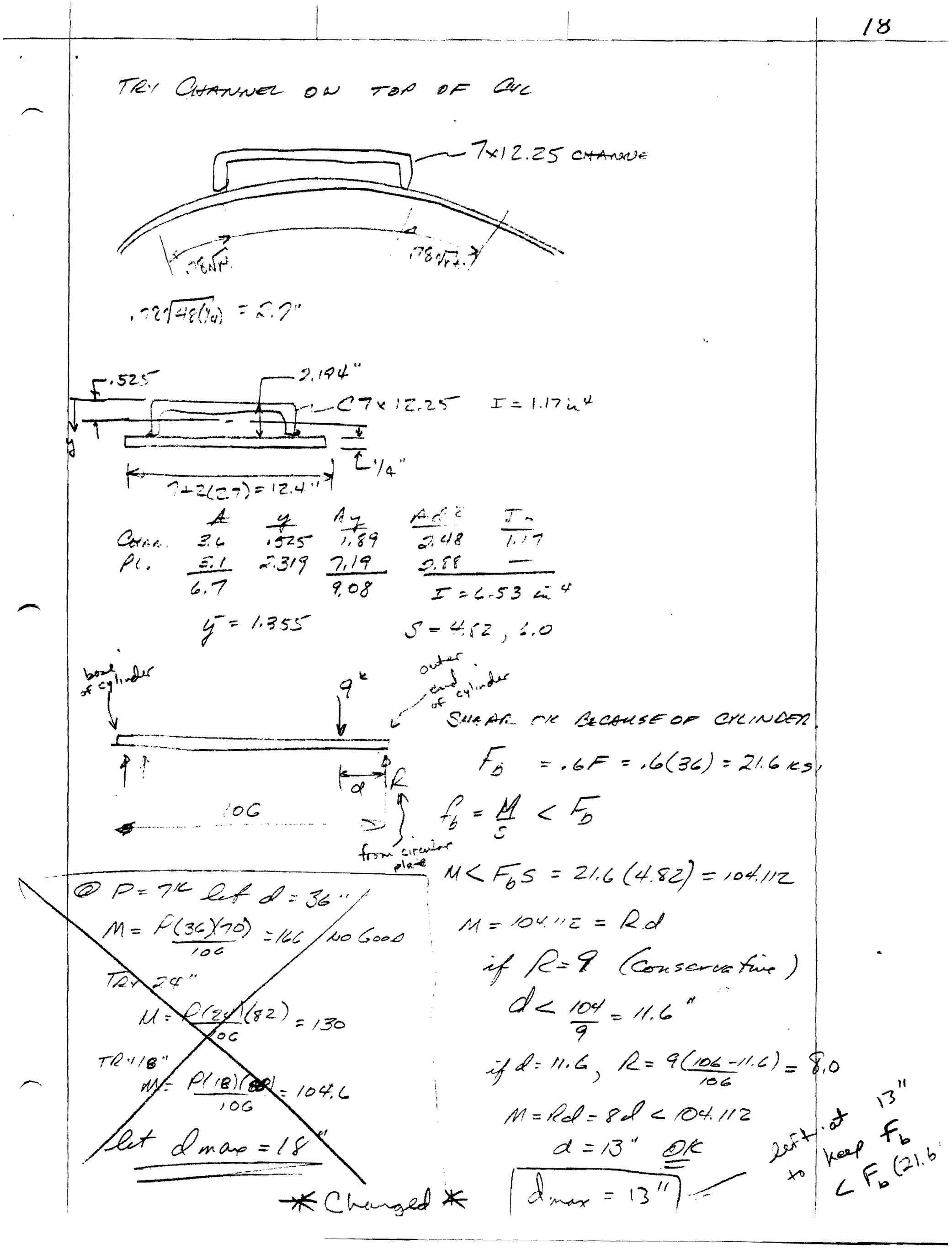




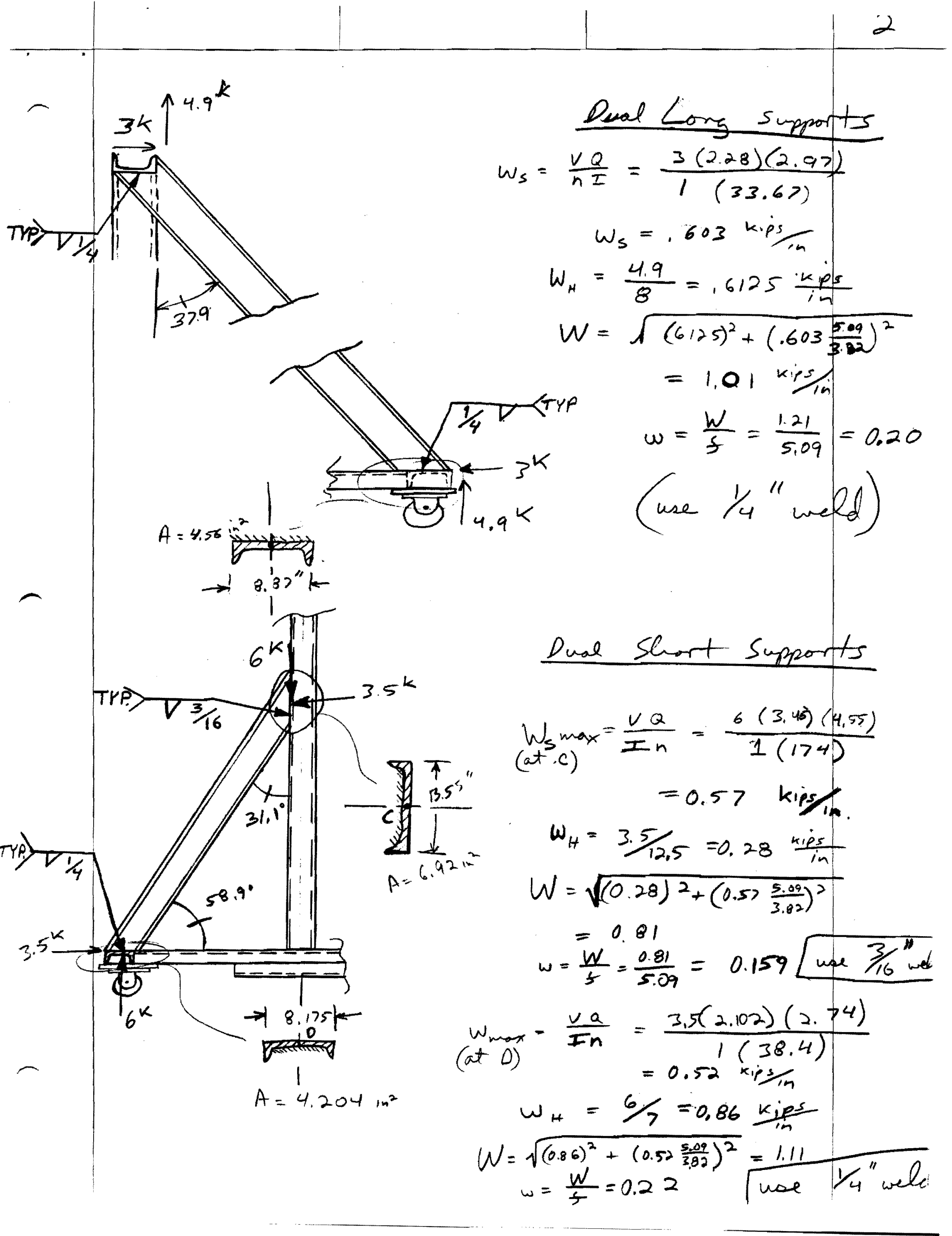




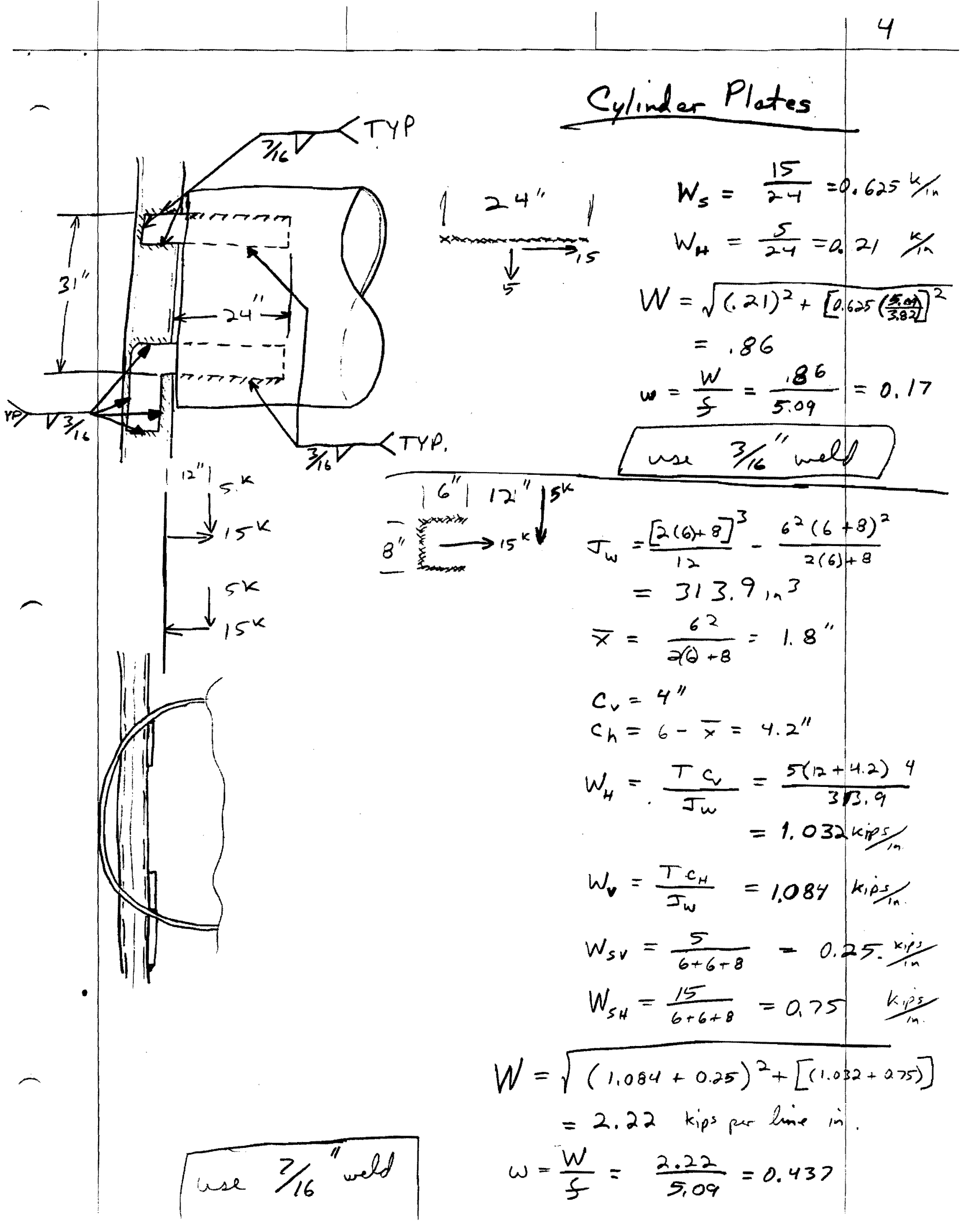




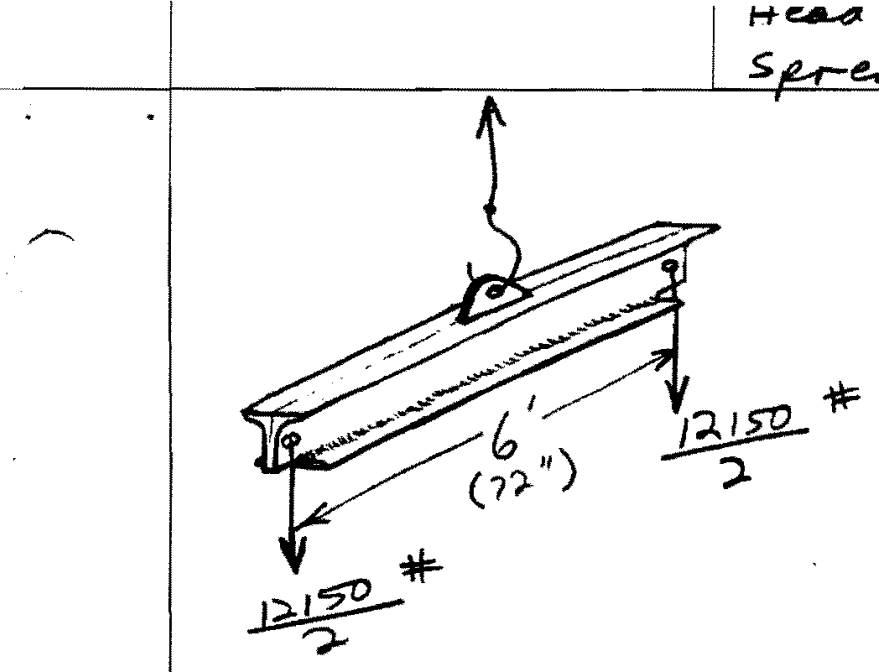

bending

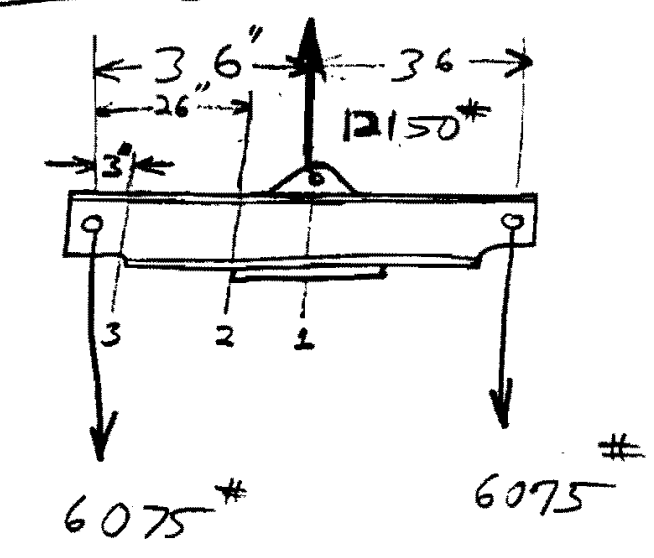

$$
\begin{aligned}
m_{1}=m_{\text {max }} & =6075(36) \\
& =218700 \mathrm{in}-\mathrm{lbs}_{\mathrm{s}} \\
s & =\frac{\mathrm{T}}{\mathrm{c}}=\frac{16243}{8.91}=18.23 \mathrm{in}^{3} \\
\sigma_{b_{1}} & =\frac{m_{\text {max }}}{\mathrm{s}}=\frac{218700}{18.23} \\
& =\frac{11.997<12 \mathrm{ksi}}{\mathrm{OK}}
\end{aligned}
$$

This spreader beam will be used to lift a $J$ and $D$ shielding blocks ( $12150^{\#}$ in order to load test the CC Cryostat Head Cart.

$$
\begin{aligned}
& \text { Material }=A 36 \begin{array}{c}
\text { structural } \\
\text { stat }
\end{array} \\
& \sigma_{A 36}=36 \mathrm{ksc} \\
& \sigma_{\text {allow }}=\frac{36}{3}=12 \mathrm{ksc} \\
& \text { per ANSI/ASME B30.20 }
\end{aligned}
$$

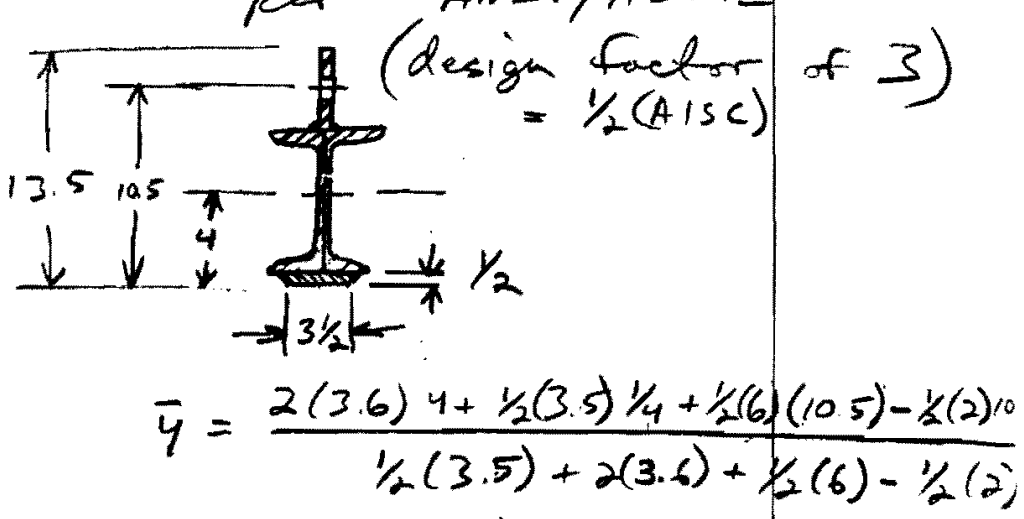

$$
\begin{aligned}
& =4.59 \mathrm{in} \\
& I=1 / 12(3.5)(0.5)^{3}+2(24.2) \\
& +1 / 12(0.5) 6^{3}-1 / 12(0.5)(2)^{3} \\
& +1 / 2(3.5)(4.59-.25)^{2}+ \\
& 2(3.6)(4.59-4)^{2}+ \\
& 1 / 2(6)(10.5-4.59)^{2}- \\
& 1 / 2(2)(10.5-4.54)^{2} \\
& =162.43 \text { in }^{4} \\
& c_{\operatorname{mox}}=13.5-\bar{y}=8.91 \mathrm{in}
\end{aligned}
$$




$$
\begin{aligned}
& m_{2}=26(6075) \\
& =157950 \mathrm{in}-\mathrm{lbs}_{\mathrm{s}}
\end{aligned}
$$

Shear

* Most critical at point 3

$$
\begin{aligned}
& V=6.075 \text { Kiss } \\
& A=3.78+1.62=5.4 \\
& \sigma_{v}=\frac{V}{A}=\frac{6.075}{5.4}=1.125 \mathrm{ksi} \\
& \quad 1.125<7.2 \mathrm{ksi}
\end{aligned}
$$

shear allowidele:

$$
\text { (DISC) } \begin{aligned}
F_{v} & =0.4 . F_{y} \\
& =0.4(36) \\
\sigma_{v_{\text {dele }}}=\gamma_{2} F_{v} & =7.2 \mathrm{ks}
\end{aligned}
$$

ok 
FRAME MAC file: HEAD CART III; Last modified at 11:24:48 AM on Mon, Aug 15, 1988

Above each load are the magnitudes in $\mathrm{lb}, \mathrm{lb} / \mathrm{in}$, and $\mathrm{lb}$-in.

Next to each support are reactions in $\mathrm{lb}$ and $\mathrm{lb}$-in.

Next to each node are deformations in inch and radians.

Rositive reactions and deformations are to the right, upwards, and counter-clockwise.

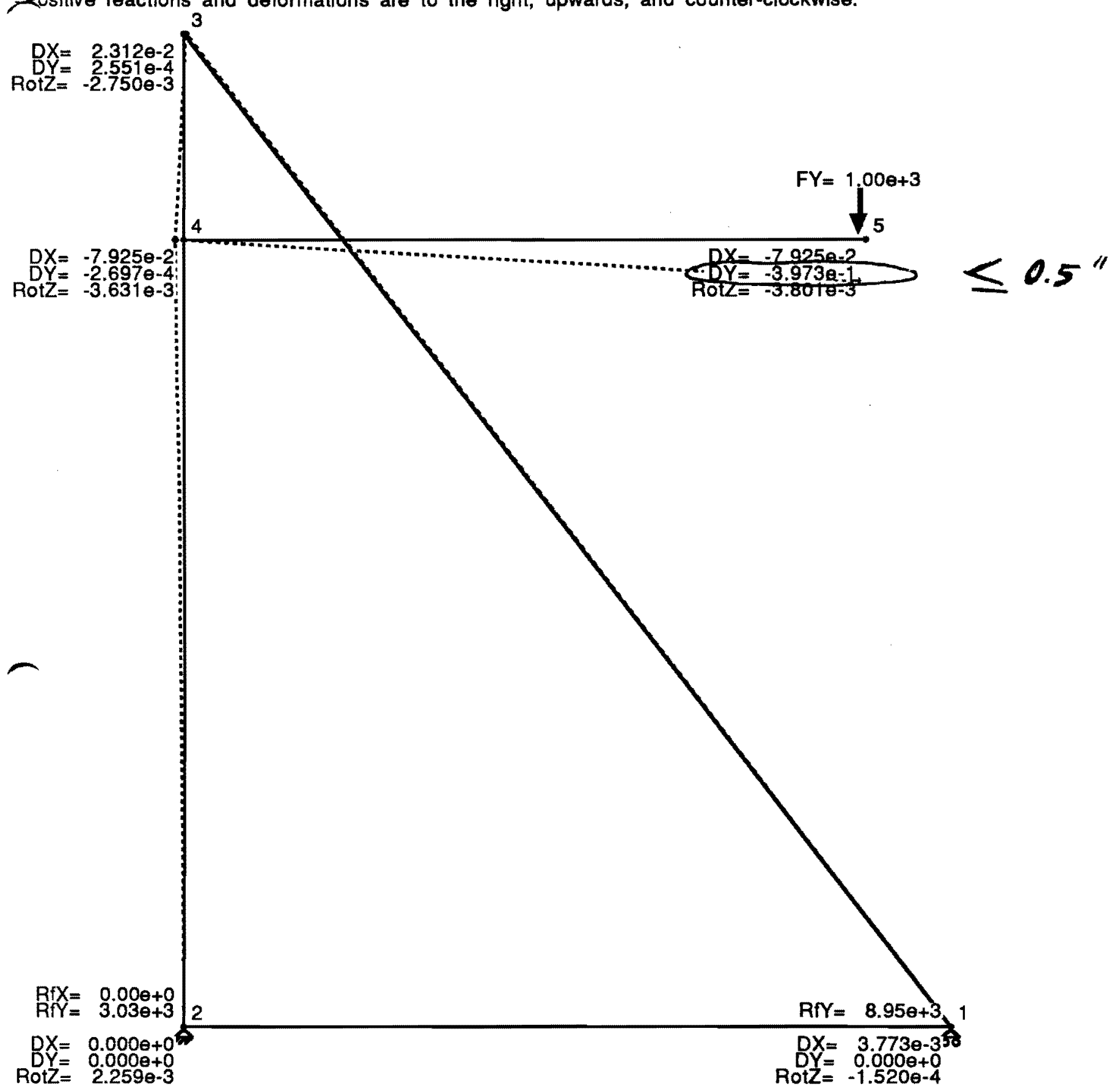


FRAME MAC file: HEAD CART; Last modified at 11:24:48 AM on Mon, Aug 15, 1988 Nóde 4 FNd2 MNd2 FNd3 MNd3 Elem 4,5 Node 5 $1.2000 \theta+1 \quad 6.62 \theta+3 \quad \cdots-6.62 \theta+3 \quad \cdots L=1.0600 \theta+2$ $1.3600 \theta+2-9.05 \theta+27.35 \theta+5-9.48 \theta+3 \quad 2.91 \dot{\theta}+5 \quad E=2.900 \theta+7$ $=1 \cdots \frac{7.35 \theta+5}{7} \longrightarrow \cdots \frac{2.91 \theta+5}{7} \mathrm{E}=2.900 \theta+7$

Load

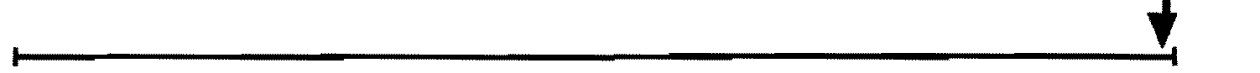

F: Ib

$\mathrm{D}$ : lb/in

$M:$ Ib-in

E: psi

$0.00 \theta+0$

10

Tension

$0.00 \theta+0$

Shear

$.04 \theta+4$

lb

$0.00 \theta+0$

$0.00 \theta+0$

Moment

lb-in

$-1.03 \theta+6$

$0.000 \theta+0$

Defl.

inch

\begin{tabular}{|c|c|c|c|}
\hline & $\prod_{0.0000 \theta+0} L / G_{2.1200 \theta+1}^{L / 4} L / 3$ & $4.2400 \theta+1$ & $\begin{array}{l}T_{6.3600 \theta+1} L / 4 L^{T} / 4 L / 6 T \\
8.4800 \theta+1\end{array}$ \\
\hline
\end{tabular}




\section{ANSYS Input file}

/prep7

/title, "Head Cart Cylinder" et, 1,63

, $1,0.25$

$r, 2,0.5$

$r, 3,0.33$

ex, $1,29 e 06$

dens, $1,7.3308465 \mathrm{e}-4$

gxy, 1, 11.5e06

acel ,, 386.04

nuxy, $1,0.27$

csys, 1

$n, 1,23.875,90.0$

$n, 2,23.875,81.57$

$n, 6,23.875,40.721$

fill

$n, 14,23.875,-40.721$

fill

$n, 19,23.875,-90.0$

fill

ngen , $9,20,1,19,1,, 3.0$

ngen , $16,20,161,179,1,1,5.4$

ngen $, 2,20,461,479,1, \ldots, 1.0$

ngen , $3,40,461,479,1,-4.4375$

csys, 0

ngen, $2,560,2,482,20,2.2$

ngen, $3,1,562,1042,20,-1.75$

nrsel, node, $564,1044,20$

nmodif, all $1.0 \mathrm{e}-8$

nall

csys, 1

$e, 1,2,22,21$

egen, $18,1,1$

egen, $24,20,1,18$

real, 2

e, $461,462,502,501$

egen, $18,1,433$

egen $, 2,40,433,450$

real, 3

$e, 2,22,582,562$

$0,562,582,583,563$

$\bullet, 563,583,584,564$

egen , 24, 20, 469, 471

knode, 1, 166

knode, 2,6

$k, 3,23.875,40.721,-6.0$

knode 7,174

knode, 8,14

$k, 14,23.875,-40.721,-6.0$

csys, 0

real, 2

kgen, $2,1,3,1,-8.0,3$

kgen, $2,7,8,1,8.0$

kgen, $2,10, \ldots,-6.0$

kgen $, 2,10,11, \ldots,-20.0$

$-1,2,1,8$

$1,8,7,8$

$1,8,10,4$

$1,5,2,4$ 


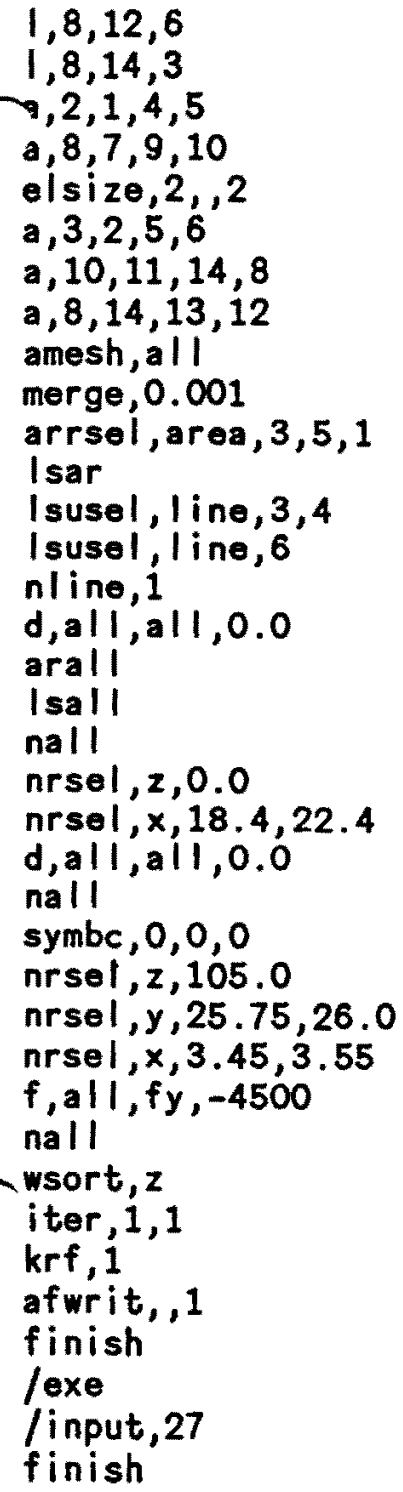




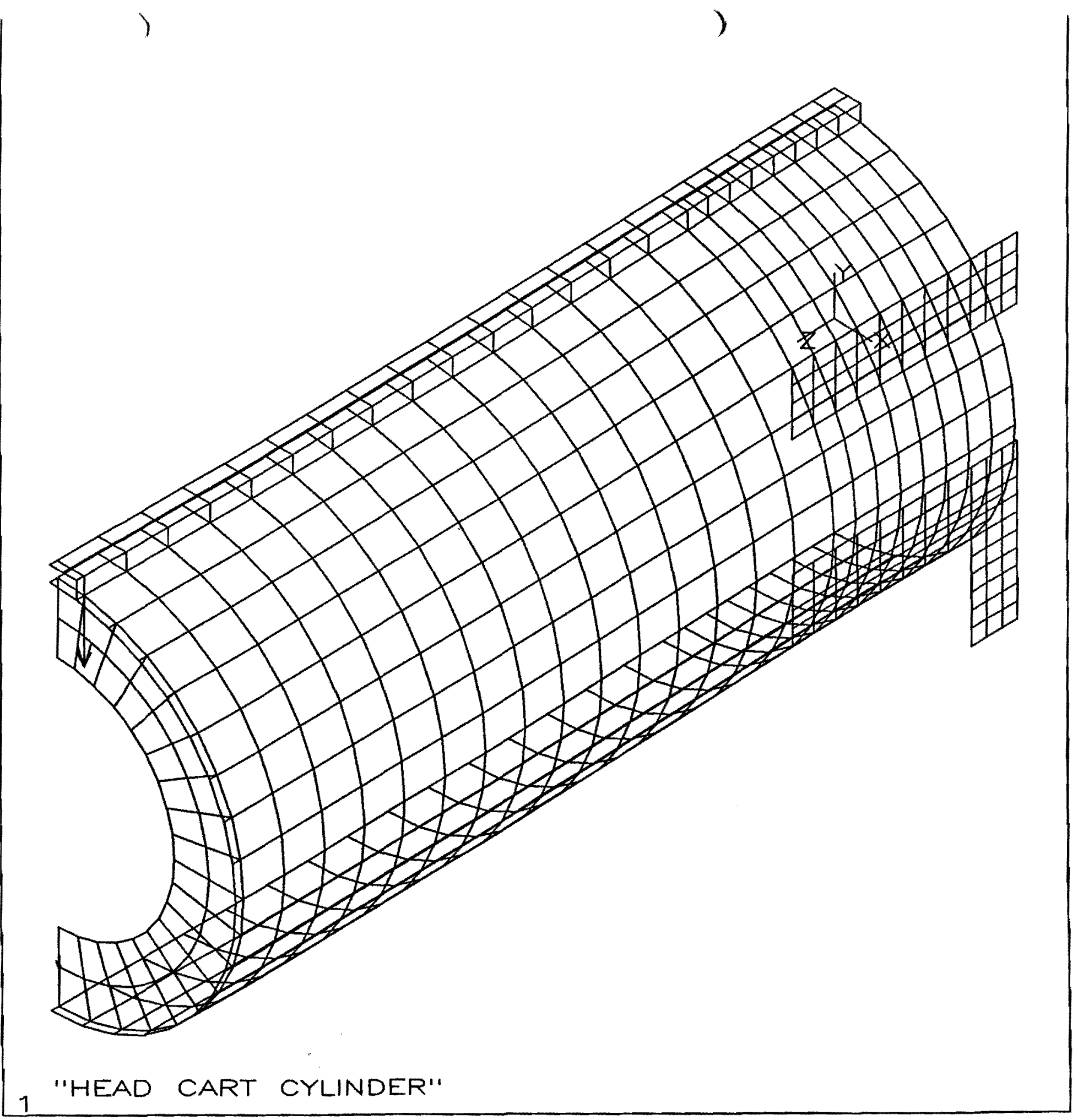

$\begin{array}{cc}\text { ANSYS } & 4.3 \\ \text { AUG } 17 & 1988^{\circ}\end{array}$

13:30:12

PLOT NO.

1

PREP7 ELEMENTS FORC BC

$$
\begin{aligned}
& \text { ORIG } \\
& X V=1 \\
& Y V=1 \\
& Z V=1 \\
& D I S T=50.6 \\
& X F=7.8 \\
& Y F=1.35 \\
& Z F=48.7
\end{aligned}
$$




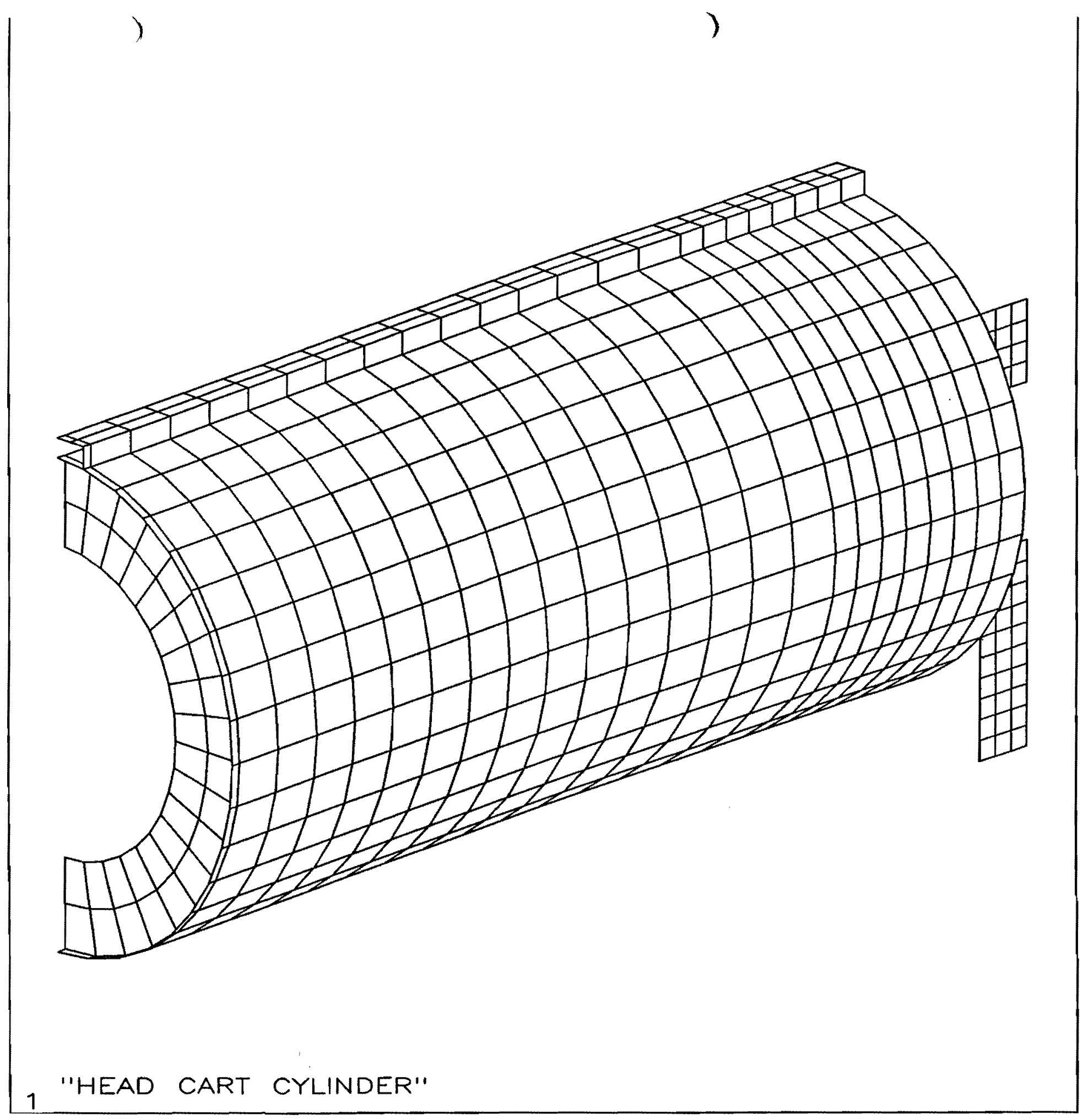

$\begin{array}{cc}\text { ANSYS } & 4.3 \\ \text { AUG } 16 & 1988\end{array}$

10:06:11

PLOT NO.

1

PREP7 ELEMENTS

ORIG

$X V=1$

$Y=.5$

$\mathrm{ZV}=1$

$\mathrm{DIST}=50.6$

$X F=9.15$

$Y F=2.2$

$Z F=50.1$

HIDDEN 


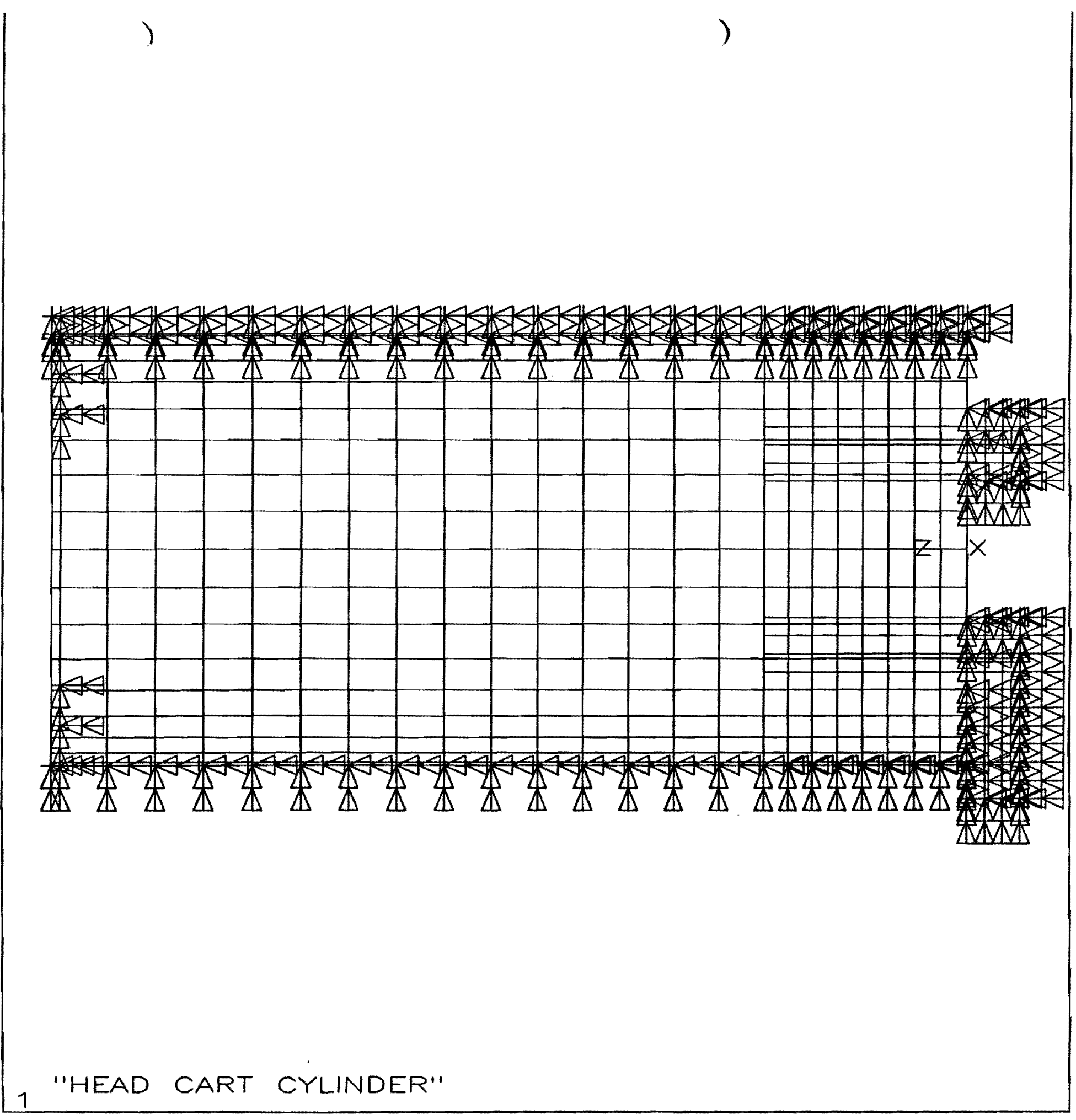

$\begin{array}{cc}\text { ANSYS } & 1.3 \\ \text { AUG } 22 & 1988 .\end{array}$

$11: 24: 35$

PLOT NO. 4

PREPT ELEMENTS

TDIS BC

RDIS BC

ORIG

$X V=1$

$\mathrm{DIST}=61.6$

$X F=11.9$

$Y F=-.879$

$Z F=50$ 


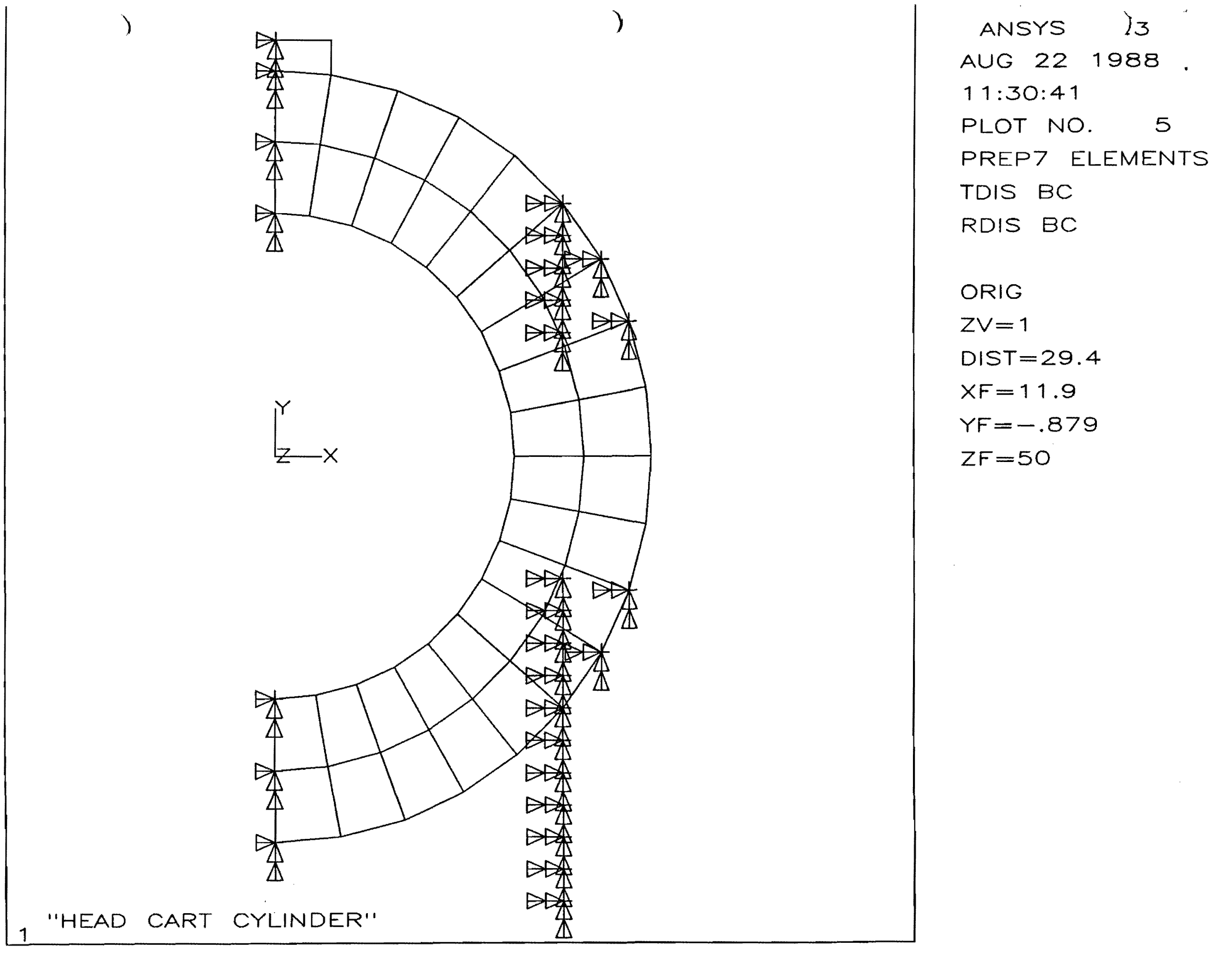




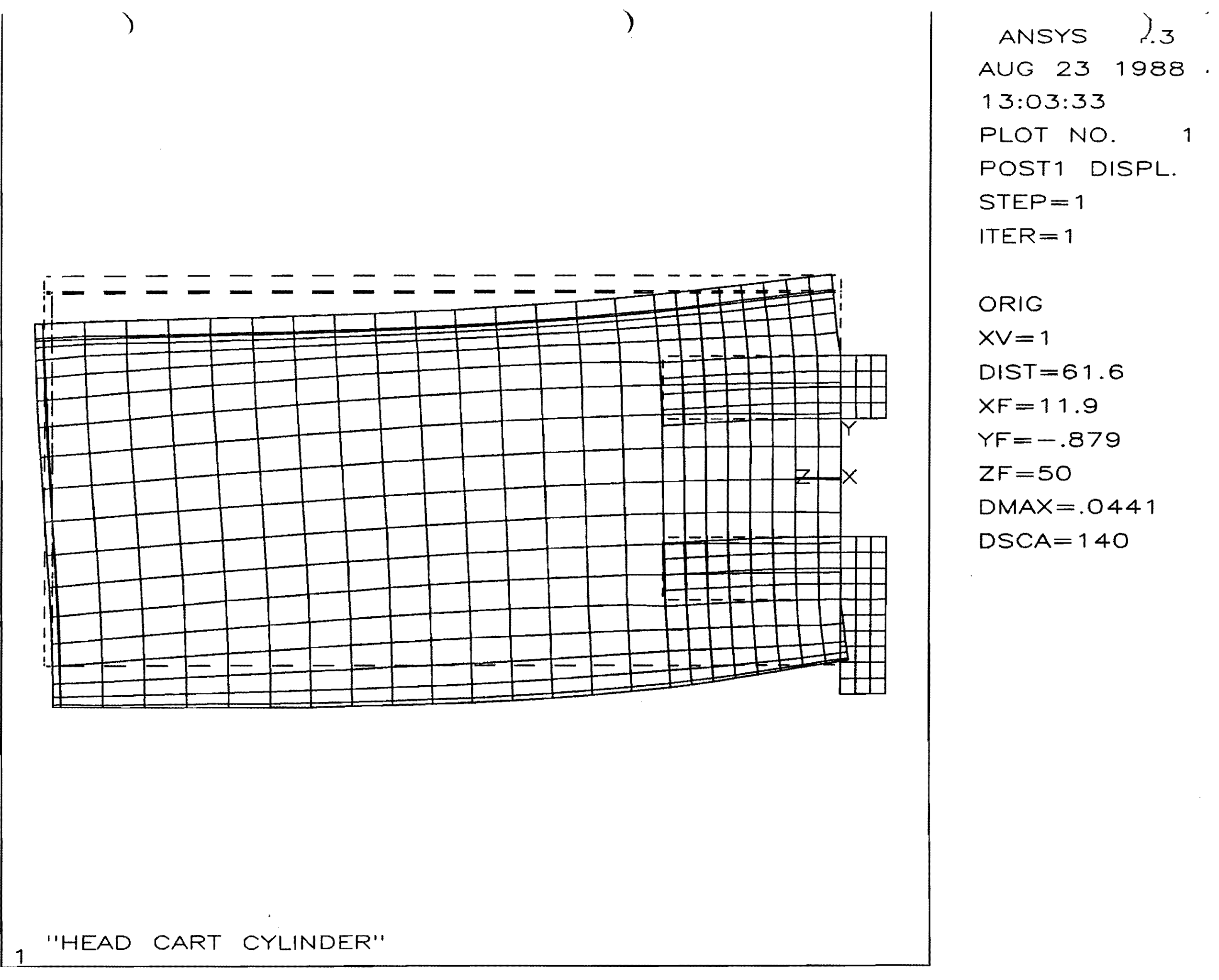




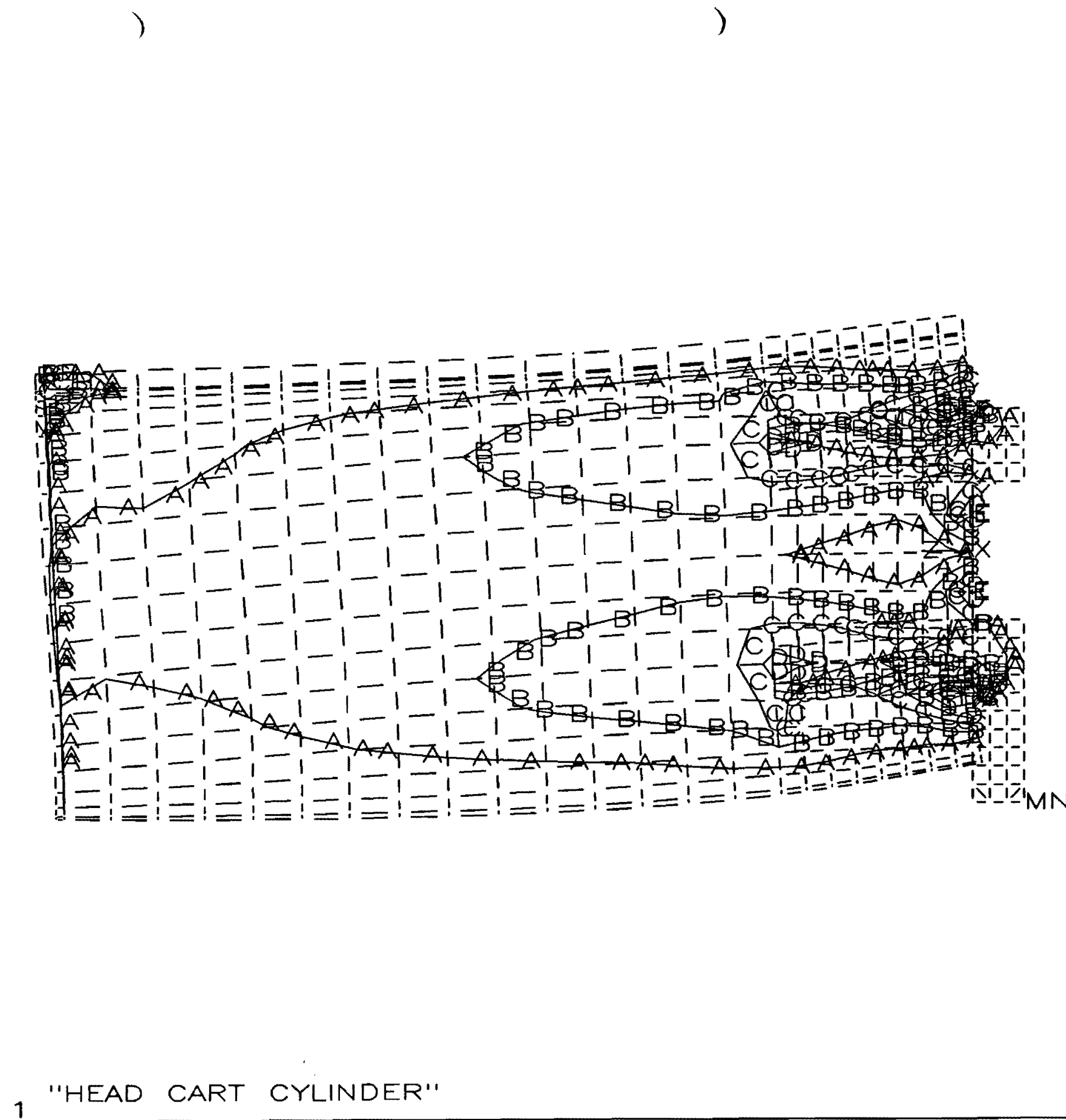

ANSYS $\quad-$ ? 3

$A \cup G 231988$.

13:06:05

PLOT NO. 2

POST1 STRESS

$S T E P=1$

ITER $=1$

SI

TOP

ORIG

$X V=1$

$\mathrm{DIST}=61.6$

$X F=11.9$

$Y F=-.879$

$Z F=50$

$M X=8036$

$M N=4.4$

$A=1150$

$B=2298$

$C=3446$

$D=4594$

$E=5742$

$F=6890$ 


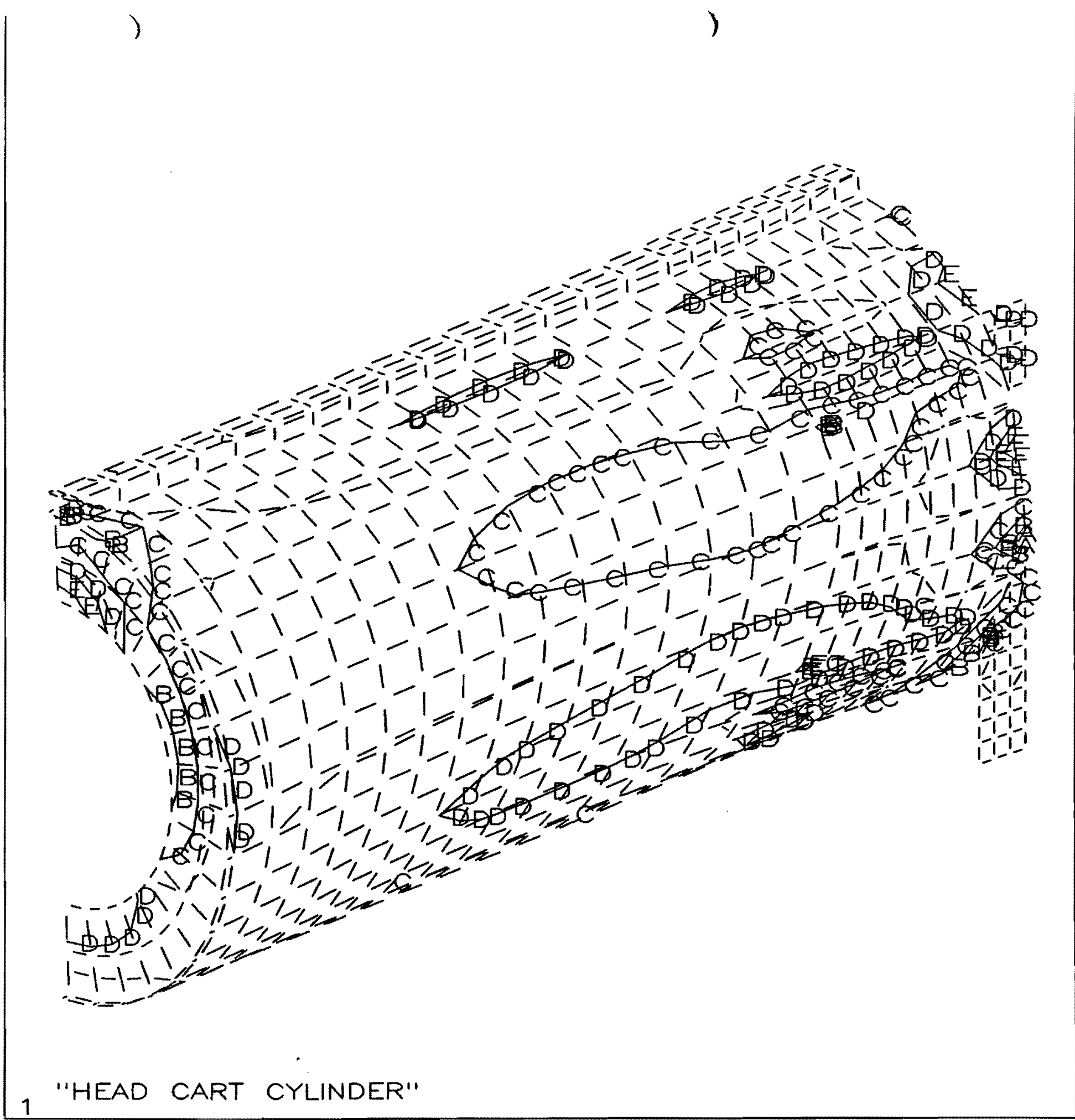

ANSYS +3

AUG $23 \quad 1988$

14:02:12

PLOT NO.

5

POST1 STRESS

$S T E P=1$

ITER $=1$

$S X$

(AVG)

TOP

STRESS ELEM CS

ORIG

$X V=1$

$Y V=.5$

$\mathrm{ZV}=1$

$\mathrm{DIST}=50.6$

$X F=9.15$

$Y F=2.2$

$Z F=50.1$

HIDDEN

$M X=5372$

$M N=-5414$

$A=-3873$

$\mathrm{B}=-2332$

$C=-791$

$\mathrm{D}=750$

$E=2291$

$F=3832$ 


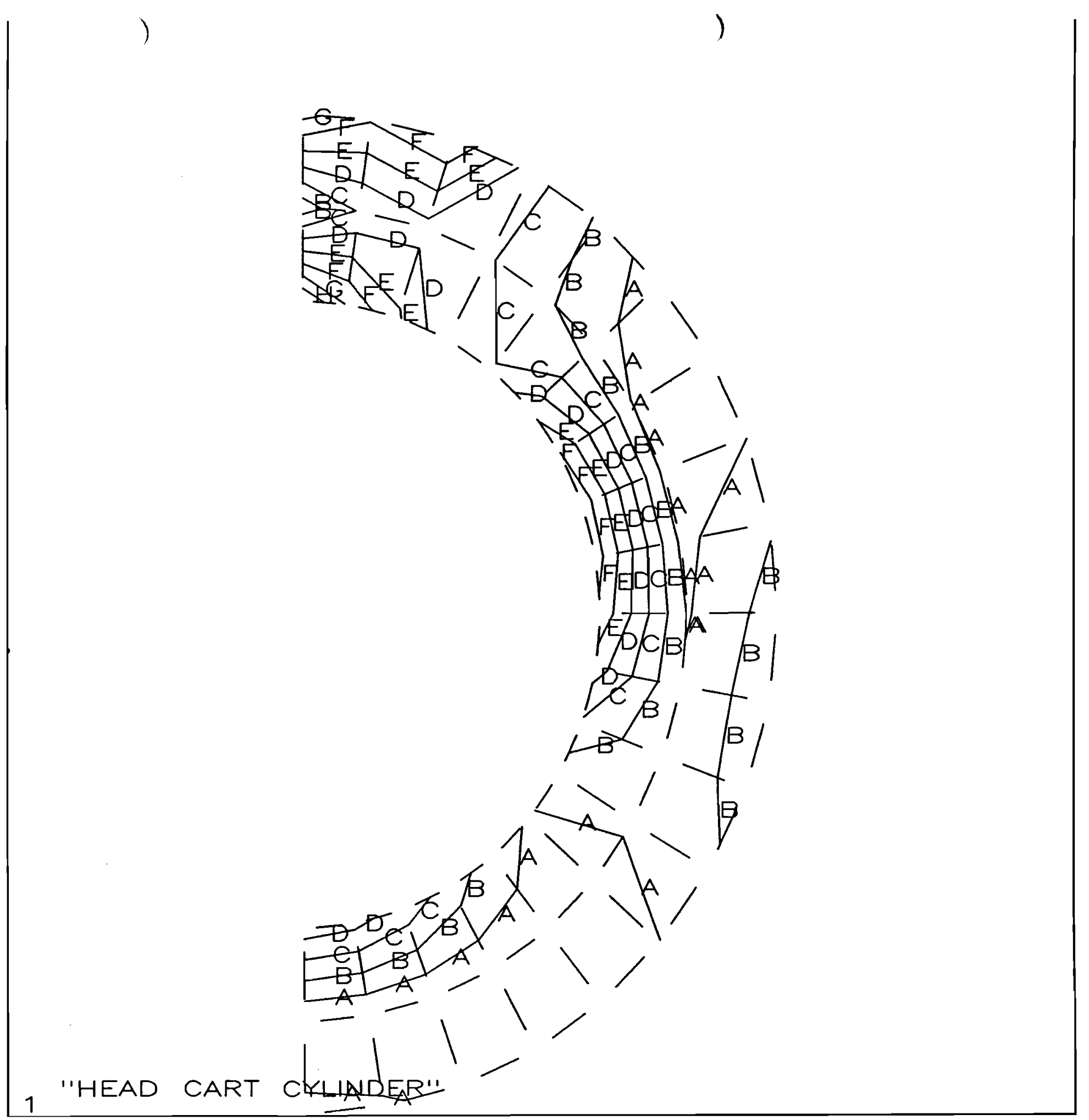

ANSYS 4.3 AUG 231988 . 15:10:19 PLOT NO. 1 POST1 STRESS $S T E P=1$ ITER $=1$ SI (AVG) TOP

ORIG

$\mathrm{ZV}=1$ $\mathrm{DIST}=26.3$ $X F=11.9$ $Z F=105$ HIDDEN $M X=4091$ $M N=407$ $A=814$ $B=1224$ $C=1634$ $D=2044$ $E=2454$ $\mathrm{F}=2864$ $G=3274$ $\mathrm{H}=3684$ 


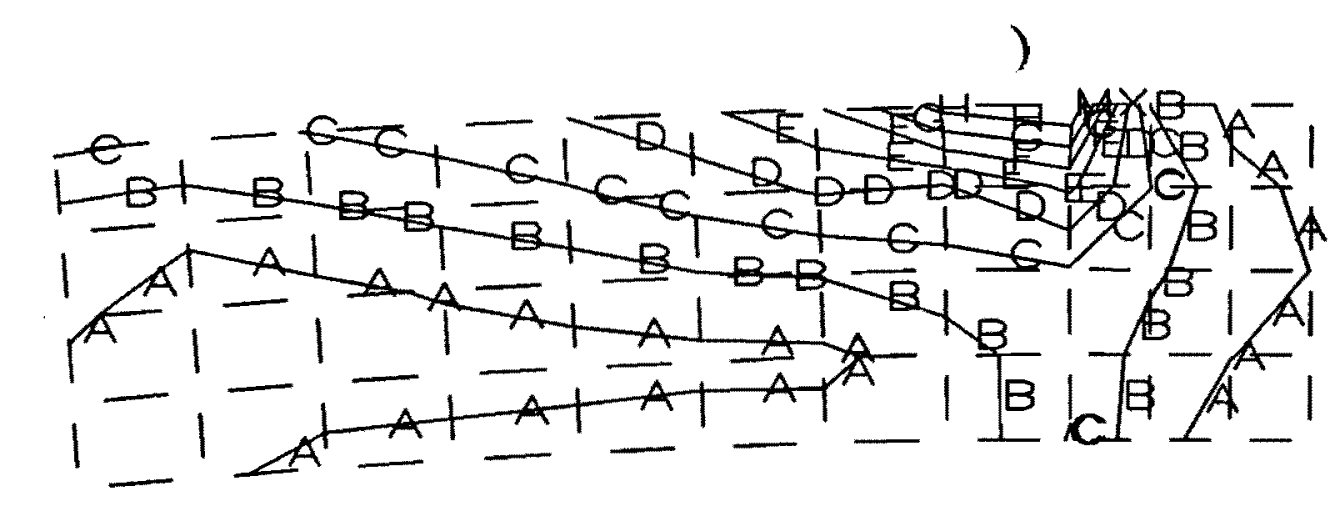

ANSYS 4.3 AUG $23 \quad 1988$ 15:34:53 PLOT NO.

POST1 STRESS $S T E P=1$

ITER $=1$

$S$<smiles>[Z][X][V]</smiles>
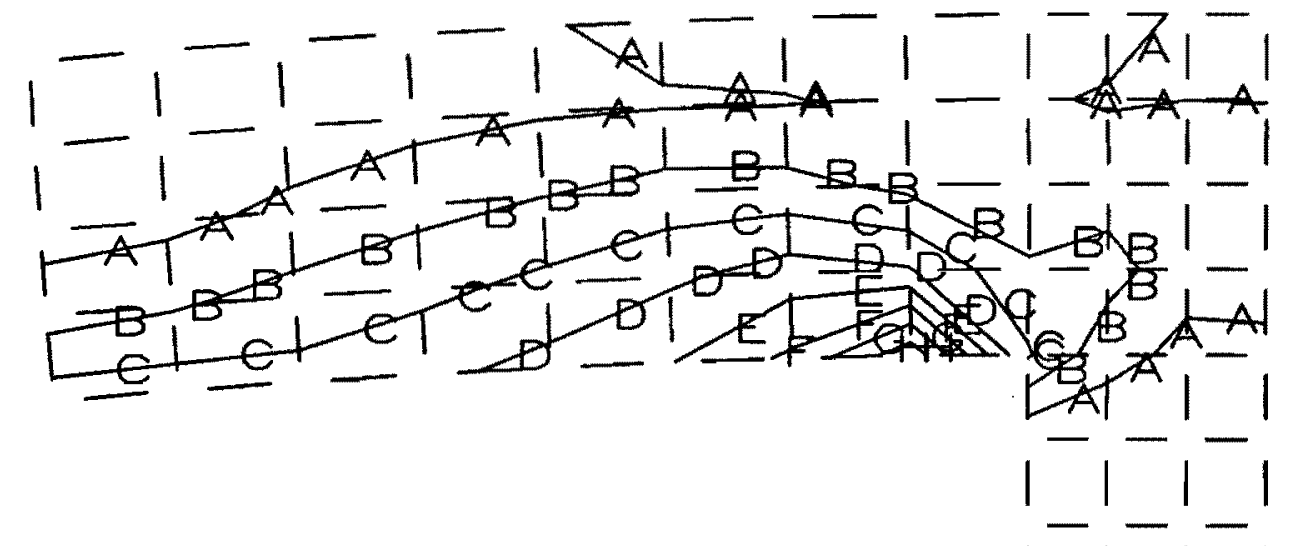

BOTTOM

\section{ORIG}

$X V=1$

$\mathrm{DIST}=23.7$

$X F=18.1$

$Y F=-6$

$Z F=9$

$M X=7034$

$M N=4.5$

$A=782$

$B=1564$

$C=2346$

$D=3128$

$E=3910$

$F=4692$

$G=5474$

$H=6256$ 
From: FNAL: :MULHOLLAND

11-AUG-1988 16:27

To: JAQUES, MULHOLLAND

Subj: Update

From: FNAL::MULHOLLAND 10-AUG-1988 $17: 19$

TO: JAQUES, MULHOLLAND

Subj: Proposed Head Cart Procedure

Head Cart Load Test Procedure...............

Updated.............................

load.

1. Design and fabricate a suitable spreader beam for the Head Cart

2. Test the spreader beam to $\mathbf{3 1 2 5 \%}$ of intended service, i.e.

$$
>1.25 * 1.25 * 9,000 *=14063 *
$$

3. Support the Head Cart ONLY at the four corners, and position to put the test load and test position neatly under the building crane.

4. Make a load of $>1.25 * 9,000=11,250 *$ of stackable materials, sling acccording to good practice, include a 25,000 spring scale, and lift to weigh the load.

5. Mark the spreader beam center clearly and carefully, mark the longitudinal point of head load on the Head Cart cylinder so it can be easily seen and check and correct the level of the Cart cylinder, as required.

6. Rope off the area of the test.

7. Provide a means of deflection measurement of the cylinder end. That means should not interfere with the loading, allow accurate ( $1 / 16^{n}$ resolution) determination, and be read without compromising the safety of the reader. yet contacted.

8. Notify any and all interested observers of the impending test not

9. Lift and load the Head Cart by gradual reduction of the crane load on the spring scale. Measure the deflection at approximately,

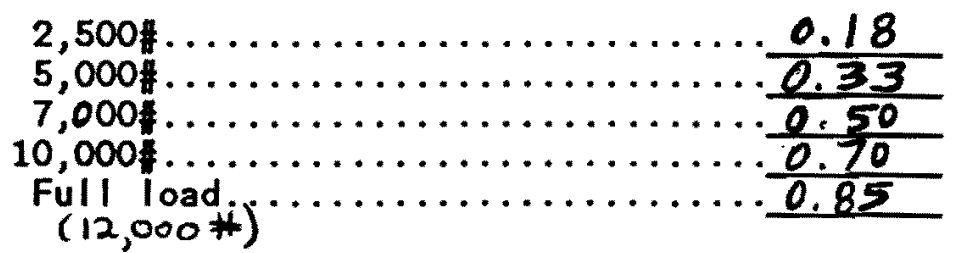

Plot the doflection as a function of load and cease loading if any significant deviation from linearity is seen or suspected. Begin again as may be required.

Continue loading to Full load and hold for 10 minutes. Lift the load and measure the return toward the initial cylinder position. Repeat the loading cycle to test repeatability. When the Full load deflections are demonstrated to have no hysteresis and the deflections are less than a half inch, the test is complete. Secure the load, take down the ropes, and secure the crane. 
From: FNAL: :MULHOLLAND

11-AUG-1988 16:27

To: JAQUES, MULHOLLAND

W/Angle Braces

Subj: Update

From: FNAL: :MULHOLLAND 10-AUG-1988 $17: 19$

To: JAQUES, MULHOLLAND

Subj: Proposed Head Cart Procedure

Head Cart Load Test Procedure................ . 8/10/88

Updated...........................

load.

1. Design and fabricate a suitable spreader beam for the Head Cart

2. Test the spreader beam to $>125 \%$ of intended service, i.e.

$>1.25 * 1.25 * 9,000 *=14063 *$

3. Support the Head Cart DNLY at the four corners, and position to put the test load and test position neatly under the building crane.

4. Make a load of $>1.25 * 9,000=11,250$ of stackable materials, sling according to good practice, include a 25,000 spring scale, and lift to weigh the load.

5. Mark the spreader beam center clearly and carefully, mark the longitudinal point of head load on the Head Cart cylinder so it can be easily seen and check and correct the level of the Cart cylinder, as required.

6. Rope off the area of the test.

7. Provide a means of deflection measurement of the cylinder end. That means should not interfere with the loading, allow accurate (1/16" resolution) determination, and be read without compromising the safety of the reader.

8. Notify any and all interested observers of the impending test not yet contacted.

9. Lift and load the Head Cart by gradual reduction of the crane load on the spring scale. Measure the deflection at approximately,

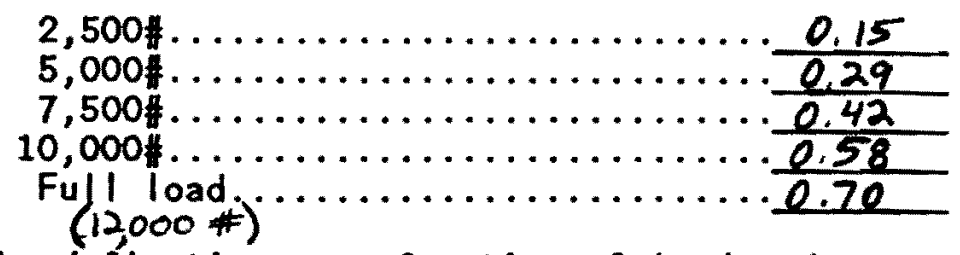

and

$$
(12,000 \#)
$$

Plot the deflection as a function of load and cease loading if any significant deviation from linearity is seen or suspected. Begin again as may be required.

Continue loading to Full load and hold for 10 minutes. Lift the load and measure the return toward the initial cylinder position. Repeat the loading cycle to test repeatability. When the Full load deflections are demonstrated to have no hysteresis and the deflections are less than a half inch, the test is complete. Secure the load, take down the ropes, and secure the crane. 


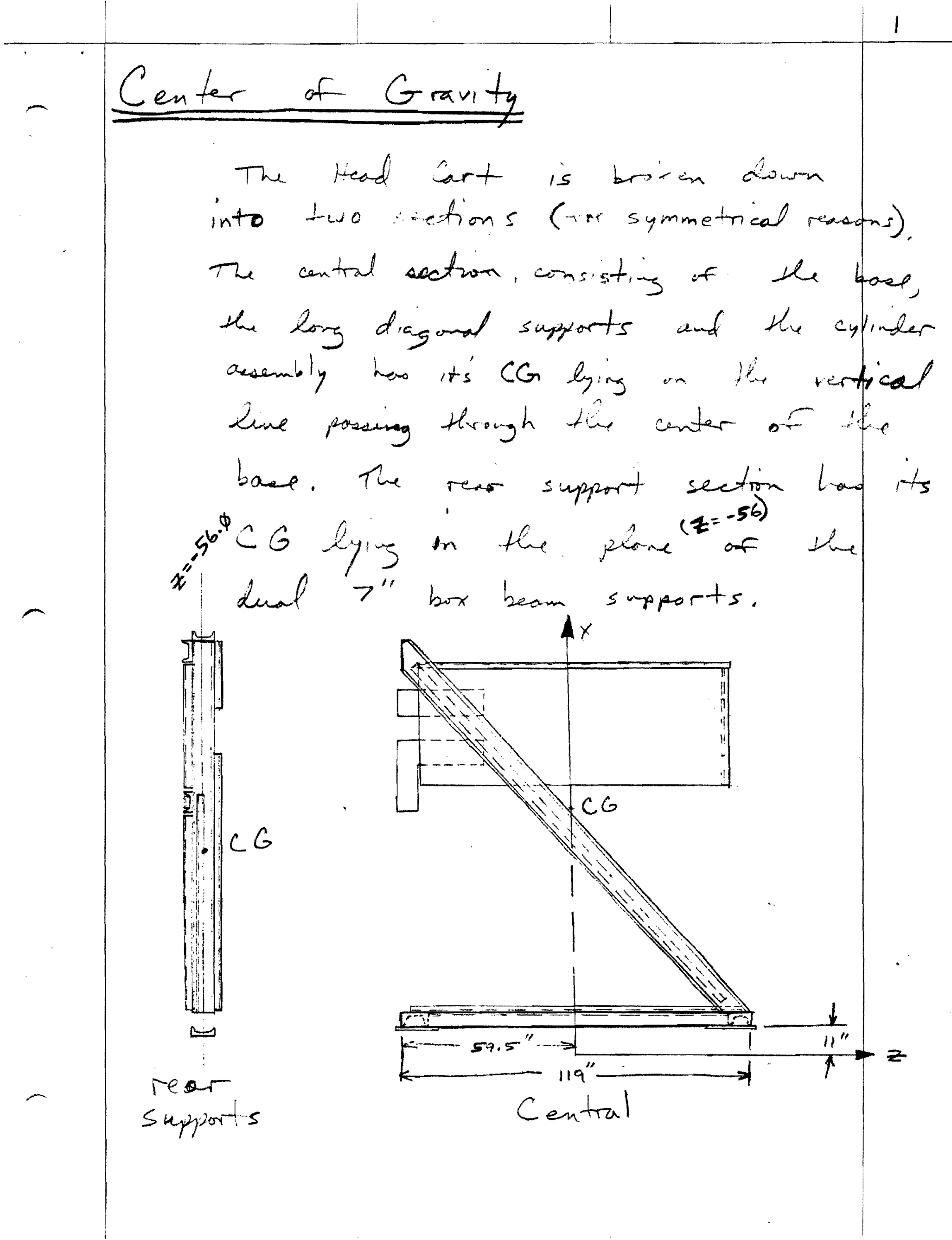




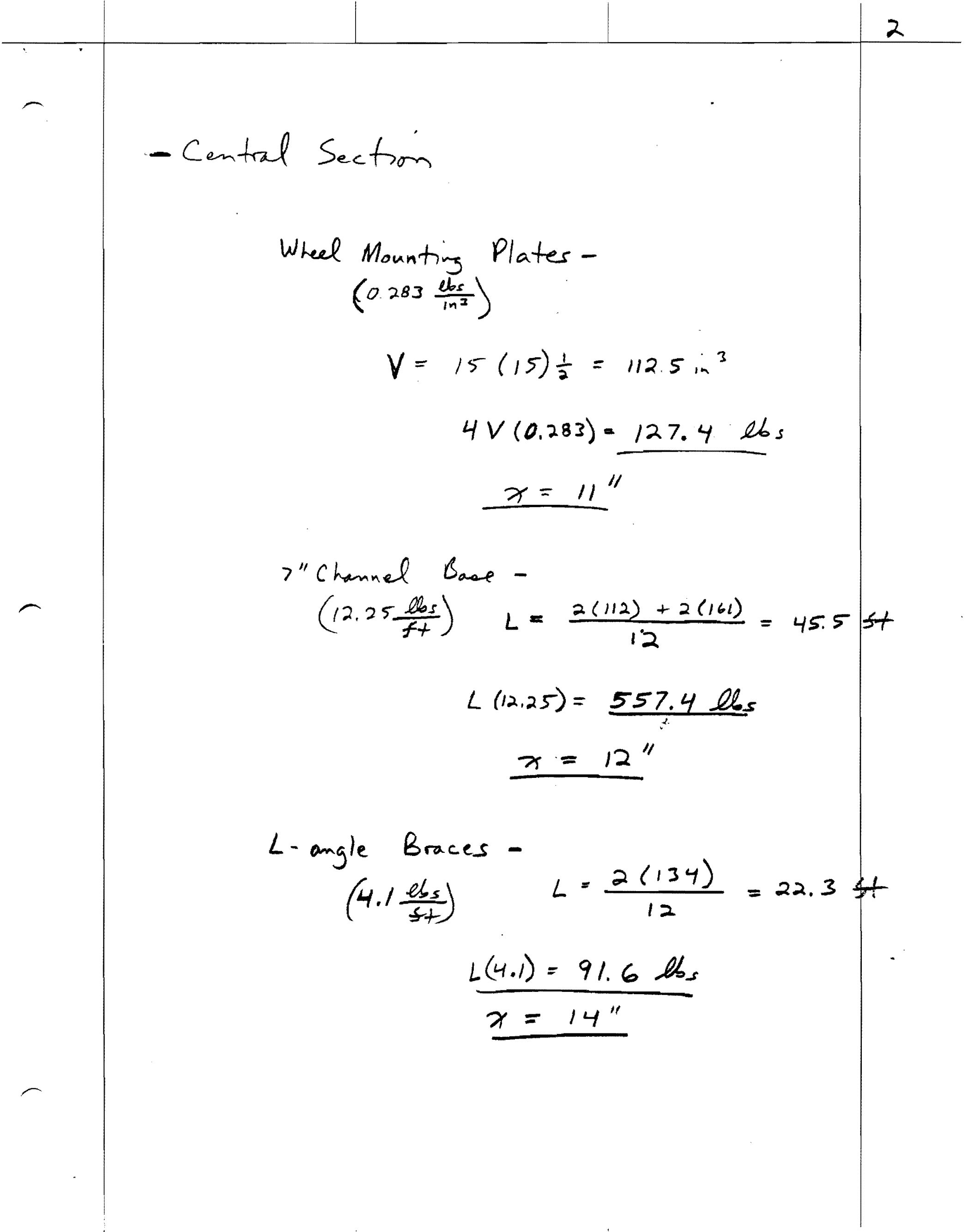




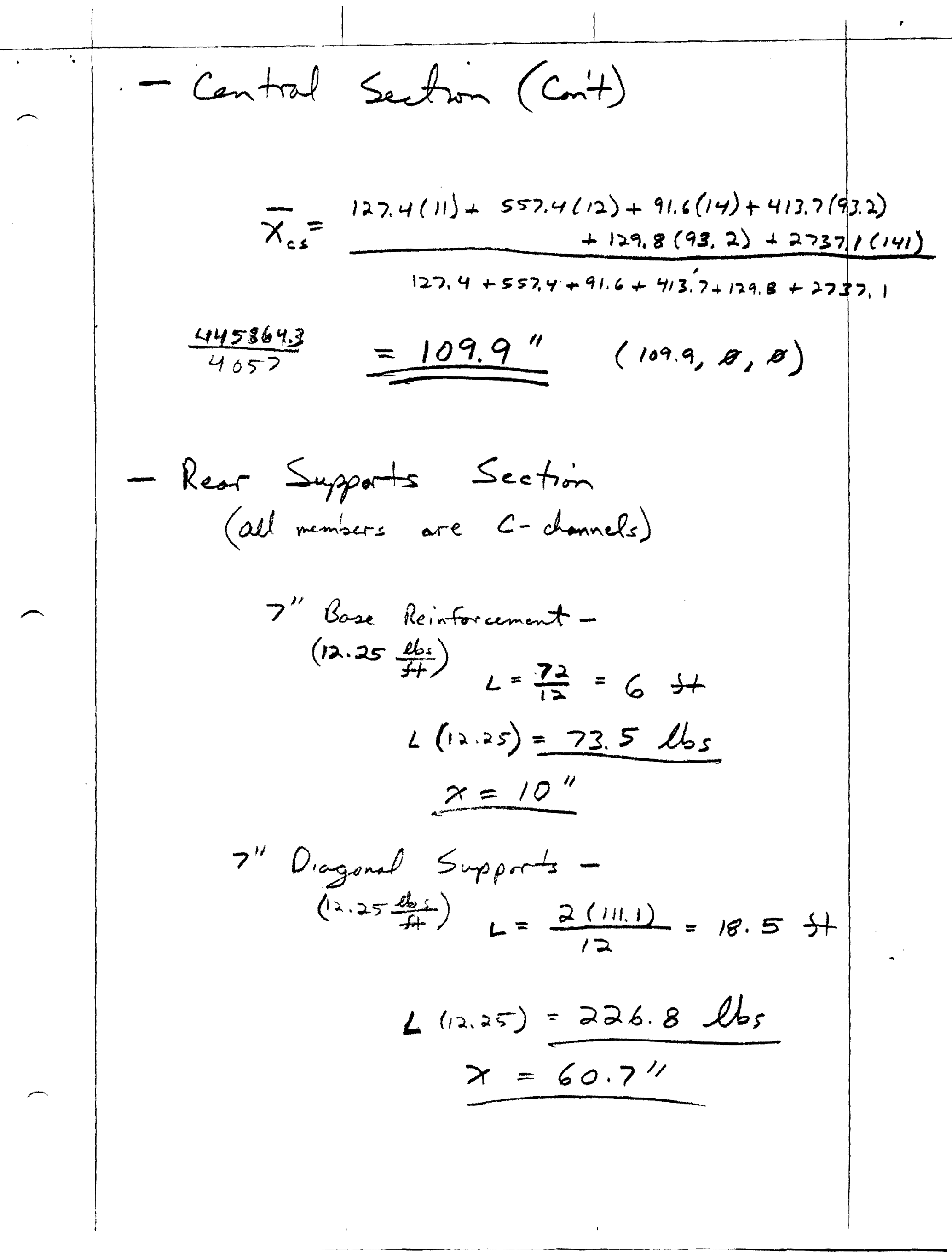




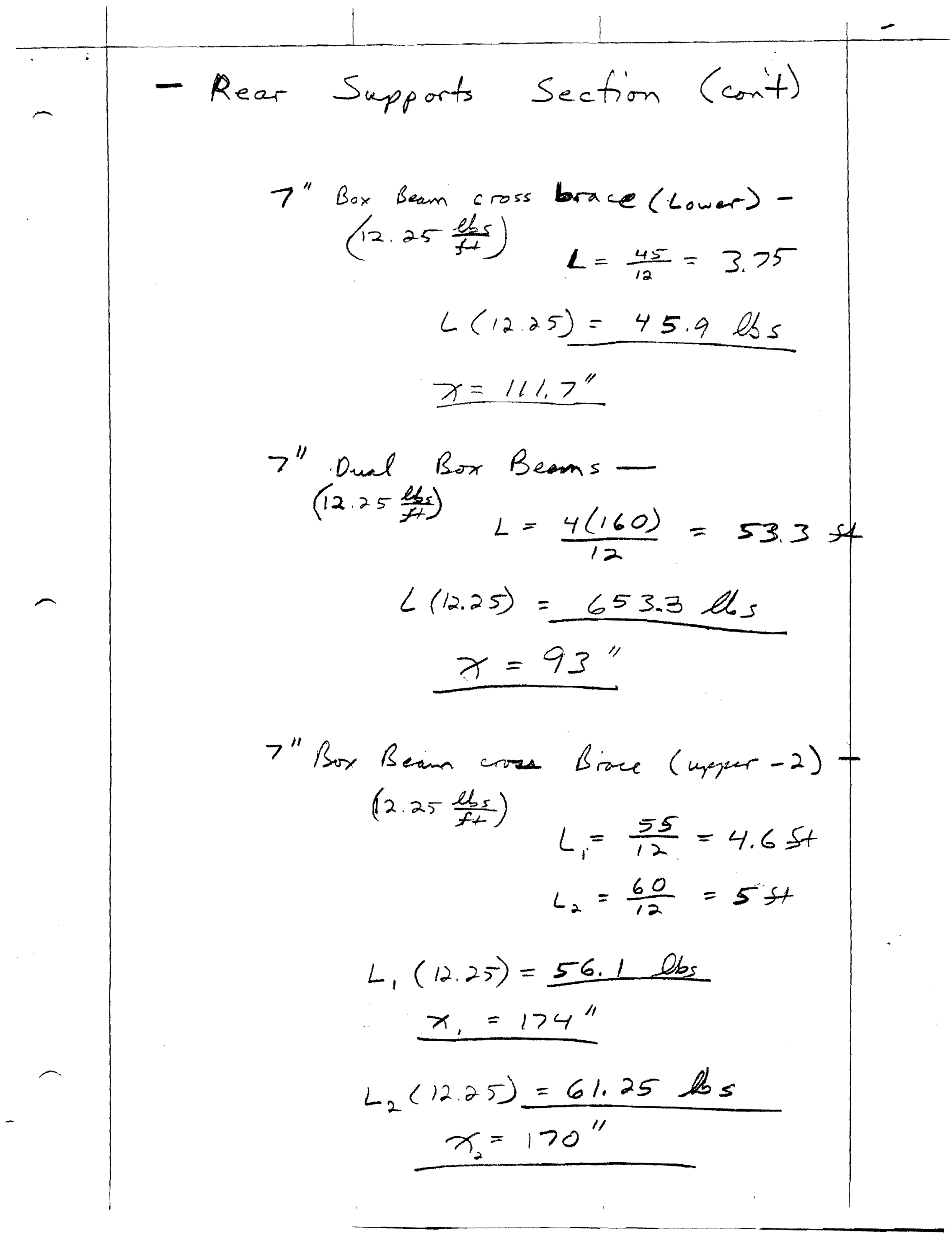




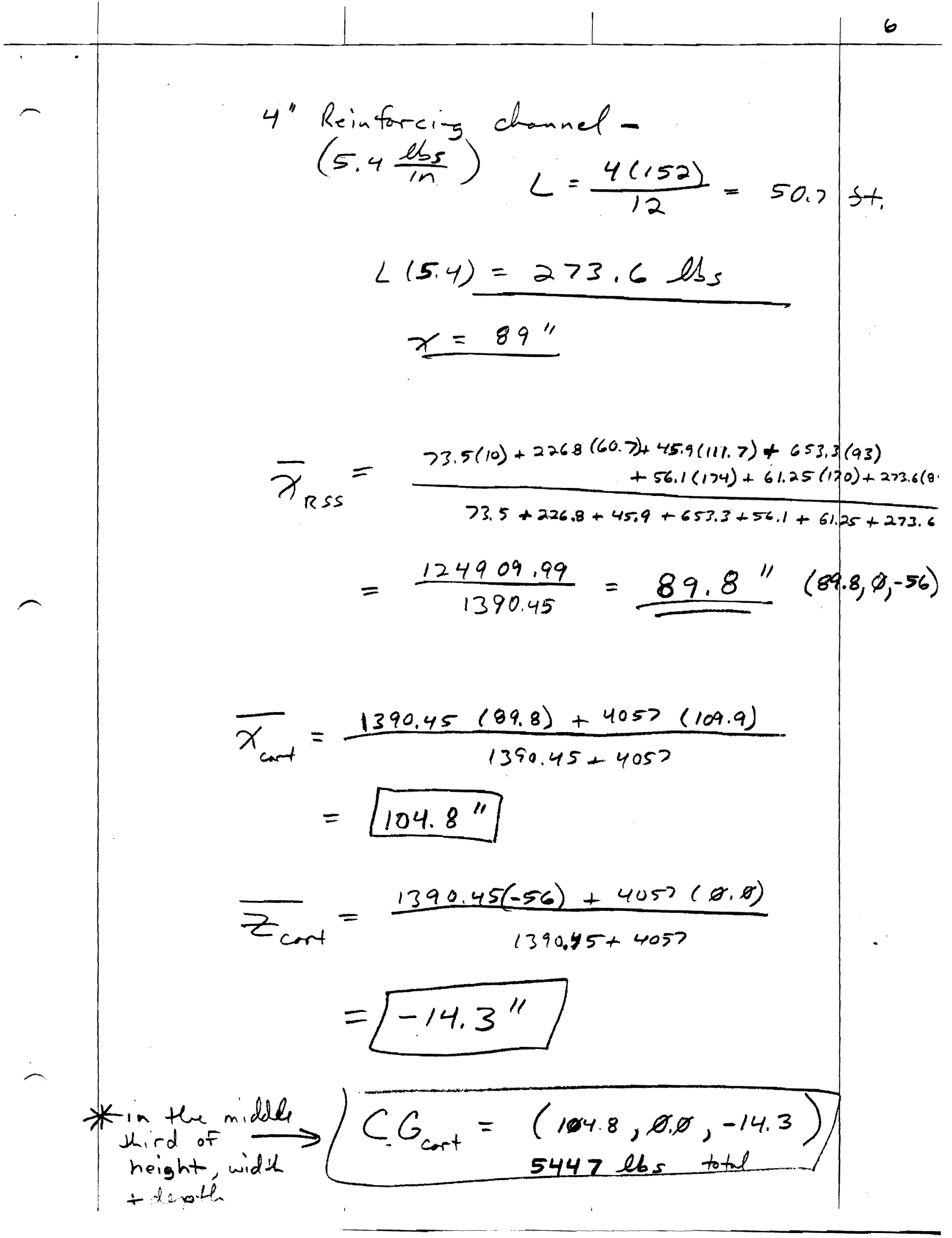




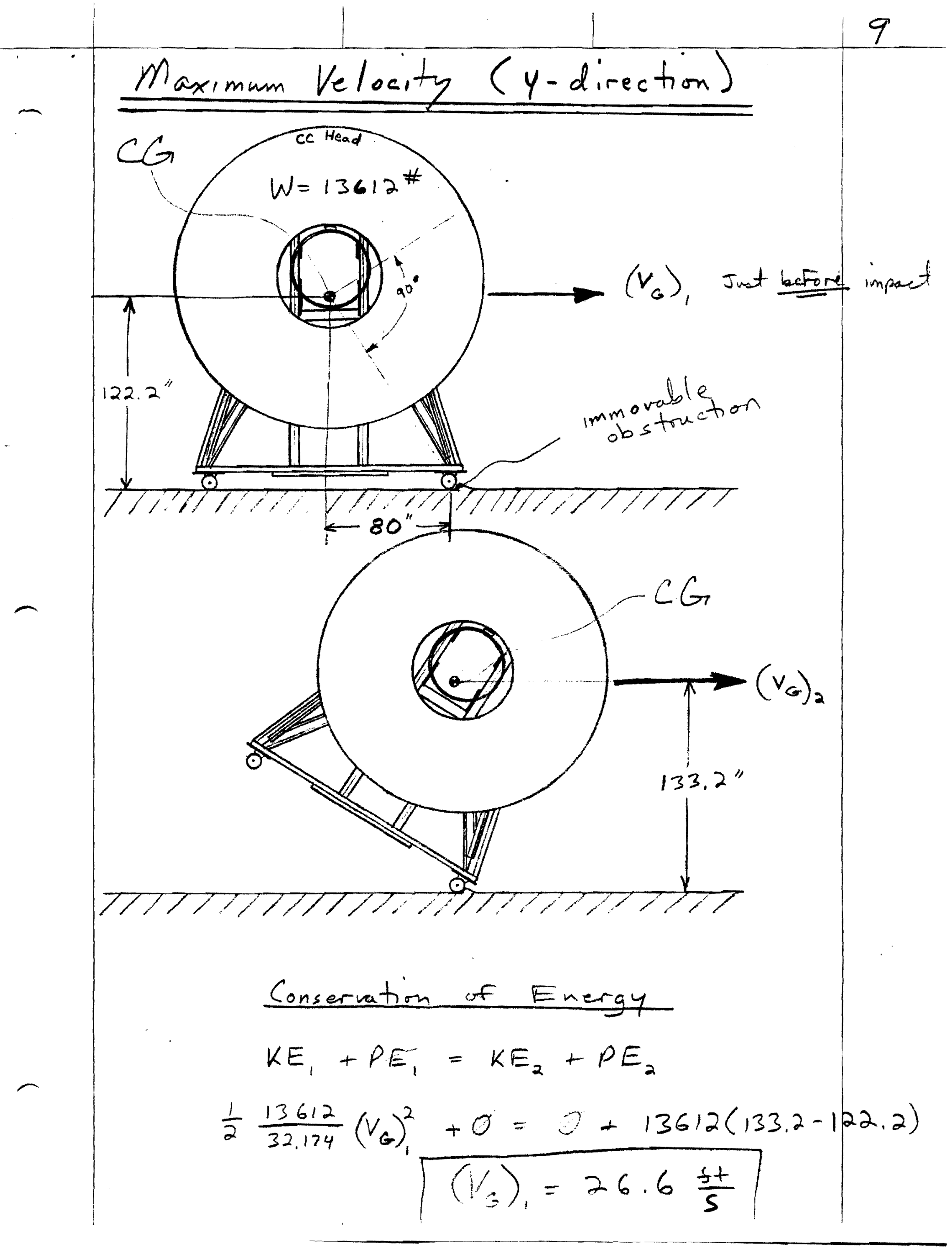




The loaded Head Cart is somarilu

The loaded Head Cart is primarily intended for rolling use in the $y$-direction.

It would be rolled in the $z$-direction only to align itself with the Clean Room door prior to entry.

In entering the Clean Room, the loaded Head Cart would realistically travel at approximately $1 \mathrm{ft} / \mathrm{sec}$. Based on the previous calculations there is little danger of tipping the structure over.

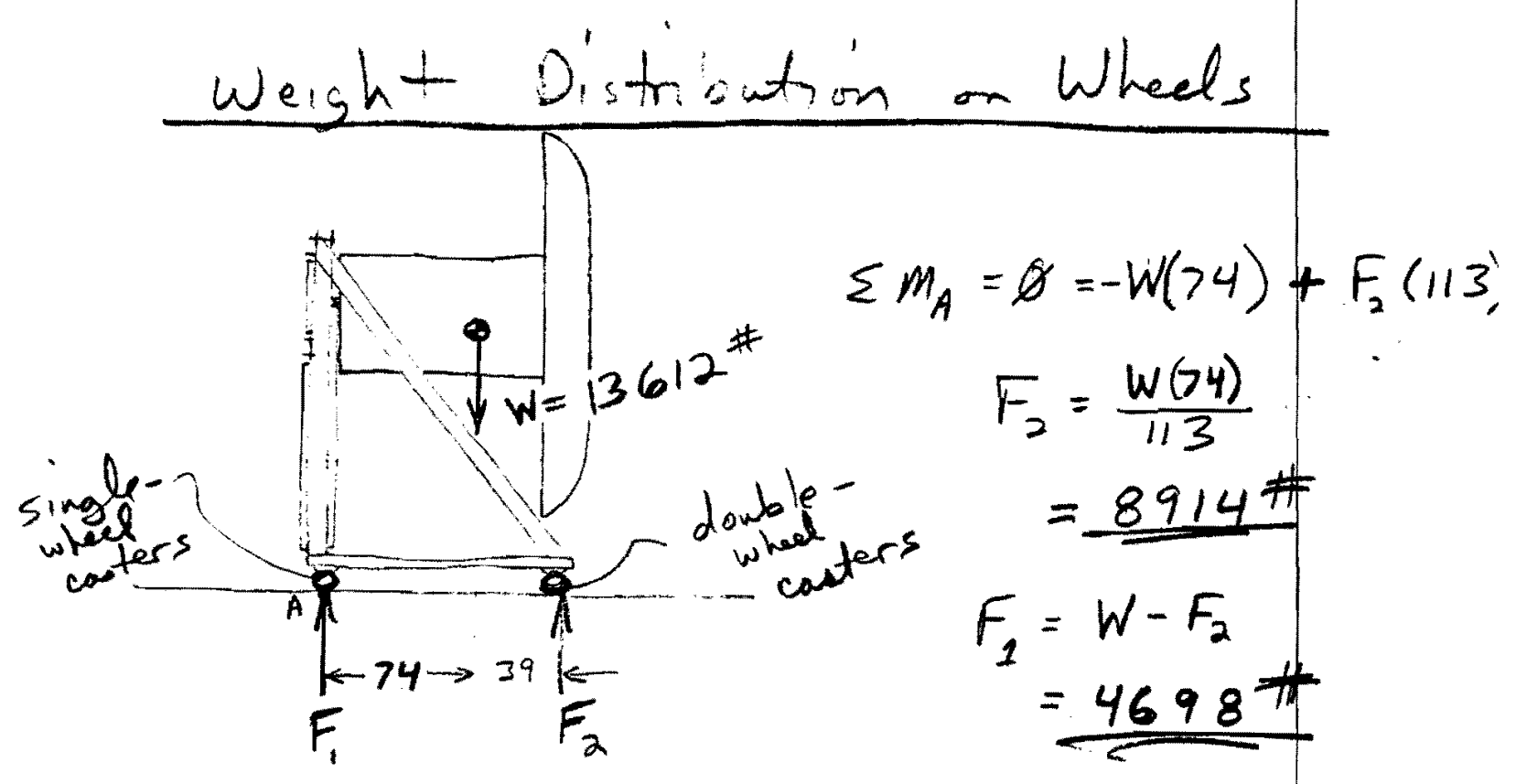




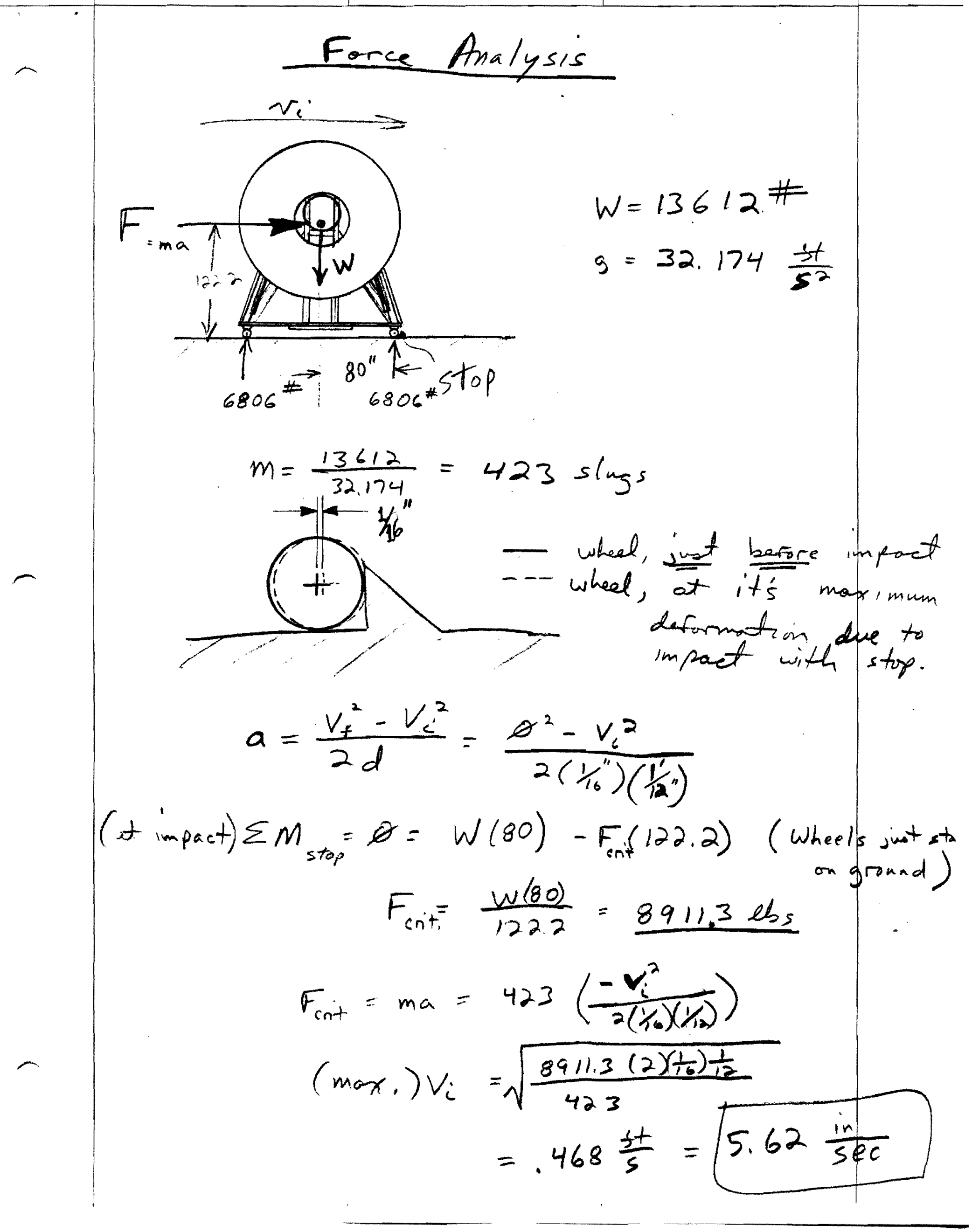




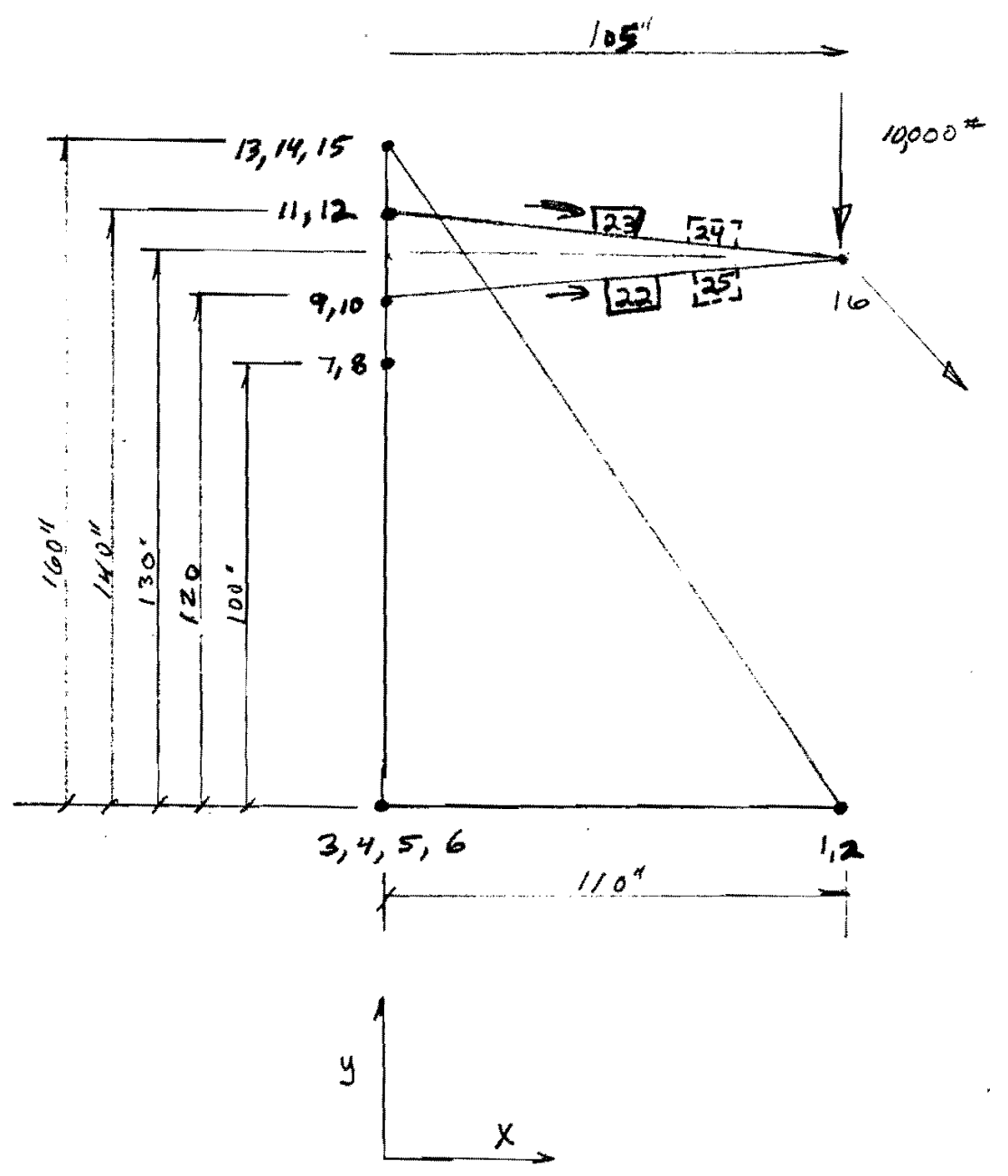




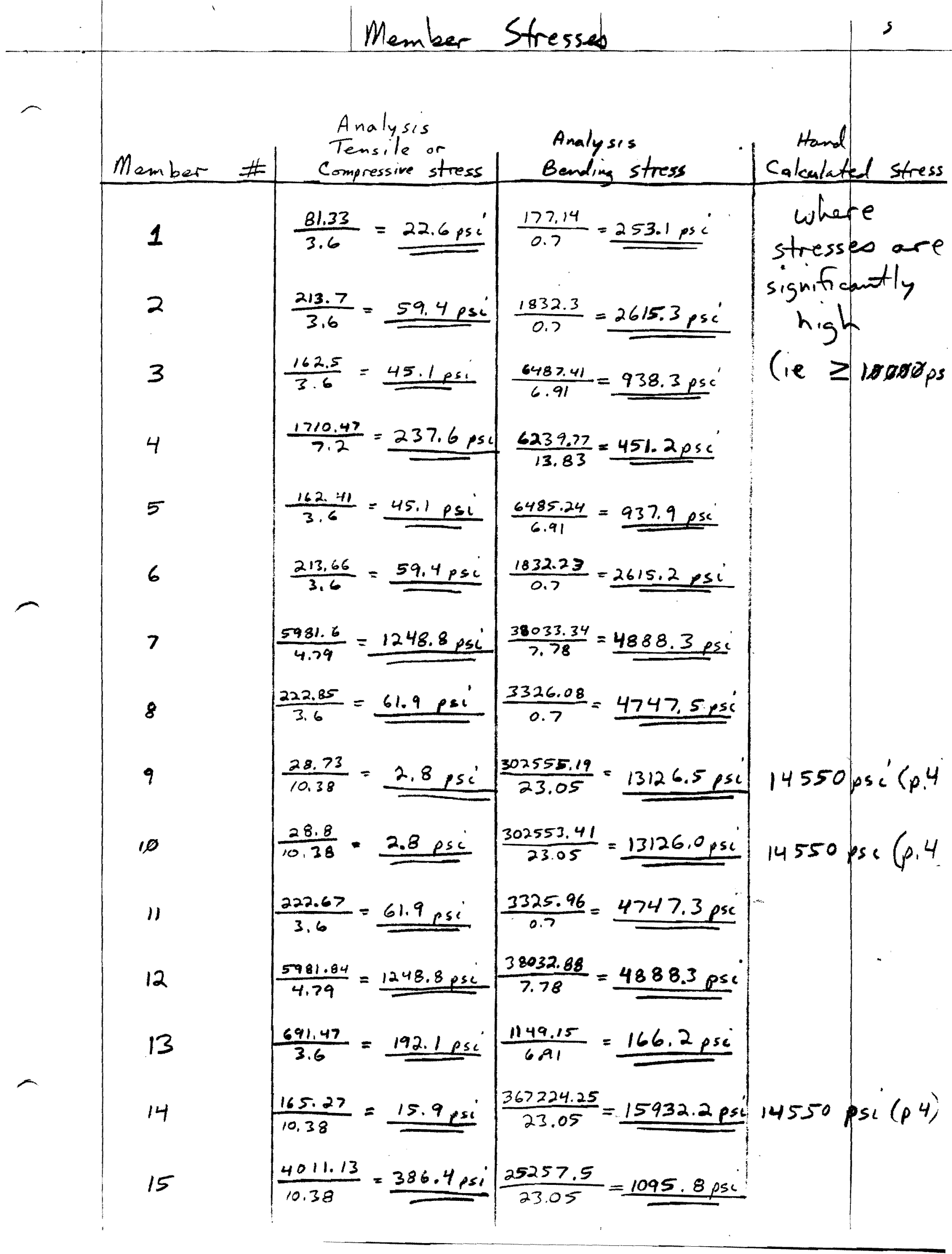




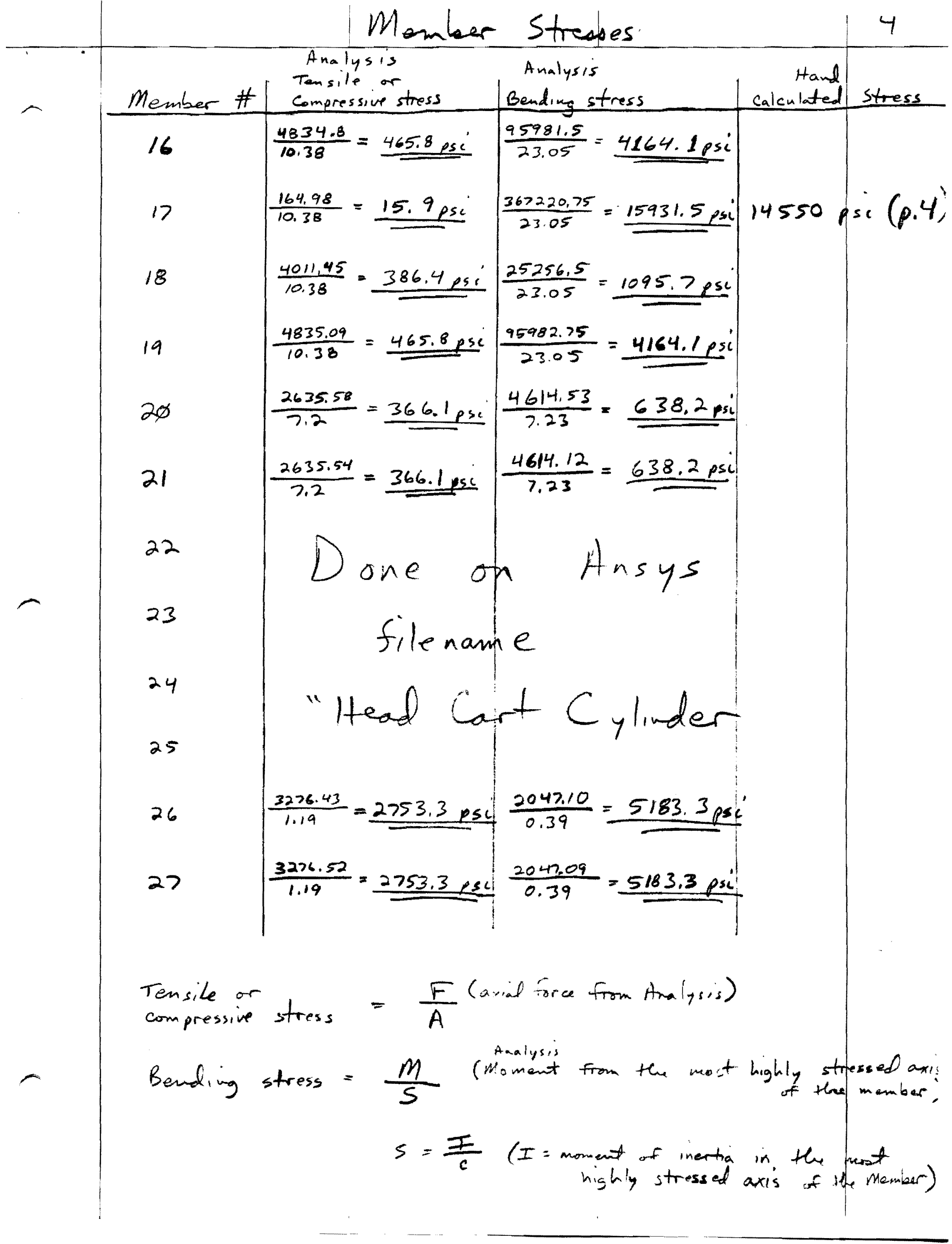


INFUT DATA FROM FILE NAME 3995. SF

PAGE \# 1

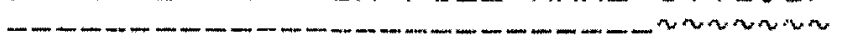

DATE OB-30-19a7

FEFMILAB

DO HEAD CAFT"

UNITS USED THFOUGHOUT AMALYSIS

Moment

Coordinates

Member Weight

Moment of Inertia

Cross Sectional Area: Sq. In.

Modulus of Elasticity: FEl

Rotation of Support Joint Fidians

Shear Modulus of Elasticity

Applied Load or Force Transmitted : Founds

Torsional Constant of a Cross - Section: In $A 4$

Displacement of Neutral Axis or Support "Inch

JOINT DATA

JOTNT \#

$* * * * * 1$

$* * * * * 2$

$* * * * * \ldots$

$* * * * * 4$

$* * * * * * 5$

$* * * * * * 6$

$* * * * * * 7$

$* * * * * 8$

$* * * * * 6$

$* * * * 15$

$* * * * * 11$

$* * * * 12$

$* * * * 1 \div$

$* * * * 14$

$* *+*+15$

$* * * * 16$

$$
+, \begin{aligned}
& -x \text { COOFiD } \\
& \text { Inch }
\end{aligned}
$$

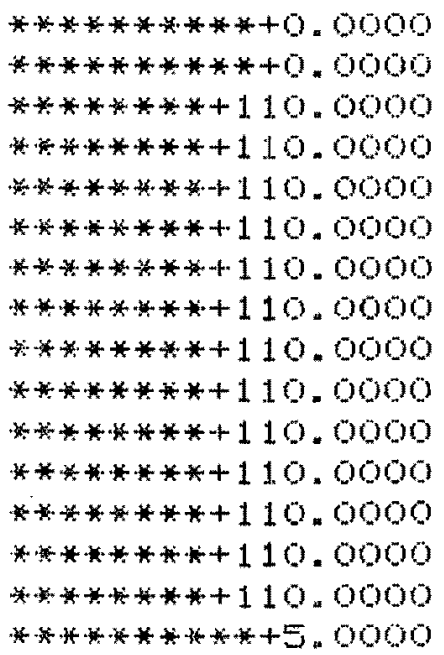

$$
\begin{aligned}
& + \text {-Y COOFD } \\
& \text { InCh }
\end{aligned}
$$

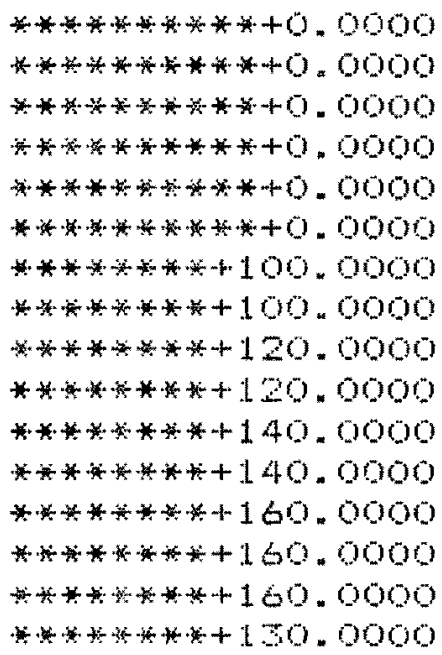

\section{+-2 COOFID Inch}

\footnotetext{
$* * * * * * * * * *+0.0000$ $* * * * * * *+160.0000$ $* * * * * * * * *+0.0000$ $* * * * * * * * 60.0000$ $* * * * * * *+100.0000$ $* * * * * * * *+160,0000$ $* * * * * * * *+60.0000$ $* * * * * * * *+100.0000$ $* * * * * * * * *+60.0000$ $* * * * * * * *+100.0000$ $* * * * * * * *+60.0000$ $* * * * * * * *+100.0000$ $* * * * * * * *+60.0000$ $* * * * * * * *+80.0000$ $* * * * * * *+100.0000$ $* * * * * * * * *+80.0000$
} 
INFUT DATA FFOM FILE NAME $3995.5 F$

DATE OB-30-1989

FEMMILAE

DO HEAD CART

SUFFOFT JOINT FESTFAINTS

$0=$ NO FESTFAINT

1 = FULL RESTFATNT

TFANSLATION

\begin{tabular}{|c|c|c|c|c|c|c|}
\hline \multirow[b]{3}{*}{ JOINT \# } & \multicolumn{3}{|c|}{ TFANSLATION } & \multicolumn{3}{|c|}{ ROTATION } \\
\hline & $--\infty$ & $-\cdots$ & $-m-m$ & --- & $--m-n$ & $-\infty$ \\
\hline & $J$ & JTY & $J 7 Z$ & JFix & JFYY & $J F I Z$ \\
\hline$* * * * * * 1$ & $* * 1$ & $* * 1$ & $* * 0$ & $* * 0$ & $* * 0$ & $* * 0$ \\
\hline$* * * * * * 2$ & $* * 0$ & $* * 1$ & $* * 1$ & $* * 0$ & $* * 0$ & $* * 0$ \\
\hline$* * * * * * 5$ & $* * 0$ & $* * 1$ & $* * 0$ & $* * 0$ & $* * 0$ & $* * 0$ \\
\hline$* * * * * * 4$ & $* * 0$ & $* * 0$ & $* * 0$ & $* * 0$ & $* * 0$ & $* * 0$ \\
\hline$* * * * * * 5$ & $* * 0$ & $* * 0$ & $* * 0$ & $* * 0$ & $* * 0$ & $* * 0$ \\
\hline$* * * * * * 6$ & $* * 0$ & $* * 1$ & $* * 0$ & $* * 0$ & $* * 0$ & $* * 0$ \\
\hline$* * * * * * 7$ & $* * 0$ & $* * 0$ & $* * 0$ & $* * 0$ & $* * 0$ & $* * 0$ \\
\hline$* * * * * * 8$ & $* * 0$ & $* * 0$ & $* * 0$ & $* * 0$ & $* * 0$ & $* * 0$ \\
\hline$* * * * * * 5$ & $* * 0$ & $* * 0$ & $* * 0$ & $* * 0$ & $* * 0$ & $* * 0$ \\
\hline$* * * * * 10$ & $* * 0$ & $* * 0$ & $* * 0$ & $* * 0$ & $* * 0$ & $* * 0$ \\
\hline$* * * * * 11$ & $* 40$ & $* * 0$ & $* * 0$ & $* * 0$ & $* * 0$ & $* * 0$ \\
\hline$* * * * * 12$ & $* * 0$ & $* * 0$ & $* * O_{n}$ & $* * 0$ & $* * 0$ & $* * 0$ \\
\hline$* * *+13$ & $* * 0$ & $*+0$ & $* * 0$ & $* 0$ & $* * 0$ & $* * 0$ \\
\hline$* * * * * 14$ & $* * 0$ & $* * 0$ & $* * 0$ & $* * 0$ & $* * 0$ & $* * 0$ \\
\hline$* * * * * 15$ & $* * 0$ & $* * 0$ & $* * 0$ & $* * 0$ & $* * 0$ & $* * 0$ \\
\hline$* * * * 16$ & $* * 0$ & $* * 0$ & $* * 0$ & $* * 0$ & $* * 0$ & $* * 0$ \\
\hline
\end{tabular}

PAGE \# 2

MEMEEF: DATA

MEMEEF \# MEMEER MEMEEF CFOSS SECTIONAL
FFOM Sq. In.

\section{MODLLUS OF ELASTICITY Fisi}

***29000000.00 $* * * 29000000.00$ ****29000000.00 ****29000000.00 $* * * 29000000.00$ $* * * 29000000.00$ ****29000000.00 ****29000000.00 *** 29000000.00
SHEAF: MODULUS DF ELASTICITY Fisi

$* * * * 11200000.00$ $* * * * 11200000.00$ ****11200000.00 ****11200000.00 ****11200000.00 *** 11200000.00 *** 1. 1200000.00 *** 11200000.00 $* * * 11200000.00$ 
INFUT DATA FFOM FILE NAME 3995. SF

DATE OQ-30-1989

FEFNIILAB

DO HEAD CAFT

MEMEEF DATA CONTINUED

MEMEER DATA CONTINUED

$\begin{array}{cc}\text { MEMEEF \# MEMEEF } & \text { MEMEEF } \\ \text { FROM } & \text { TO }\end{array}$

$\begin{array}{lll}* * * * 10 & * * * * 45 & * * * * 6 \\ * * * * 11 & * * * * * 6 & * * * * * 8 \\ * * * * 12 & * * * * 2 & * * * * 15 \\ * * * * 13 & * * * * * 7 & * * * * * 8 \\ * * * * 14 & * * * * * 7 & * * * * * 9 \\ * * * * 15 & * * * * * 9 & * * * * 11 \\ * * * * 16 & * * * 11 & * * * * 13 \\ * * * * 17 & * * * * * 8 & * * * * 10 \\ * * * * 18 & * * * 10 & * * * * 12 \\ * * * * 19 & * * * * 12 & * * * 15 \\ * * * * 20 & * * * 13 & * * * * 14 \\ * * * * 21 & * * * 14 & * * * * 15 \\ * * * * 22 & * * * * * 9 & * * * 16 \\ * * * * 29 & * * * * 11 & * * * * 16 \\ * * * * 24 & * * * * 12 & * * * * 16 \\ * * * * 25 & * * * * 10 & * * * * 16 \\ * * * * 26 & * * * * * 1 & * * * * 4 \\ * * * * 27 & * * * * * 2 & * * * * * 5\end{array}$

\author{
CFOSS SECTIONAL \\ AFEA \\ Scl. In.
}

\begin{abstract}
$* * * * * 10.3800$
$* * * * * * 2.6000$

$* * * * * * 4.7900$

$* * * * * 3.5000$

$* * * * * * 10.3900$

*****10. 3800

$* * * * * 10.3800$

$* * * * * 10.3800$

$* * * * *+10.3800$

$* * * * * 10.3000$

$* * * * * * 7.2000$

$* * * * * * 7.2000$

$* * * * * 10.5000$

$* * * * * 10.5000$

$* * * * * 10.5000$

$* * * * 10.5000$

$* * * * * 1.1900$

$* * * * * * 1.1900$
\end{abstract} FAGE \# 3 
INFUT DATA FROM FILE NAME 3995. SF

DATE $\quad 08-30-1989$

FEFIMILAE

DO HEAD CAFT

MEMEEF FROFEFTIES CONTINUED

MEMBEF \#

$* * * * * 11$

$* * * * 12$

$* * * * 1 \leq$

$* * * * * 14$

$* * * * 15$

$* * * * * 16$

$* * * * 17$

$* * * * * 18$

$* * * * 19$

$* * * * 20$

$* * * 21$

*** $* 2$

$* * * * 25$

$* 4 * 24$

****25

$* * * * 20$

$* * * * 27$

$$
\begin{aligned}
& \text { MOMENT OF } \\
& \text { INEFTIA IY } \\
& \text { IN } \therefore 4
\end{aligned}
$$

Cy
MOMENT OF

INEFT IA IZ

$$
\text { In } 4
$$

$c$

TOFSS IONAL

CONSTANT J

In $\therefore 4$

$* * * * * * * * 24,200,3.5 \quad * * * * * * * * * 0.161$ $* * * * * * * 2,6004.19>* * * * * * * * 0.180$ $* * * * * * * 24.2003 .5$ $* * * * * * 17.090308 * * * * * * * 62.530$ $* * * * * * 117.0905 .085 * * * * * * * 62.530$ $* * * * * * * 117.0905 .090 * * * * * * 62.530$ $* * * * * * 117.0905 .08$. $* * * * * * * 22.530$ $* * * * * * 117.0905 .005 * * * * * * * 62.530$ $* * * * * * 117.0905 .03 * * * * * * * 62.530$ $* * * * * * * 39.660$ 5.51 $* * * * * * * * * 0.186$ ******39.860 $3.35 * * * * * * * * 0.186$ $* * * 12,940.000=* * * * 5, .44 .000$ $* * * * 12,940.000-* * * * 5, \pm 44.000$ $* * * * 12,940,000-\quad * * * * 5, \$ 44.000$ $* * * 12,940.000 \longrightarrow * * * * 0,344.000$ $* * * * * * * * 0,703 / 28>* * * * * * * 0.023$ $* * * * * * * * 0.7031 .78 * * * * * * * * 0.023$

METEEF: DESCFIFTION

MEMEER \#

MEM.WT. /LENGTH LOE./ Ft.

$* * * * * * 1$ $* * * * * * 2$ $* * * * * * 3$ $* * * * * * 4$ $* * * * * 5$ $* * * * * * 6$ $* * * * * 7$ $* * * * * 3$ $* * * * *+*$ $* * * 10$ $+* *+\ldots+1$

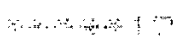

$* * * * * * * * * 12.25$ $* * * * * * * * * 12.25$ $* * * * * * * * 12.25$ $* * * * * * * * 24.50$ $* * * * * * * * 12.25$ $* * * * * * * * * 12.25$ $* * * * * * * * 16.55$ $* * * * * * * * 12.25$ $* * * * * * * 75.50$ $* * * * * * * * 55.50$ $x+x+12,25$

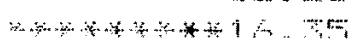

MEMEER DESCRIFTION (max. 50 chrs.) 
INFUT DATA FFOM FILE NAME 3995. SF

DATE 08-30-1989

FEFIMILAE

DO HEAD CAFT

MEMEEF DESCFIFTION CONTINUED

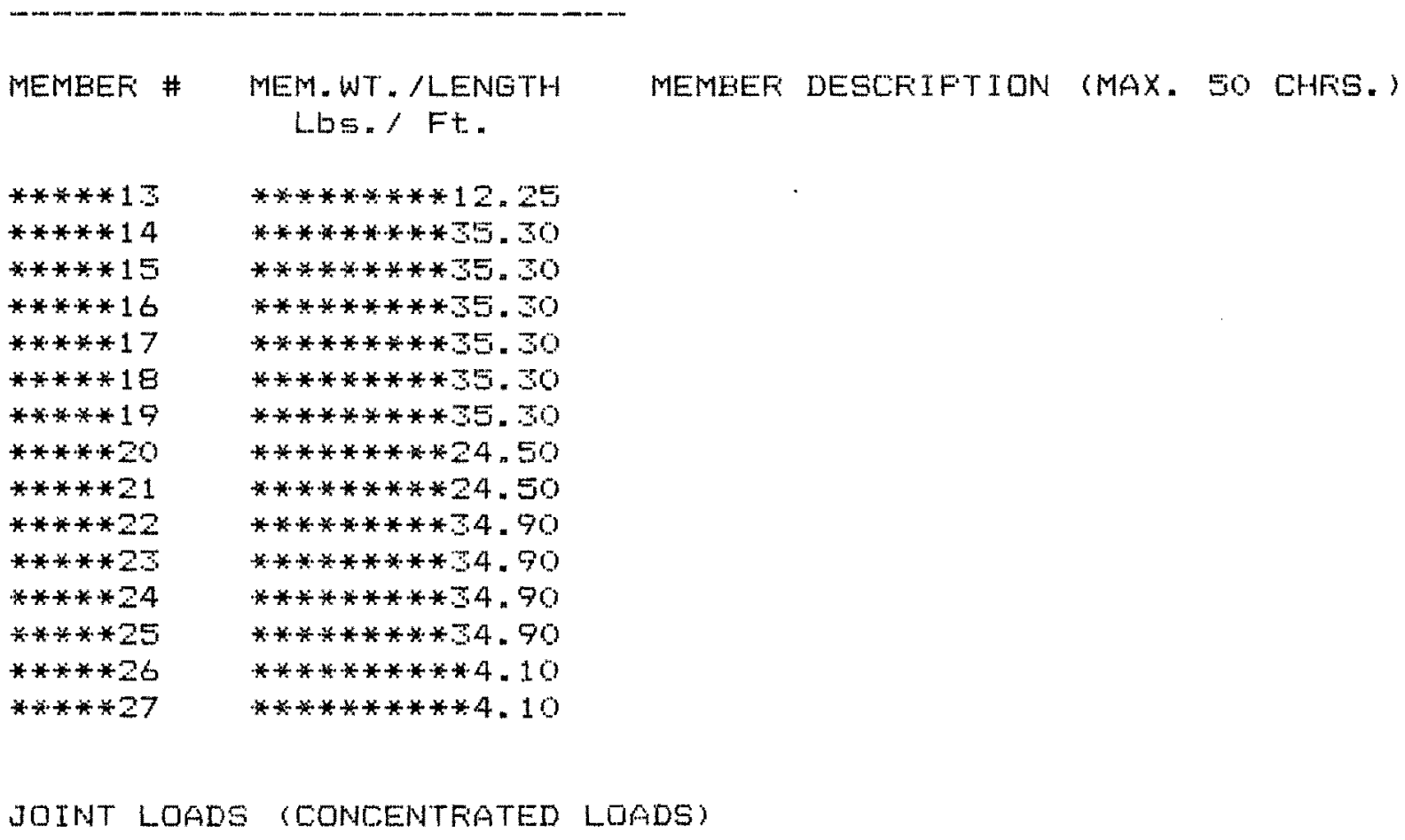


STFESS CALCULATION RESULTS FOF FILE NAME $3795 . \mathrm{SF}$

DATE OB-30-1989

FEFMILAE

DO HEAD CAFT

UNITS USED THFOUGHOUT ANALYSIS

Moment

Coordinates

Member weight

Moment of Inertia

Cross Sectional Area : Sq. In.

Modulus of EIasticity: Fsi

Fotation of Support Joint : Fadians

Shear Modulus of Elasticity

: F'si

Applied Load or Force Tranemitted : Founds

Torsional Constant of a Cross Section : In 4

Displacement of Neutral Axis or Support: Inch

JOINT DISPLACEMENTS (TranSlations)

JQINT \# $+\underset{\text { InCH }}{-x \text { DISF }}$

$* * * * * * 1$

$* * * * * * 2$

$* * * * * * 3$

$* * * * * * 4$

$* * * * * * 5$

$* *+* * 6$

$* * * * * * 7$

$* * * * * 0$

$* * * * * 0$

$* * * * 10$

$* * * * 11$

$* * * * * 12$

$* * * * 1$.

$* * * * * 14$

$* * * * 15$

$* * * * 16$

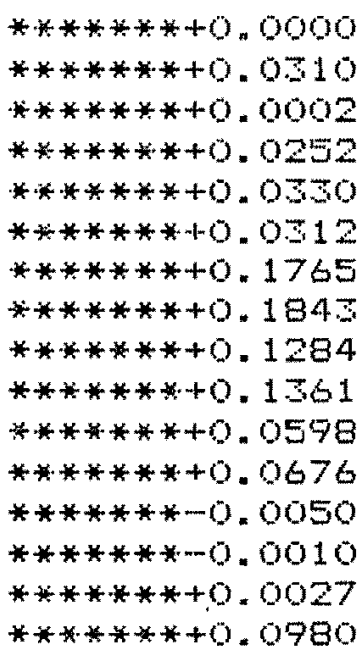

$* * * * * * *+0,0000$

$* * * * * * *+0.0310$

$* * * * * *+0.0002$

$* * * * * * *+0.0252$

$* * * * * *+0.0330$

$* * * * * * *+0.0 \pm 12$

$* * * * * *+0.1765$

$* * * * * * *+0.1284$

$* * * * * * *+0.1 \leq 61$

$* * * * * * * 0.0598$

$* * * * * * * 0.0676$

$* * * * * * * 0.0050$

$* * * * * *+0.0027$

$* * * * * * * 0.0980$

$$
+, \underset{\text { Inch }}{-Y} \text { DISF }
$$

$+\underset{\text { Inch }}{-Z \text { DISF }}$

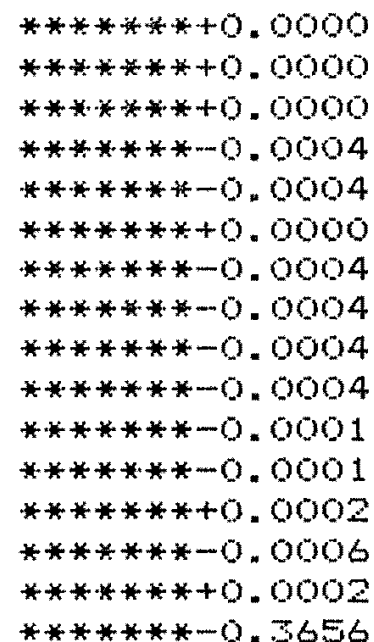

$* * * * * * * 0.0001$ $* * * * * * *+0.0000$ $* * * * * * *-0.0216$ $* * * * * * *-0.0216$ $* * * * * * *-0.0212$

$* * * * * * *-0.0211$

$* * * * * * *-0.0215$

$* * * * * * * 0.0213$

$* * * * * * *-0.0217$

$* * * * * * *-0.0211$

$* * * * * * * 00,0214$

$* * * * * * *-0.0214$

$* * * * * * *-0,0211$

$* * * * * * *-0.0214$

$* * * * * * *-0.0216$

$* * * * * * *-0.0010$ 
STFESS CALCULATION RESULTS FOF FILE NAME $3995.5 F$

DATE $08-30-1989$

FEFMILAB

DO HEAD CAFT

JOINT DISFLACEMENTS (FOTATIONS)

JOINT \#

$* * * * * 1$

$* * * * 2$

$* * * * * \div$

$* * * * * * 4$

*十****5

$* * * * * 6$

$* * * * * 7$

$* * * * * * 8$

******\%

$* * * * 10$

$* * * * 11$

$* * * * 1 \div$

$* * * * 1=$

$+4 * *+14$

$* * *+15$

$* * * * 16$ ,$+-x$ Fiot.

Fiadi ans

\begin{abstract}
$* * * * * * 0.00042$
$* * * * * 0.00042$

$* * * * * *+0.00002$

$* * * * * *+0.00000$

$* * * * * * 0.00001$

$* * * * * * 0.00000$

$* * * * * *+0,00000$

$* * * * *+0.00003$

******0.00008

$* * * * * *+0.00000$

$* * * * * *+0.00002$

$* * * * * *+0.00000$

$* * * * *+0.00000$

$* * * * * * 0.00000$

$* * * * * * 0.00000$

$* * * * *+0.00000$
\end{abstract}

,$+-Y$ Fot. Fiadi ans

******0.00015

$* * * * *+0.00025$

$* * * * *+0.00041$

$* * * * * *+0.00028$

$* * * * * *+0.00010$

$* * * * * * 0.00000$

******+0.00025

******+0.00014

$* * * * * * 0.00019$

$* * * * *+0.00020$

$* * * * *+0.00019$

$* * * * * *+0.00019$

******+10.0002 1

$* * * * * * 0.00019$

$* * * * * * 0.00019$

$* * * * * 0.00019$
+. - Z Fot.

Fiadians

MEMEER END LOADS (For"ces)

$* * * * *-0.00100$
$* * * * * *-0.00100$
$* * * * * *-0.00098$
$* * * * * *-0.00298$
$* * * * * *-0.00298$
$* * * * * *-0.00098$
$* * * * * *+0.00145$
$* * * * * *+0.00145$
$* * * * * *+0.00343$
$* * * * * *+0.00543$
$* * * * * *+0.00546$
$* * * * * *+0.00546$
$* * * * * *+0.00308$
$* * * * * *+0.00308$
$* * * * * *+0.00509$
$* * * * * *+0.00549$

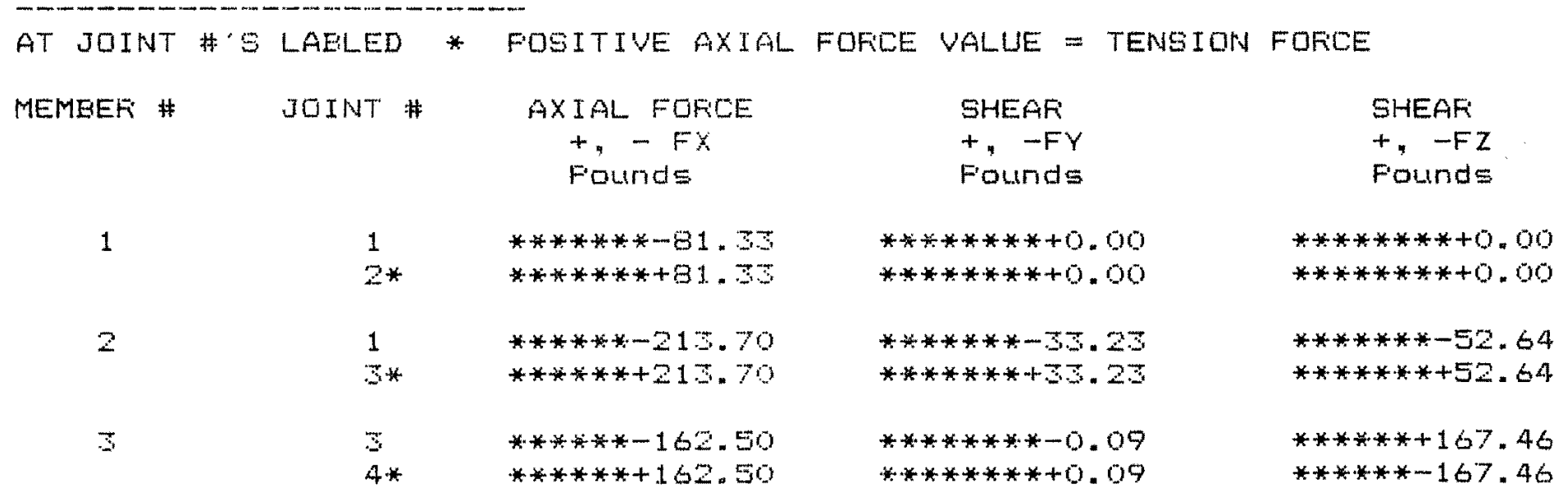


STFESS CALCLLATION RESULTS FOF FILE NAME 3995. SF

FAGE \# 3

DATE $\quad 00-30-1989$

FERMILAE

DO HEAD CAFIT

MEMEEF END LOADS (FomeEs) Continued

AT JOINT *'S LAELED * FOSITIVE AXIAL FOFCE VALUE = TENSION FOFCE

MEMEEF: \# JOINT \#

4

5

6

7

8

9

10

11

12

13

14

15

$5 *$

2

$6 *$

1

$\Xi$

$7 x$

$15 *$

$8 *$
AXIAL. FORCE $+-F X$

Founds

$* * * * * 1710.47$

$* * * *+1710.47$

$5 \quad * * * * *-162.41$

6* $* * * * * *+162.41$

$* * * * * 215.66$

$* * * * *+213.66$

$* * * * *+5981.60$

$* * * * *-5981.60$

$* * * * * 222.85$

$* * * * *-222.85$

$4 \quad * * * * * * *-28.75$

$7 * \quad * * * * * *+28.73$

$5 \quad * * * * * *-28.80$

$8 * \quad * * * * * *+28.80$

$1 \quad 6 \quad * * * * *+222.67$

$6 * \quad * * * * * *-222.67$

$2 \quad * * * * *+5981.84$

$* * * * *-5981.64$

$7 \quad * * * * * *-691.47$

$* * * * * *+691.47$

$7 \quad * * * * * * 165.27$

$9 * \quad * * * * *-165.27$

$9 \quad * * * * *-4011.13$

$1 . *$
SHEAFi

$+,-F Y$

Founds

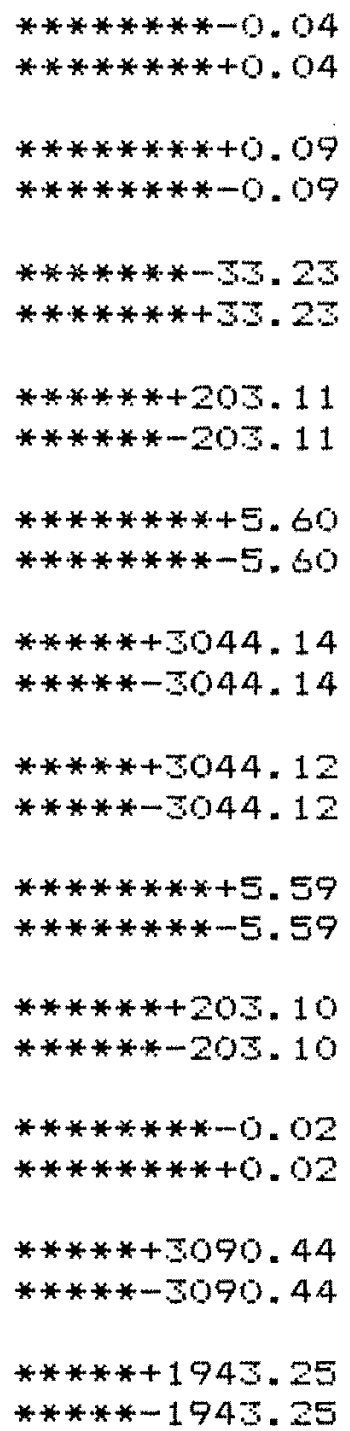

SHEAR

$+,-F Z$

Founds

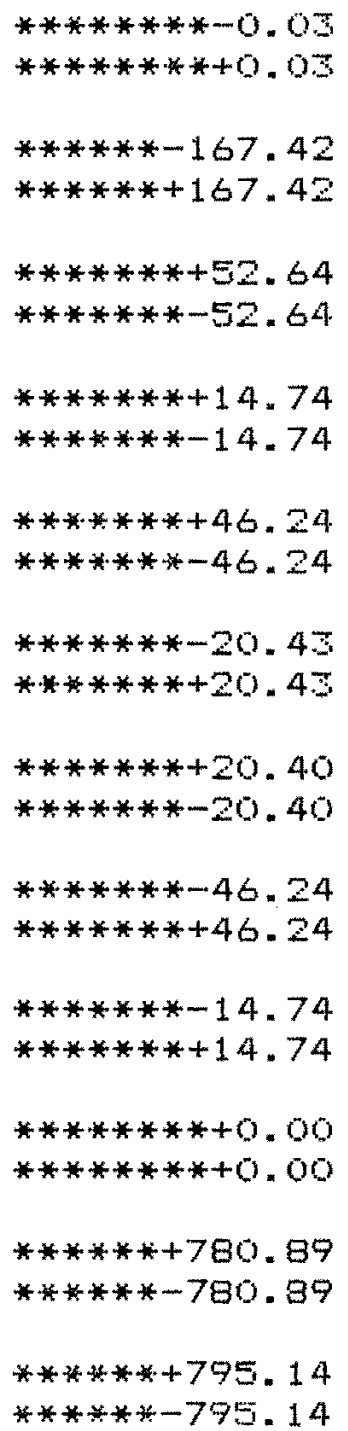


STFESS CALCULATION RESULTS FOF FILE MAME 3995. SF

F'AGE \# 4

DATE $08-30-1989$

FEFMILAB

DO HEAD CAFT

MEMEEF END LOADS (Forces) Continued AT JOINT \#:S LABLED * FOSITTVE AXIAL FOFCE VALUE = TENSION FOFCE

MEMEEF \# JOINT \# AXIAL FOFICE

$+-F X$

Founds

16

17

18

19

20

21

22

2.5

24

25

26

27
$11 \quad * * * * *-4034.80$

$13 *$

$* * * *+48.4 .50$

8
$10 *$

$* * * * *+164.98$

$* * * * *-164.99$

10

$12 *$

$* * * * *-4011.45$

$* * * *+4011.45$

$12 \quad * * * * *-48.5 .09$

$15 *$

$* * * *+4835.09$

$1 \mp$

$14 *$

$* * * * *+26.5 .58$

$* * * *+2635.58$

\section{4}

$15 *$

$* * * * *+2635.54$

$* * * *-2635.54$

9

$* * * *+1508.43$

$16 *$

$* * * *-1508.45$

11.

$* * * * *-1224.32$

$16 *$

$* * * *+1224.32$

12

$10 *$

$* * * * *-1224.45$

$* * * * *+1224.45$

10

$* * * *+1500$. 2

$* * * *-1508.29$

\section{1}

$4 *$

$* * * * *-5276.43$

$* * * *+3276.43$

5
$* * * * *-3276.52$

$* * * * *+3276.52$
SHEAR

$+\cdots F Y$

Founds

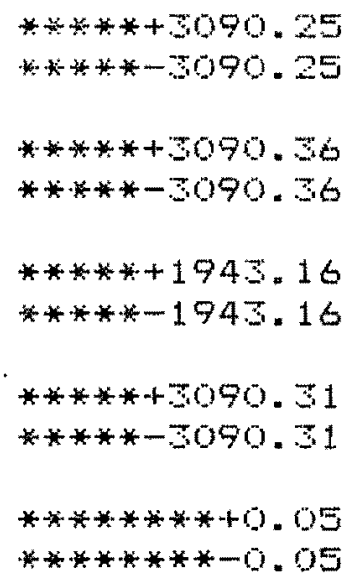

$* * * * * * *+0.00$

$* * * * * * *+0.00$

$* * * *+4053.63$

$* * * *-4053.65$

$* * * * *+712.75$

$* * * * *-712.75$

$* * * 4 *+712.75$

$* * * * *-712.75$

$* * * *+4053.50$

$* * * * 405.50$

$* * * * * *-28.68$

$* * * * * *+28.68$

$* * * * * 20.68$

$* * * * * *+28.68$
SHEAF:

$+,-F Z$

Founds

$* * * * * *+9=19$

$* * * * * *-933.19$

$* * * * *-780.84$

$* * * * * *+780.84$

$* * * * * *-79=11$ $* * * * * *+79=11$

$* * * * * *-935.13$ $* * * * * *+935.13$

$* * * * * * *+0.00$ $* * * * * * * *+0.01$

$* * * * * * * *+0.00$ $* * * * * * *+0.00$

$* * * * *+228.65$ ******-228. 65

$* * * * * *-79.02$ $* * * * * *+79.02$

$* * * * * * * 79.03$ $* * * * * * *-79.03$

$* * * * * *-220.65$ $* * * * *+220.65$

*******0*0.59 $* * * * * * * *-0.59$

********0.59 $* * * * * * *+0.59$ 
STRESS CALCULATION RESULTS FOF FILE NAME $3995.5 F$

DATE $\quad 08-30-1989$

FERMILAB

DO HEAD CART

MEMBEF END LOADS (MOmentS)

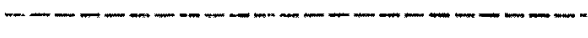

\begin{tabular}{|c|c|c|c|}
\hline MEMEER \# & JOINT \# & $\begin{array}{c}\text { TWIST ING MOMENT } \\
+, \quad-M X \\
\text { In-LDS }\end{array}$ & $\begin{array}{c}\text { BEND ING MOMENT } \\
+,-M Y \\
\text { In-LbS }\end{array}$ \\
\hline 1 & $\begin{array}{l}1 \\
2\end{array}$ & $\begin{array}{l}* * * * * * *+0.00 \\
* * * * * * * * 0.00\end{array}$ & $\begin{array}{l}* * * * * *-519.00 \\
* * * * * *+519.23\end{array}$ \\
\hline 2 & $\frac{1}{3}$ & $\begin{array}{l}* * * * * * * *+6.52 \\
* * * * * * * *-6.52\end{array}$ & $\begin{array}{l}* * * * *+1152.38 \\
* * * * *+4638.06\end{array}$ \\
\hline 3 & $\begin{array}{l}3 \\
4\end{array}$ & $\begin{array}{l}* * * * * * *+60.10 \\
* * * * * * *-60.10\end{array}$ & *****-3560,39 \\
\hline 4 & $\begin{array}{l}4 \\
5\end{array}$ & $\begin{array}{l}* * * * * * * *-0.37 \\
* * * * * * * * 0.37\end{array}$ & ${ }^{* * * *+6239.77}$ \\
\hline 5 & $\begin{array}{l}5 \\
6\end{array}$ & $\begin{array}{l}* * * * * *-60.10 \\
* * * * * *+60.10\end{array}$ & ****+6485. 23 \\
\hline s & $\frac{2}{6}$ & $\begin{array}{l}* * * * * * * *-6.52 \\
* * * * * * * * 6.52\end{array}$ & $\begin{array}{l}* * * * *-1152.53 \\
* * * * *-4637.81\end{array}$ \\
\hline 7 & $\begin{array}{r}1 \\
13\end{array}$ & $\begin{array}{l}* * * * * * *-10.69 \\
* * * * * * *+10.69\end{array}$ & $\begin{array}{l}* * * * * *-914.61 \\
* * * * *-2081.4 .5\end{array}$ \\
\hline 8 & $\frac{5}{7}$ & $\begin{array}{l}* * * * * * *-17.16 \\
* * * * * * *+17.16\end{array}$ & $* * * * * 2066.01$ \\
\hline 9 & $\begin{array}{l}4 \\
7\end{array}$ & $\begin{array}{l}* * * * * *+260.52 \\
* * * * * * 260.52\end{array}$ & $\begin{array}{l}* * * * * *+784.56 \\
* * * * *+1258.14\end{array}$ \\
\hline 10 & 8 & $\begin{array}{l}* * * * * *-259.58 \\
* * * * * *+259.58\end{array}$ & $\begin{array}{l}* * * * * *-783.17 \\
* * * * *-1256.63\end{array}$ \\
\hline 11 & $\begin{array}{l}6 \\
8\end{array}$ & $\begin{array}{l}* * * * * * *+17.17 \\
* * * * * * *-17.17\end{array}$ & $\frac{* * * * *+2065.95}{* * * * *+355.96}$ \\
\hline
\end{tabular}

FAGE \# 5 
STRESS CALCULATION FESULTS FOF FILE NAME S995. SF

DATE $\quad 08-30-1989$

FERMILAE

DO HEAD CAFIT

MEMEEF END LOADS (Moments) Continued

MEMEEF \# JOINT \# TWISTING MOMENT

$$
\begin{aligned}
& +,-M X \\
& \text { Iri-LbS }
\end{aligned}
$$

12

$1 \Xi$

14

15

16

17

18

19

20

21

22

23
2

15

7

8

7

9

7

11

11.

1.3

8

10

10

12

12

15

13

14

14

15

9

16

1.1

16
$* * * * * *+10.69$

$* * * * * 10.69$

$* * * * *+* * 0.00$

$* * * * * * *+0.00$

*****+1869.19

$* * * * *-1869.19$

$* * * * * * *-62.26$

$* * * * * * *+62.26$

$* * * * * *-477,14$

$* * * * * *+4.77 .14$

*****-1963. 26

$* * * * *+1868.26$

$* * * * * * * 62.25$

$* * * * * *-62$ - 25

******476.93

$* * * * *-476.95$

$* * * * * * * * 0.00$

$* * * * * *+7+0,00$

$* * * * * * * * 0.00$

$* * * * * * * *+0.00$

$* * * * 48088.50$

$* * * *+48088.50$

$* * * *-1.094 .56$

$* * *+11094.26$
BENDING MOMENT

$$
+,-M Y
$$

In-Lbs

$* * * * *+914.52$

$* * * * 2081.22$

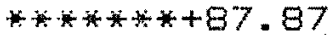

$* * * * * *-87.79$

$* * * *-3048.53$

****-12569. 4

****-10621.25

$* * * * * 5281.59$

$* * * * *-6509.76$

$* * * *-1215 \% .96$

$* * * *+7047.79$

$* * *+12569.38$

$* * *+10620.94$

$* * * * *+5281.32$

$* * * * 6509.15$

$* * *+12155.42$

$* * * * *+797.90$

*证**-797.79

$* * * * * *+797.85$

$* * * * * *-797.82$

$* * * *+6459.00$

$* * *-30985.00$

$* * * * *-619.50$

$* * * *+9102.50$
FAGE \# 6

BENDING MOMENT

$+-M Z$

In-Lbs

$* * * * *+3242.57$

$* * *+38032.88$

$* * * * *+1148.20$

$* * * 1149.15$

***-305416. 25

$* *+367224.25$

****+13606.25

$* *+25257.50$

$* * *+95981.50$

$* * * *-34177.00$

***-305414.00

$* * *+367220.75$

$* * * *+1 * 405.25$

$* * * * 25256.50$

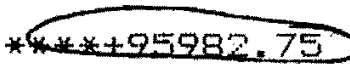

$* * *-34177.00$

$* * * *-461 \pm .44$

$* * * *+4614.5 .5$

$* * * *-4614.12$

$* * * *+4614.10$

$* * *+378448.00$

$* * *+56728.00$

$* * *+121304.00$

****-44784.00 
STRESS LALCULATION RESULTS FOF FILE NAME $5995.5 F$

DATE $\quad 08-30-1989$

FEFMILAE

DO HEAD CART

MEMBEF END LOADS (Moments) Continued

\begin{tabular}{|c|c|c|c|}
\hline MEMEEF: & JOINT \# & $\begin{array}{c}\text { TWISTING MOMENT } \\
+,-M X \\
\text { In-LOS }\end{array}$ & $\begin{array}{c}\text { BENDING MOMEN } \\
+,-M Y \\
\text { In-LDS }\end{array}$ \\
\hline 24 & $\begin{array}{l}12 \\
16\end{array}$ & $\begin{array}{l}* * *+11094.51 \\
* * * *-11094.51\end{array}$ & $\begin{array}{l}* * * * * *+619.25 \\
* * * * *-9104.00\end{array}$ \\
\hline 25 & $\begin{array}{l}10 \\
16\end{array}$ & $\begin{array}{l}* * * *+48088.39 \\
* * * *-48088.39\end{array}$ & $\begin{array}{l}* * * * *-6458.00 \\
* * * *+30984.00\end{array}$ \\
\hline 26 & $\begin{array}{l}1 \\
4\end{array}$ & $\begin{array}{l}* * * * * * * *+2.72 \\
* * * * * * * *-2.72\end{array}$ & $\begin{array}{l}* * * * * * *-61.05 \\
* * * * * * *-12.88\end{array}$ \\
\hline 27 & $\frac{2}{5}$ & $\begin{array}{l}* * * * * * *-2.72 \\
* * * * * * 2.72\end{array}$ & $\begin{array}{l}* * * * * * *+61.03 \\
* * * * * * *+12.83\end{array}$ \\
\hline
\end{tabular}

FAGE \# 7 
DATE OB-30-1969

FEFMILAE

DO HEAD CAFT

MEMEER LENGTH AND WEIGHT CONTINUED

\begin{tabular}{|c|c|c|c|}
\hline MEMEEF \# & $\begin{array}{c}\text { MENBEF: LENGTH } \\
\text { InCh }\end{array}$ & $\begin{array}{c}\text { MEMBEF WT./L } \\
\text { Lbs. Ft. Ft. }\end{array}$ & TOTAL MEM. WT. \\
\hline$* * * * 19$ & $* * * * * * * 20.000$ & $* * * * * * * * 35,30$ & $* * * * * * * * * 58.8 .5$ \\
\hline$* * * * * 20$ & $* * * * * * * * 20.000$ & $* * * * * * * * 24.50$ & $* * * * * * * * 40.83$ \\
\hline$* * * * * 21$ & $* * * * * * * * 20,000$ & $* * * * * * * * * 24.50$ & $* * * * * * * * 40.83$ \\
\hline$* * * * * 22$ & $* * * * * * 107.000$ & $* * 4 * * * 254.90$ & $* * * * * * * * 311.19$ \\
\hline$* * * * 2 \Xi$ & $3 * * * *+107.000$ & $* * * * * * * * 2,4.90$ & $* * * * * * * * 311.19$ \\
\hline$* * * * 24$ & $* * * * * * * * 107.000$ & $* * * * * * * * 34.90$ & $* * * * * * * * 31.19$ \\
\hline$* * * * * 25$ & $* * * * * * * 107.000$ & $* * * * * * * 34.90$ & $* * * * * * * * 311.19$ \\
\hline$* x * * 26$ & $* * * * * * * * 125.000$ & $* * * * * * * *+4,10$ & $* * * * * * * * * 42.71$ \\
\hline$* * * * 27$ & $* * * * * * * 125.000$ & $* * * * * * * * * * 4.10$ & $* * * * * * * * * 42.71$ \\
\hline
\end{tabular}

SUFPORT REACTIONS (FOREES)

JOINT \#

$+,-F X$

Founds

$* * * * * 1$

$* * * * * * 2$

$* * * * * * 3$

$* * * * * * 6$

$* * * * * * * * * * * *-0,10$

$* * * * * * * * * * * *+0,00$

$* * * * * * * * * * * *+0.00$

$* * * * * * * * * * * * *+1), 00$
$+,-F Y Y$

Fiounds

$* x * * * * * *+4,772.68$

$* * * * * * *+4,772.68$

************+227.11

***********226.95
$+,-\mathrm{RZ}$

Founds

\section{SUFPOFT FEACTIONS (MOMENTS)}

JOINT \#

$+,-M X$

In-Lbs
$+,-M Y$

In-Lbs
$* * * * * * * * * * * * 0.00$

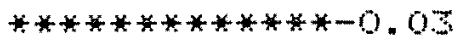
$* * * * * * * * * * * * *+0.00$ $* * * * * * * * * * * * *+0.00$

END DF ANALYSIS 

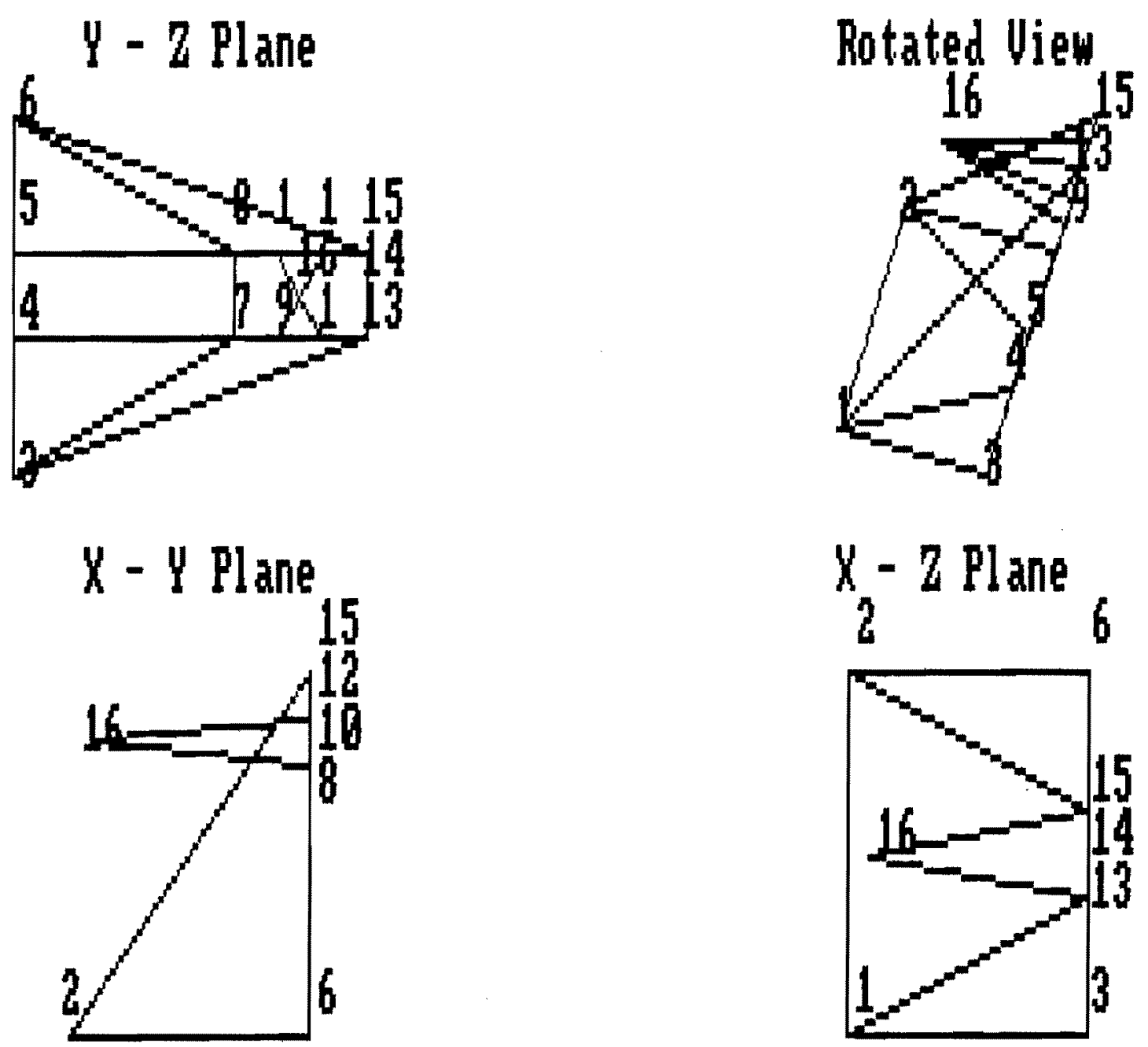

Plot of truss geometry for file name $3995 . \mathrm{SF}$ 


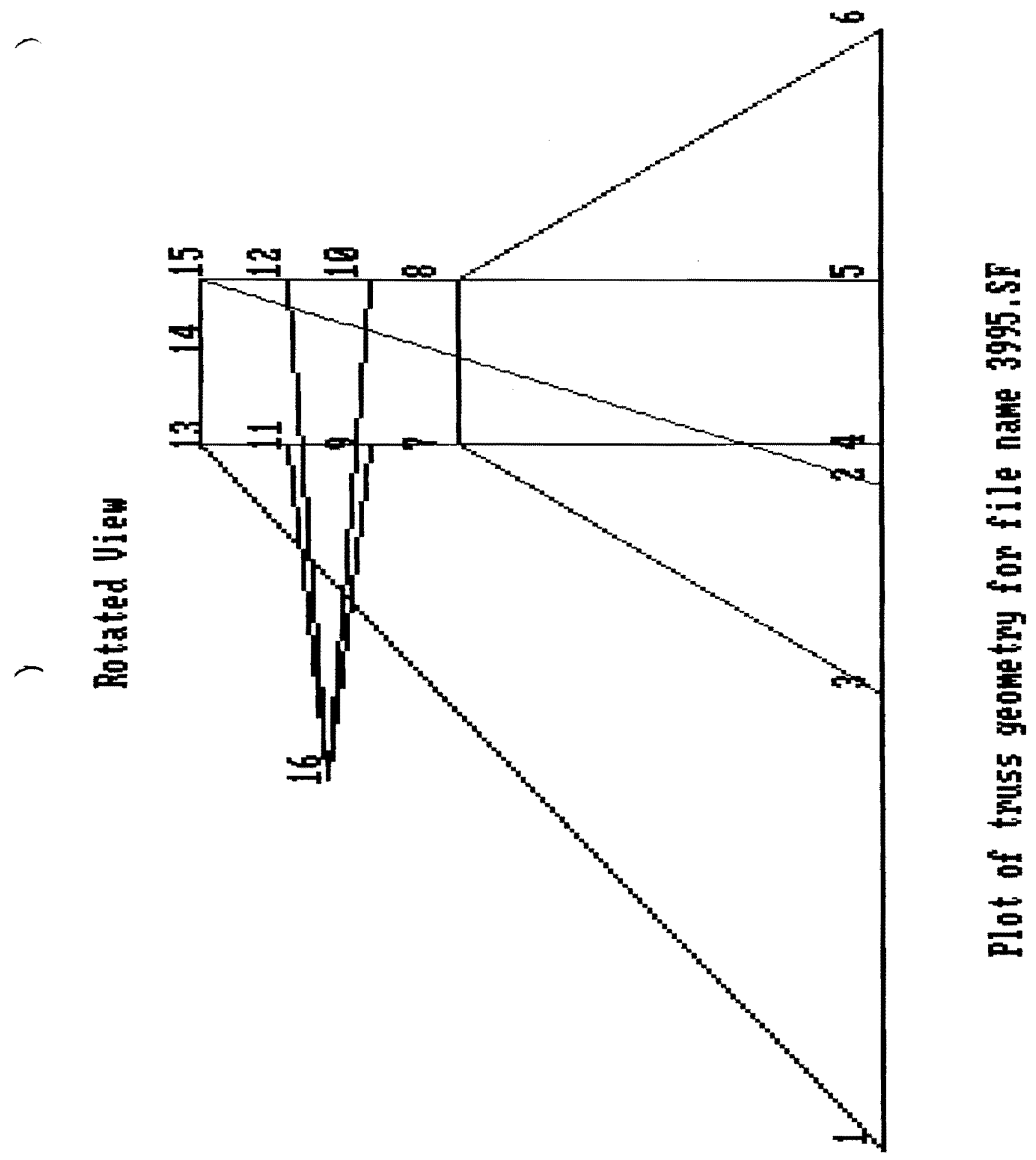




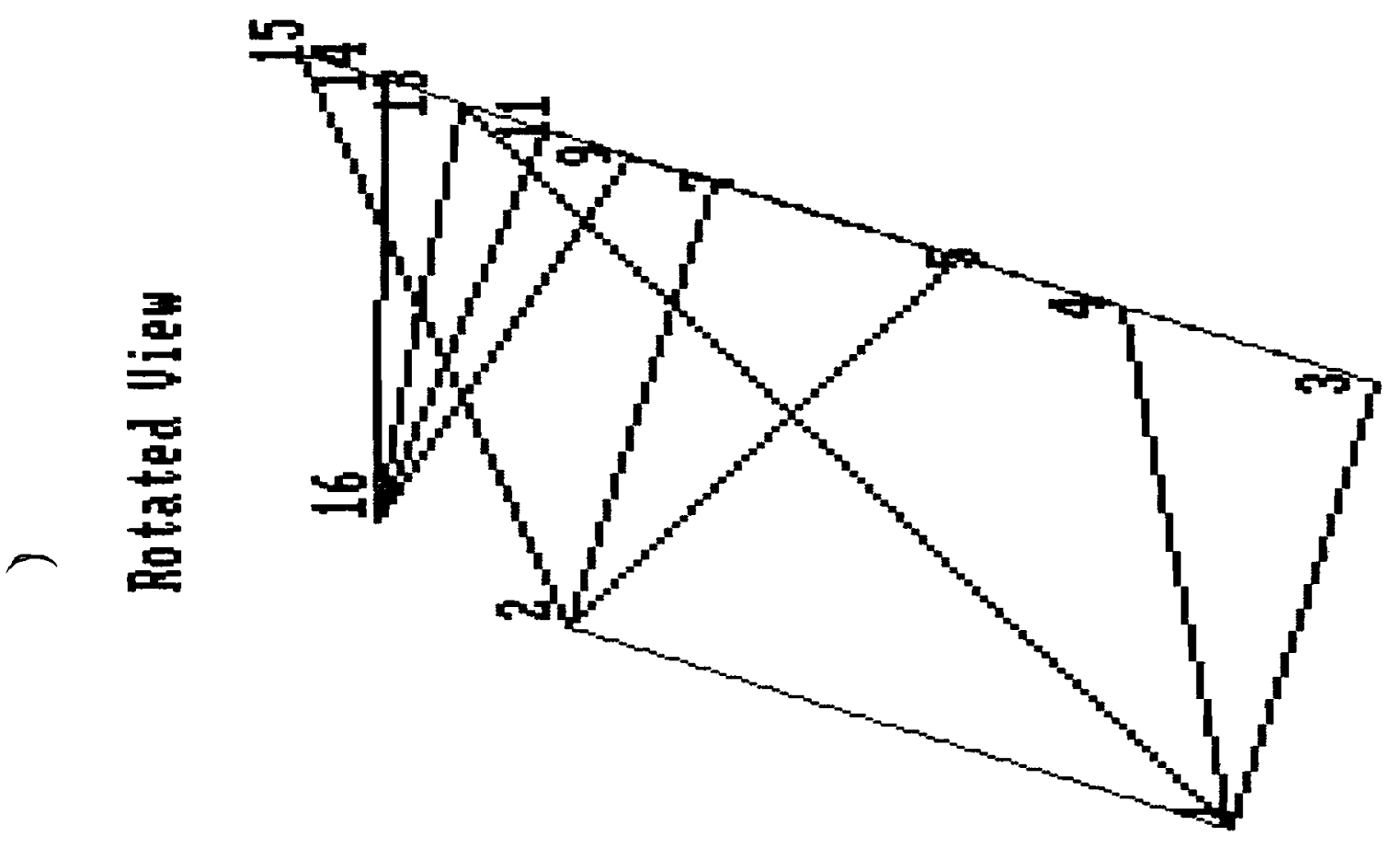

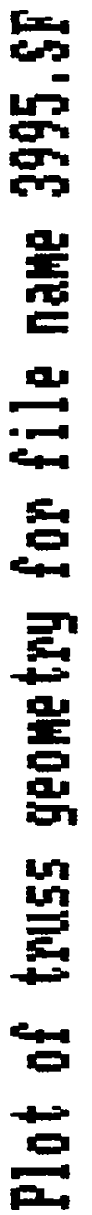




\section{Head Cart Load Test Procedure}

1. Position Head Cart in designated area and attach come-alongs to front, rear and both right and left sides.

2. Anchor the free ends of come-alongs and lock Head Cart wheels in place.

3. Obtain a "B" size concrete shielding block for the load test.

$$
8165 \# \times 125 \%=10206.25 \#
$$

$($ Head wt. $=8165 \#, " B "$ block wt. $=10150 \#)$

4. Position slings approximately $12^{\prime \prime}$ from the outer end of the barrel, ready to accept load.

5. Load "B" block onto Head Cart barrel and slings using a forklift.

6. Once the barrel is fully bearing the load, stop and inspect the Head Cart visually for any signs of yield or fracture.

7. Lock wheels in lateral direction and move the loaded Head Cart with the come-alongs about 4 or 5 feet.

8. Lock wheels in forward direction and place 1.5" ramps in front of the two front wheels. Move the loaded Head Cart over the two 1.5" ramps using the comealongs.

* A second sling attached to the "B" block and accessible to the overhead crane will be loosely fitted to the load and crane as a back-up in case of Head Cart failure.
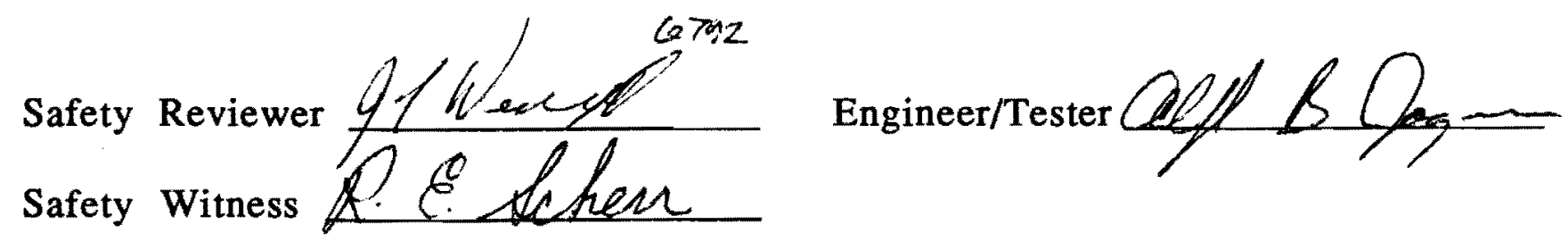


\section{HEAD CART PROCEDURE}

1. Place the cart on the south sidewalk outside the prep room with the tube pointing north. Lock the casters for E-W motion.

2. Clean the cart by wiping with solvent coated rags, paying special attention to the tube.

3. Using the overhead crane position the south head on the tube of the cart. Secure the bottom edge of the head to the rear bottom rail of the cart to prevent swaying of the head on the cart.

4. Position ramps on the floor of the prep room to allow the cart to roll over the tracks on the floor. Attach a chain-fall, come-along, or similar manual towing mechanism to an anchor(s) in the east wall of the prep room. Attach a similar device (to be used for braking) at some point on the sidewalk to the west of the cart.

5. Raise the prep room overhead door and attach the chain-falls to the bottom rails of the cart near the corners.

6. Draw the cart into the prep room in line with the cryostat, disconnect the chain-falls, and close the overhead door.

7. Wipe clean the head and the cart.

8. Rotate the casters on the cart 90 degrees and lock. Place ramps over the tracks on the cleanroom floor.

9. Attach a towing device to the north bottom rail of the cart and a braking device to the south rail.

10. Draw the cart into the cleanroom under the overhead crane.

11. Rig and lift the head off the cart.

12. Return the cart to the south sidewalk for the next head. 